Reprod. Nutr. Dévelop., 1988, 28 (6 A), 1387-1453

\title{
Propriétés des fibres musculaires squelettiques. 1. Influence de l'innervation motrice
}

\author{
F. BACOU, P. VIGNERON
}

Physiologie animale, Unité Différenciation cellulaire et croissance, I.N.R.A.-ENSA, Place Viala, 34060 Montpellier Cedex, France.

\section{Introduction.}

La fibre musculaire représente l'élément de base de l'activité motrice. Elle contient, outre l'équipement enzymatique nécessaire à la couverture énergétique de la motricité, un ensemble de protéines spécifiques groupées en myofibrilles myosine, actine, tropomyosine, troponine - qui sont le support de la contraction. Un réseau tubulaire particulier, le système $T$, associé au réticulum sarcoplasmique assurent respectivement la propagation de l'onde de dépolarisation membranaire et le cycle libération/reprise de l'ion $\mathrm{Ca}^{++}$qui régule la contraction et la relaxation musculaire.

Au cours de la période néonatale, les fibres musculaires des vertébrés supérieurs acquièrent des propriétés métaboliques et fonctionnelles les adaptant à des fonctions précises du mouvement ou de la posture : métabolisme énergétique oxydatif ou glycolytique, mode de contraction lent ou rapide autorisent ainsi l'activité modérée mais prolongée, ou l'activité brève de forte intensité. Les muscles squelettiques des organismes animaux possèdent ainsi des caractéristiques variables adaptées à la fonction qu'ils auront à assurer.

Dans la première partie de cette revue, seront détaillées les propriétés métaboliques et fonctionnelles des fibres musculaires chez l'adulte et au cours du développement. Dans une deuxième partie, nous décrirons l'importance de l'innervation motrice dans la genèse et le maintien des propriétés des différents types de fibres musculaires squelettiques; un paragraphe particulier a été consacré à la matrice extracellulaire, en raison du rôle prépondérant de cette structure dans l'établissement des jonctions neuromusculaires au cours de la réinnervation expérimentale.

\section{A) Propriétés des fibres musculaires}

On sait depuis longtemps que les muscles squelettiques des mammifères diffèrent par leur couleur (Lorenzini, 1678 cf. Ciaccio, 1898). Parallèlement, l'aspect microscopique des fibres constituant ces muscles varie (Ranvier, 1873, 1874). A l'intérieur d'un même muscle, les fibres diffèrent entre elles par leur 
aspect morphologique (Grützner, 1884; Knoll, 1891) et, dès 1919, Bullard en décrivait trois types (Gauthier, 1970). Nous nous intéresserons dans ce chapitre à définir les propriétés des fibres qui ont permis de les classer : c'est-à-dire essentiellement les critères métaboliques et fonctionnels (Guth, 1972).

\section{I) Propriétés métaboliques des fibres musculaires.}

Les premiers anatomistes divisèrent les tissus musculaires squelettiques en muscles " rouges» et "blancs», marquant ainsi un ensemble de différences dans leurs propriétés morphologiques et physiologiques (Needham, 1926). Les premiers travaux faisant intervenir des notions de biochimie métabolique montrèrent que les muscles blancs, capables de contractions rapides et brèves, utilisent essentiellement la glycolyse pour couvrir leurs besoins énergétiques (Ogata, 1960 ; Beatty et al., 1963 ; Blanchaer et al., 1963 ; Bacou, 1972 ; Ansay, 1974 ; Lefaucheur et Vigneron, 1986) alors que les muscles rouges, qui peuvent se contracter pendant de longues périodes, puisent principalement leur énergie dans les mécanismes oxydatifs (Domonkos et Latzkovits, 1961; Bacou et Vigneron, 1976 ; Hooker et Baldwin, 1979). L'étude des propriétés métaboliques des fibres musculaires, généralement hétérogènes à l'intérieur d'un même muscle, a nécessité soit l'introduction de techniques histochimiques révélant certaines caractéristiques enzymatiques, soit l'utilisation de muscles homogènes autorisant la comparaison des mesures métaboliques quantitatives et des caractéristiques histochimiques qualitatives. Plus récemment, des techniques de mesures sur fibres isolées ont permis d'établir sans ambiguïté les corrélations entre caractères histochimiques et activités enzymatiques (Essen et al., 1975; Spamer et Pette, 1977 ; Lowry et al., 1978 ; Lowry, 1984).

C'est particulièrement par l'étude des enzymes impliquées dans les voies principales du métabolisme intermédiaire que les capacités métaboliques des différents types de muscle ont été établies (Dawson et Romanul, 1964 ; Pette, 1966 ; Bass et al., 1969, 1970; Golish et al., 1970; Hofer et al., 1971; Pette, 1975 ; Hintz et al., 1980). En effet, parmi les méthodes biochimiques permettant d'étudier le métabolisme musculaire au cours de la contraction, celles se rapportant soit à la détermination du quotient respiratoire (rapport $\mathrm{CO}_{2}$ libéré $/ \mathrm{O}_{2}$ absorbé), soit aux modifications des substrats endogènes ou à l'utilisation des substrats exogènes in vivo et in vitro ont montré leurs limites techniques: difficulté des mesures de substrats spécifiques (entre différents glucides par exemple), difficulté de quantifier des substrats phosphorylés ou non, catabolisés rapidement au cours du prélèvement de l'échantillon musculaire (Corsi et al., 1969). Les bases théoriques justifiant l'emploi d'enzymes clés du métabolisme intermédiaire en tant que critère quantitatif de l'utilisation maximale des substrats ont été établies parallèlement par l'école de Pette, et par l'école de Newsholme et Crabtree (1976).

Au cours du paragraphe suivant, où nous décrivons succinctement les potentialités métaboliques des différents types de muscles, nous insisterons donc particulièrement sur les travaux effectués en utilisant cette méthodologie. 


\section{Glycogénolyse et glycolyse.}

On connaît depuis longtemps l'importance du glycogène musculaire en tant que source d'énergie, et de nombreux articles ont souligné l'effet des facteurs nutritionnels, hormonaux,... sur sa concentration musculaire (voir par exemple les revues de Stetten et Stetten, 1960 ; Cohen, 1983). Toutefois, des études plus récentes montrent que la glycogénolyse n'aurait un rôle important qu'au début de l'activité physique en produisant un surplus d'ATP, ou lorsque l'énergie nécessaire à l'accomplissement de travaux musculaires intenses excède celle produite par l'utilisation des acides gras et autres substrats circulants (Rowell et al., 1966 ; Bergström et al., 1967; Havel, 1970; Beatty et al., 1972; Newsholme et al., 1978).

Par ailleurs, l'utilisation du glycogène dépend de façon caractéristique du type de muscle (Villa Moruzzi et al., 1981) : glycogénolyse et glycolyse, mesurées par la production de pyruvate et de lactate, sont deux fois plus élevées dans les muscles blancs que dans les muscles rouges (Domonkos, 1961 ; Bocek et al., 1966). Ce type de production d'énergie s'effectue soit en anaérobiose (avec conversion du glycogène en lactate), soit en aérobiose, par l'intermédiaire du cycle de Krebs.

Au cours de la glycolyse anaérobie, les réserves de glycogène produisent peu d'énergie ( 3 ATP/molécule de glucose fournis seulement), l'accumulation de lactate tendant en outre à freiner la glycolyse. L'énergie encore disponible dans le lactate n'est cependant pas gaspillée. Une partie de celui-ci quitte la fibre musculaire pour être oxydée au niveau du cœur et du foie, ou participe à la glycogénogenèse hépatique, avec transfert au muscle sous forme de glucose sanguin (cycle de Cori). Le lactate intramusculaire peut être oxydé en pyruvate en présence d'oxygène, ou être utilisé pour la synthèse du glycogène musculaire : cette néosynthèse n'existe que dans les muscles de type blanc. Il a été montré expérimentalement chez le rat que du lactate marqué au $\mathrm{C}^{14}$ est rapidement incorporé dans le glycogène du muscle Plantaris (constitué de $90 \%$ de fibres blanches), tandis que le Soleus, qui possède une très faible activité fructose 1-6 biphosphatase (Opie et Newsholme, 1967), n'en incorpore que très peu (McLane et Holloszy, 1979). La glycolyse anaérobie permet à la fibre musculaire de maintenir des pointes d'activités intenses, dépassant les possibilités d'oxygénation du muscle. Comme le montre leur équipement enzymatique, elle est surtout développée dans les fibres de type «blanc", à contraction rapide (Bass et al., 1973 ; Pette, 1978).

Le rendement de la glycolyse aérobie (39 ATP par unité d'hexose) est suffisamment élevé pour permettre les activités toniques caractéristiques des muscles "rouges", à condition que l'apport en $\mathrm{O}_{2}$ soit suffisant. Celui-ci est un facteur limitant du niveau de l'activité, lié en partie à sa capacité de transport par la circulation sanguine, en partie à son taux d'utilisation par les mitochondries. Seule parmi les enzymes de la glycolyse, l'activité de l'hexokinase est plus élevée dans les muscles rouges que dans les muscles blancs (Peter et al., 1968 ; Burleigh et Schimke, 1968 ; Crabtree et Newsholme, 1972a), ce qui suggère que le glucose est une source d'énergie plus importante dans les premiers que dans les seconds. Ces résultats sont en concordance avec ceux de Beatty et Bocek (1970) qui 
montrent que la vitesse d'absorption du glucose, et la production de $\mathrm{CO}_{2}$ à partir de ce métabolite, sont respectivement plus élevées dans les muscles rouges que dans les muscles blancs. L'ensemble de ces données est en accord avec l'activité importante des enzymes du cycle de Krebs dans les muscles rouges.

\section{Métabolisme oxydatif.}

Parmi les substrats oxydables par les muscles au cours de leurs contractions, figurent à la fois les glucides d'origine hépatique et musculaire, et les lipides stockés dans la cellule musculaire ou apportés par le sang sous forme d'acides gras libres et de particules lipoprotéiques. Les nombreuses controverses quant à la contribution réelle et relative de ces substrats pour la couverture énergétique musculaire - liées en grande partie aux différentes conditions expérimentales ont été levées (Issekutz, 1970; Beatty et Bocek, 1971; Pande et Blanchaer, 1971). Il est maintenant clairement établi que les lipides sont directement assimilables par le muscle sous plusieurs formes: soit circulantes, acides gras libres (AGL), diglycérides, triglycérides (disponibles sous forme de Very Low Density Lipoproteins chez les mammifères) exogènes; soit endogènes, sous forme de triglycérides (Crabtree et Newsholme, 1972b). Toutefois, l'utilisation préférentielle des glucides ou des lipides dépend d'une part du type de travail fourni par les muscles, d'autre part des types de muscles eux-mêmes (Reitman et al., 1973 ; revue de Holloszy et Booth, 1976).

Lors d'une activité modérée, les tissus musculaires squelettiques ont un approvisionnement en $\mathrm{O}_{2}$ suffisant pour assurer une dégradation oxydative des nutriments : les lipides sont alors utilisés plutôt que les glucides. Ainsi, lors d'un exercice de faible intensité, le niveau des AGL plasmatiques augmente progressivement (Rennie et Johnson, 1974) et peut atteindre au bout de 4-5 heures de 3 à 5 fois la valeur de repos. Parallèlement à ces modifications humorales, la vitesse d'utilisation des AGL par le muscle augmente, et 70 à $75 \%$ du $\mathrm{CO}_{2}$ expiré provient de l'oxydation des AGL plasmatiques (Issekutz, 1970). Dans ces exercices légers ou modérés, la glycolyse anaérobie et, dans une moindre mesure aérobie, n'est donc que faiblement impliquée d'autant plus que la disponibilité en AGL réduit la mobilisation du glycogène hépatique (Rennie et al., 1976) et inhibe l'utilisation des glucides dans le cœur ou les muscles squelettiques (Randle et al., 1964 ; Newsholme et Randle, 1964 ; Rennie et Holloszy, 1977). Le taux de lactate sanguin sera donc faible $(20 \mathrm{mg} \%$ ) et relativement constant (Issekutz, 1970).

La situation est différente dans les cas d'activité musculaire intense. En raison de l'approvisionnement insuffisant en $\mathrm{O}_{2}$, la concentration en acide lactique dans le sang augmente (plus de 5 fois), proportionnellement à l'intensité du travail. Les glucides sont alors la principale source d'énergie car le lactate accumulé limite par un mécanisme encore non élucidé - la mobilisation des lipides à partir du tissu adipeux (Dunn et Critz, 1975) et réduit la disponibilité des acides gras des lipides intramusculaires (Issekutz et Miller, 1962; Issekutz et al., 1965). Ce dernier point est particulièrement important puisqu'on estime qu'après 30 min d'exercice intense, la moitié des lipides oxydés provient du tissu adipeux intramusculaire (Issekutz et al., 1964). Ainsi, chaque fois que les besoins en $\mathrm{O}_{2}$ 
excèdent l'approvisionnement, le métabolisme oxydatif se déplace vers l'utilisation des glucides, les lipides ne fournissant alors que 20-30\% de l'énergie nécessaire (Issekutz, 1970). Parallèlement à I'utilisation variable, selon l'intensité de l'activité, des différentes sources d'énergie, il est important de considérer ce problème selon le type - continu ou intermittent - d'activité musculaire.

Le muscle cardiaque a longtemps constitué l'exemple majeur des muscles fournissant un travail continu mais les résultats obtenus dans ce domaine ont été par la suite étendus aux muscles squelettiques rouges, tels que les muscles Pectoralis de nombreux oiseaux (Kaiser et George, 1973 ; Khan, 1980). Ces tissus fonctionnent d'ordinaire en aérobiose, situation favorisée par leur abondante vascularisation, le nombre de capillaires entourant chaque fibre rouge étant en rapport avec leur activité métabolique oxydative (Romanul, 1965 ; Hilton, 1974), ainsi que par le nombre élevé de mitochondries, donc des enzymes du cycle de Krebs (Ashmore et al., 1972a ; Hudlicka et al., 1973). Les muscles rouges utilisent le glucose, le lactate mais surtout les AGL (Opie, 1969 ; Okano et Shimojo, 1982). Cependant, au cours d'un exercice intense, le lactate produit par les muscles squelettiques devient le substrat majeur du métabolisme. Continuellement extrait du sang, le lactate est transformé en pyruvate disponible pour le cycle de Krebs grâce à la forme isozymique $\mathrm{H}$ qui caractérise la lactate déshydrogénase des muscles rouges (Baldwin et al., 1978; Briand et al., 1981 ; Leberer et Pette, 1984).

Les fibres constituant les muscles blancs ont un comportement différent. Plus grosses, moins irriguées (Appel, 1984), elles contiennent moins de mitochondries et de triglycérides de réserve que les fibres des muscles rouges (Okano et al., 1980). Intervenant dans des mouvements rapides et brefs, leur concentration élevée en glycogène et la richesse de leur équipement en enzymes glycolytiques assurent l'apport énergétique à partir des voies de la glycolyse anaérobie.

Toutefois il est nécessaire de se rappeler que les muscles des mammifères et particulièrement les gros mammifères - sont rarement homogènes (Planche $1 \mathrm{~A}-\mathrm{F}$ ), mais composés d'un pourcentage variable de fibres rouges ou blanches (Barnard et al., 1971 ; Fardeau, 1973; Edgerton et al., 1975 ; Vigneron et al., 1976). En ce sens, l'utilisation des métabolites par les différents muscles dépendra de leur composition en types de fibres, mais une complémentarité fonctionnelle a été expérimentalement montrée. La stimulation électrique du muscle Pectoralis de certains oiseaux épuise rapidement le glycogène des fibres blanches, mais pas celui des fibres rouges (George et Berger, 1966 ; Parker et George, 1972). Ce qui a amené ces auteurs à suggérer que les fibres blanches pourraient se contracter séparément au début du vol, les fibres rouges prenant ensuite la relève. Cette hypothèse est étayée par le fait que des individus atteints de la maladie de McArdle — dans laquelle la dégradation du glycogène en lactate ne peut s'effectuer par manque de myophosphorylase et de phosphofructokinase - présentent des difficultés pour débuter un exercice intense (McArdle, 1951 ; Pernow et al., 1967 ; Hofmann, 1978).

- Conclusion. - Selon les circonstances, différents substrats sont préférentiellement utilisés pour assurer les besoins énergétiques des fibres musculaires : lipides lors d'activité ordinaire, système glycogène — lactate lors d'activités 
intenses. La dégradation de ces substrats fait intervenir des enzymes dont l'activité diffère selon le type de fibres: activités glycolytiques et activités oxydatives prédominent respectivement dans les fibres blanches et dans les fibres rouges. Ces propriétés permettent de distinguer et de classer les fibres musculaires, les activités de la phosphorylase (voie glycolytique) et surtout de la succinate déshydrogénase (SDH, voie oxydative) constituant les marqueurs de type métabolique les plus utilisés. Les propriétés métaboliques sont par ailleurs en rapport avec le mode de contraction des différents types de fibres: contraction rapide et de courte durée, contraction lente mais soutenue et puissante, caractéristiques liées en particulier aux protéines contractiles qui constituent les myofibrilles.

\section{1) Propriétés fonctionne/les des fibres musculaires.}

Parmi les structures intracellulaires importantes constituant les fibres musculaires striées - mitochondries, myofibrilles et réticulum sarcoplasmique - nous nous limiterons à l'étude des myofibrilles. Ces éléments constituent en effet le support de l'activité contractile, et par leur myosine celui de l'activité ATPasique qui permet en particulier de différencier en histochimie les propriétés contractiles lentes ou rapides des fibres.

Les myofibrilles des muscles squelettiques occupent la plus grande partie du volume des fibres. Elles sont alignées selon le grand axe et ont une longueur identique à celle de la fibre, de l'ordre de plusieurs centimètres, et un diamètre de 1 à $3 \mu \mathrm{m}$. Il est important de noter que les myofibrilles n'ont pas de surface membranaire, de sorte que les substances en solution dans le sarcoplasme se retrouvent entre les filaments protéiques des myofibrilles, favorisant ainsi les échanges et la dégradation des métabolites (Huxley et Hanson, 1960). Les protéines myofibrillaires sont nombreuses (tabl. 1) et représentent environ $50 \%$ des protéines musculaires. Parmi ces protéines, les plus abondantes sont la myosine (40 à $60 \%$ des protéines myofibrillaires) et l'actine $(20 \%)$ : elles peuvent se combiner en interagissant avec I'ATP pour former l'actomyosine. Deux autres protéines, la tropomyosine et les troponines (3 et 4,5\%) interviennent dans la régulation de la contraction par le calcium (Obinata et al., 1981 ; Yates et Greaser, 1983 ; revues de Gröschel-Stewart et Drenckhahn, 1982 et de Robert, 1987).

\section{L. myosine.}

Selon Lowey et al. (1969), la myosine est « an unsual protein; it cannot be classified as either a globular enzyme or a fibrous, structural protein. Rather, it combines both classes of molecules in a functional, covalently linked unit ». La molécule de myosine est constituée principalement de deux longues chaînes lourdes polypeptidiques ( $P M=200000)$ enroulées l'une autour de l'autre sur une longueur de $1400 \AA ̊$ : cette région fibrillaire forme la « queue » de la molécule. Ces chaînes lourdes se séparent à une extrémité pour se combiner chacune à deux chaînes légères chimiquement distinctes formant ainsi deux régions globulaires d'un diamètre de $100 \AA$ (fig. 1). L'action ménagée de la trypsine sépare les deux 
TABLEAU 1

Propriétés des protéines structurales myofibrillaires du muscle squelettique de lapin. (D'après Obinata et al., 1981).

\begin{tabular}{|c|c|c|c|c|c|}
\hline Proteins & $M W=$ & $\begin{array}{l}\text { Content } \\
\text { as } \% \text { of } \\
\text { total } \\
\text { protein }\end{array}$ & $\begin{array}{l}\text { Local- } \\
\text { ization }\end{array}$ & Function or structure & Reference \\
\hline \multicolumn{6}{|l|}{ Contractile proteins } \\
\hline Myosin & 480,000 & 60 & A-band & $\begin{array}{l}\text { Interacts with actin } \\
\text { ATPase action }\end{array}$ & $\begin{array}{l}\text { Szent-Györgyi } \\
\text { (1951) }\end{array}$ \\
\hline Heavy-chain & 200,000 & & & & \\
\hline \multicolumn{6}{|l|}{ Light-chain } \\
\hline$L_{1}$ & 25.000 & & & & \\
\hline$L_{2}$ & 20.000 & & & & \\
\hline$L_{3}$ & 16,000 & & & & \\
\hline Actin & $.41,785$ & 20 & I-band & $\begin{array}{l}\text { Interacts with myosin, } \\
\text { binds to tropomyosin } \\
\text { and other proteins }\end{array}$ & Straub (1942) \\
\hline \multicolumn{6}{|l|}{ Reguiatory proteins } \\
\hline \multicolumn{6}{|l|}{ Major } \\
\hline Tropornyosin & 65,000 & 3 & I-band & $\begin{array}{l}\text { Binds to actin and } \\
\text { troponin }\end{array}$ & Bailey (1948) \\
\hline a-chain & 32,758 & & & & \\
\hline$\beta$-chain & - & & & & \\
\hline Troponin & 70,000 & 4.5 & I-band & Ca regulation & Ebashi (1965) \\
\hline Troponin C & 17,965 & & & Ca binding & Hartshorne (1968) \\
\hline Troponin I & 20,864 & & & $\begin{array}{l}\text { Inhibits actin-myosin } \\
\text { interaction }\end{array}$ & Perry (1967) \\
\hline Troponin T & 30.503 & & & Binds to tropomyosin & Ebashi (1972) \\
\hline \multicolumn{6}{|l|}{ Minor } \\
\hline M-Protein & 165.000 & 2 & M-line & Binds to myosin & $\begin{array}{l}\text { Masaki et al } \\
(1972)\end{array}$ \\
\hline C-Protein & 135,000 & 2 & A-band & Binds to myosin & OHer (1973) \\
\hline F-Protein & 121.000 & 0.1 & A-band & Binds to myosin & Offer (1973) \\
\hline I-Protein & 50,000 & 0.1 & A-band & Binds to myosin & $\begin{array}{l}\text { Ohashi et al } \\
\quad(1977)\end{array}$ \\
\hline \multicolumn{6}{|l|}{ Actinins } \\
\hline$\alpha$-Actinin & 95,000 & 1 & Z-line & Binds to actin & Ebashi (1965) \\
\hline$\beta$-Actinin & $\begin{array}{l}37.000 \\
34.000^{\circ}\end{array}$ & 0.1 & $\begin{array}{l}\text { Free end of } \\
\text { l-filament }\end{array}$ & Binds to actin & Maruyama (1965) \\
\hline$\gamma$-Actinin & 35.000 & 0.1 & 1-band(?) & Binds to actin & Kuroda (1976) \\
\hline Eu-Actinin & 42.000 & 0.3 & Z-line & Binds to actin & Kuroda (1980) \\
\hline $\begin{array}{l}\text { Actir-binding protein } \\
\text { (filamin) }\end{array}$ & 240.000 & 0.1 & Z-line & Gelates F-actin & Hartwig (1975) \\
\hline \multicolumn{6}{|l|}{ Scaffold proteins } \\
\hline Connectin & $10^{*}$ & 5 & A-, l-band & $\begin{array}{l}\text { Nets of 2-nm } \\
\text { filaments }\end{array}$ & Maruyama (1977) \\
\hline Z-protein & 55.000 & 0.1 & Z-line & Lattice structure & Onashi (1979) \\
\hline Desmin (skeletin) & 55,000 & 0.1 & $\begin{array}{l}\text { Periphery of } \\
\text { Z-line }\end{array}$ & $\begin{array}{l}\text { 10-nm filament linking } \\
\text { neighboring } Z \text {-ines }\end{array}$ & Granger (1978) \\
\hline
\end{tabular}

WW = molecular weight.

- $\beta$-actinin consists of 2 chains of these MWs.

tiers environ de la « queue » fibrillaire du reste de la molécule : ces deux fragments constituent les méromyosines légère et lourde ( $L M M$ et HMM). Une digestion prolongée à la papaïne sépare à son tour la méromyosine lourde en deux fragments : le fragment $S_{1}$ constitué des deux têtes globulaires et le fragment $S_{2}$ qui les rattache au reste de la molécule (Mannherz et Goody, 1976; Franzini-Armstrong et Peachey, 1981). Chacune des têtes de la myosine contient, outre la partie terminale globulaire de la chaîne lourde, deux chaînes légères: 
l'une phosphorylable ou « régulatrice » ( $L C_{2}$ d'un $P M=18000$ à 20000$)$, l'autre alcaline $\left(A_{1}\right.$ ou $L C_{1}, A_{2}$ ou $L_{3}$, d'un $P M=16000$ à 27000$)$ car dissociée de la myosine à pH 11 (Weeds et Lowey, 1971).

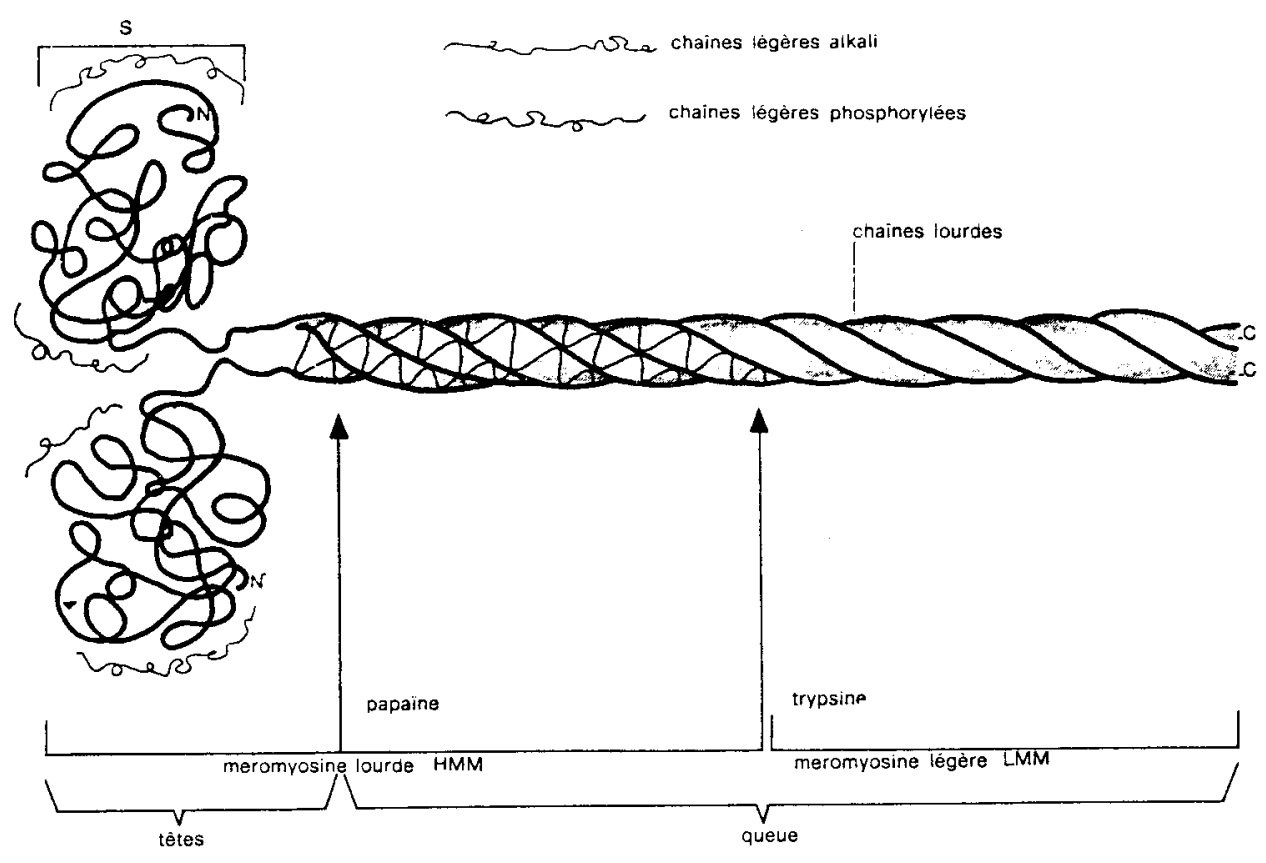

FIG. 1. - Présentation schématique d'une molécule de myosine. (D'après Schwartz, 1978).

C'est par son fragment $S_{1}$ que la myosine catalyse l'hydrolyse du groupement phosphoryl terminal de I'ATP, les deux têtes de la myosine ayant une activité ATPasique équivalente (Lowey et al., 1969). Le rôle exact des chaînes légères dans l'activité catalytique de la molécule de myosine est encore flou (Kunz et al., 1985). Si les chaînes "régulatrices» peuvent être enlevées de la molécule de myosine sans que celle-ci perde son activité ATPasique, la présence de chaînes alcalines était considérée comme indispensable (Wagner et Weeds, 1977; Weeds, 1980). Cependant, en utilisant des conditions de dissociation douces combinées à la chromatographie d'affinité, Wagner et Giniger (1981) ont montré que la chaîne lourde du fragment $S_{1}$ débarrassée de toutes les chaînes légères se lie réversiblement à l'actine et conserve 30 à $80 \%$ de l'activité ATPasique du segment $S_{1}$ natif.

Par ailleurs, de nombreux travaux ont montré une relation entre vitesse d'hydrolyse de I'ATP par l'ATPase et vitesse de contraction des fibres : I'activité ATPasique est plus élevée dans les muscles rapides que dans les muscles lents 
(Barany et al., 1965 ; Sreter et al., 1966 ; Barany, 1967 ; Samaha et al., 1970 ; Marston et Taylor, 1980). Ces résultats sont à mettre en parallèle avec les différences observées dans les caractéristiques physicochimiques des chaînes lourdes (Jean et al., 1975) et des chaînes légères de myosine des différents types de muscle (Lowey et Risby, 1971 ; Sarkar et al., 1971 ; Weeds et Pope, 1971). Au cours des dix dernières années, deux types de techniques électrophorétiques ont été utilisés pour étudier ces différences chez l'adulte et au cours du développement (Hoh, 1979 ; Lowey et al., 1982 ; Whalen et al., 1982).

La première technique, en milieu non dissociant, permet d'étudier les myosines natives constituées par les diverses combinaisons des chaînes légères avec les chaînes lourdes. On distingue trois types de myosine native dans les muscles rapides: $\mathrm{FM}_{1}, \mathrm{FM}_{2}$ et $\mathrm{FM}_{3}$ (Hoh et al., 1976 ; Hoh, 1978 ; d'Albis et al., 1979 ; Hoh et Yeoh, $1979 \mathrm{chez}$ le lapin ; Nougues, 1980 chez le poulet; Whalen et al., 1981 chez le rat ; Billeter et al., 1981 chez l'homme). Cette même technique appliquée à la myosine de muscle lent permet la mise en évidence d'un type SM d'isozymes chez le lapin (Hoh et Yeoh, 1979) et de deux types $\mathrm{SM}_{1}$ et $\mathrm{SM}_{2}$ chez le poulet (Hoh et al., 1976 ; d'Albis et al., 1979 ; Nougues, 1980) migrant moins vite que ceux des muscles rapides.

L'analyse en milieu dissociant de la composition peptidique des bandes précédentes montre que ces isoenzymes de myosine native correspondent à des associations complexes de plusieurs types de chaînes légères à plusieurs types de chaînes lourdes. Le schéma suivant représente la situation des différentes isoenzymes de la myosine dans les muscles lent et rapide de poulet :

TABLEAU 2

\begin{tabular}{|c|c|c|c|c|}
\hline Muscle & $\begin{array}{l}\text { Myosine } \\
\text { native }\end{array}$ & $\begin{array}{l}\text { Chaînes } \\
\text { lourdes }\end{array}$ & \multicolumn{2}{|c|}{ Chaînes légères } \\
\hline \multirow[t]{2}{*}{$\begin{array}{l}\text { Pectoralis major } \\
\text { (contraction rapide) }\end{array}$} & $\mathrm{FM}_{1}$ & $\mathrm{MHC}_{F}$ & $\left(L C_{2} f\right)_{2}\left(L C_{3} f\right)_{2}$ & Homodimère \\
\hline & $\begin{array}{l}\mathrm{FM}_{2} \\
\mathrm{FM}_{3}\end{array}$ & $\begin{array}{l}\mathrm{MHC}_{F} \\
\mathrm{MHC}_{\mathrm{F}}\end{array}$ & $\begin{array}{l}\left(L C_{2} f\right)_{2} L C_{1} f L C_{3} f \\
\left(L C_{2} f\right)_{2}\left(L C_{1} f\right)_{2}\end{array}$ & $\begin{array}{l}\text { Hétérodimère } \\
\text { Homodimère }\end{array}$ \\
\hline \multirow{2}{*}{$\begin{array}{l}\text { Latissimus dorsi } \\
\text { anterior } \\
\text { (contraction lente) }\end{array}$} & $\mathrm{SM}_{1}$ & $\mathrm{MHC}_{\mathrm{S}}$ & $\left(L_{2} s\right)_{2}\left(L C_{1} s\right)_{2}$ & Homodimère \\
\hline & $\mathrm{SM}_{2}$ & $\mathrm{MHC}_{\mathrm{S}}$ & $\left(L_{2} s\right)_{2}\left(L C_{1} s\right)_{2}$ & Homodimère \\
\hline
\end{tabular}

Outre les différents types de chaînes légères, une douzaine de chaînes lourdes (dont trois dans le muscle adulte) ont été mises en évidence par des techniques de cartes polypeptidiques dans différents tissus de vertébrés (Whalen et al., 1981 ) : les résultats obtenus à ce jour sur les chaînes légères et lourdes de la myosine de muscles rapide et lent des Vertébrés sont résumés dans le tableau 3. L'ensemble de ces protéines est codé par des familles multigéniques, qui sont 
exprimées différentiellement dans les divers tissus adultes ou au cours du développement (Barton et al., 1985 ; Barton et Buckingham, 1985 ; Buckingham, 1985 ; Wieczorek et al., 1985 ; revue de Weydert, 1988).

\section{TABLEAU 3}

Isoformes de l'actine et de la myosine dans différents tissus musculaires et non musculaires. (D'après Buckingham, 1985).

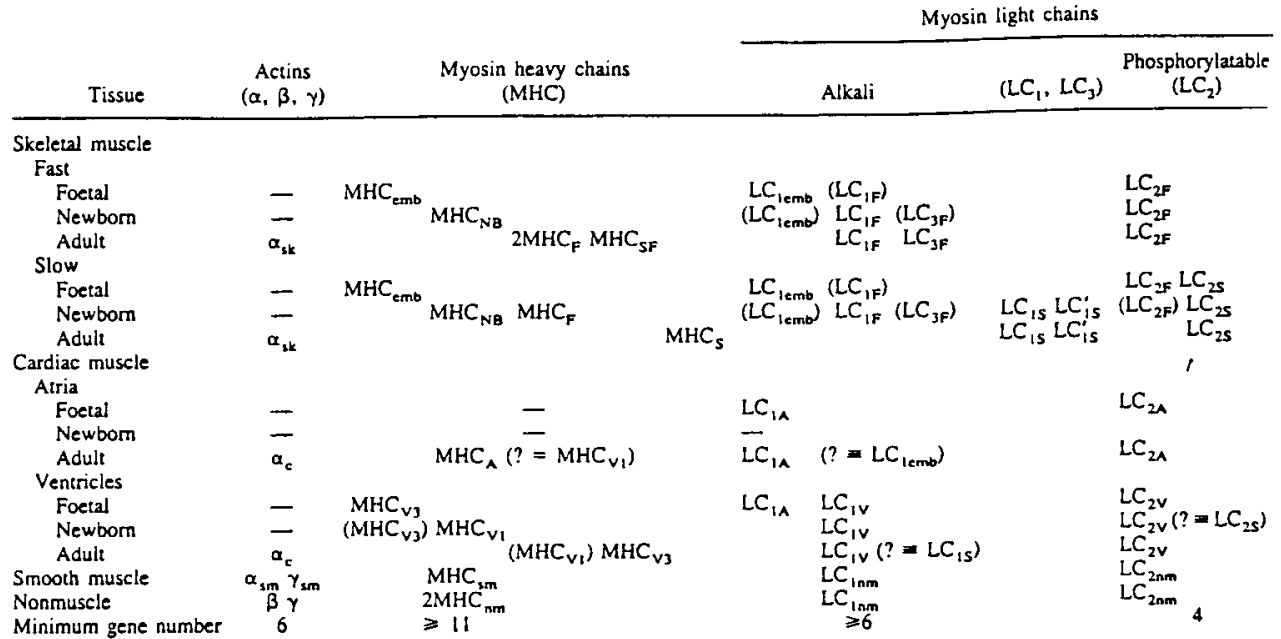

\section{L'actine.}

Protéine globulaire (actine $\mathrm{G}, \mathrm{PM}=42000$ ), l'actine $\mathrm{G}$ se polymérise à force ionique physiologique pour former dans les tissus musculaires un double filament hélicoidal (ou actine F). A côté de son rôle structural (filaments fins des myofibrilles), l'actine a la propriété d'activer de 100 à 200 fois la vitesse à laquelle la myosine hydrolyse l'ATP en présence de $\mathrm{Mg}^{++}$(Adelstein et Eisenberg, 1980). Cette activation s'effectue indépendamment $\mathrm{du} \mathrm{Ca}^{++}$; cependant, celui-ci régule in situ la contraction musculaire par le système troponine-tropomyosine lié au filament d'actine (voir paragraphe suivant). L'actine musculaire n'existe que sous deux formes isozymiques $\alpha_{\mathrm{c}}$ et $\alpha_{\mathrm{sk}}$ présentes respectivement dans le cœur et dans le muscle squelettique adultes. Dans le muscle squelettique embryonnaire, l'actine myofibrillaire existe sous trois formes $\alpha, \beta$ et $\gamma$; au cours du développement, les formes $\beta$ et $\gamma$ disparaissent des fibres musculaires et it ne demeure que la forme $\alpha_{\text {sk }}$ chez l'adulte (Shimizu et Obinata, 1980). Toutefois, selon Buckingham (1985), il n'existe pas de forme embryonnaire ou néonatale de cette protéine, mais les deux types isozymiques $\alpha_{\mathrm{c}}$ et $\alpha_{\mathrm{sk}}$ sont exprimés dans les deux tissus dès le début du développement. Un seul type de transcrit (cardiaque ou squelettique) prédomine à $90 \%$ chez l'adulte. 


\section{Tropomyosines et troponines.}

Les travaux de l'école d'Ebashi (Ebashi, 1963 ; Ebashi et Endo, 1968 ; Ebashi et al., 1969, 1971; Ebashi, 1980) ont montré l'importance de ce complexe constituant environ $7 \%$ des protéines myofibrillaires.

La tropomyosine des muscles squelettique, lisse ou cardiaque, qui a une forte affinité pour l'actine, a un poids moléculaire de l'ordre de 65000 et est constituée de deux chaînes s'enroulant l'une autour de l'autre dans le sillon créé par les deux brins du filament d'actine (Adelstein et Eisenberg, 1980).

Les troponines sont des protéines globulaires dénommées troponine $C$ $(P M=18000), I(P M=21000-24000)$ et $T(P M=31000-36000)$ présentant une grande affinité respectivement pour le $\mathrm{CA}^{++}$, pour l'actine et pour la tropomyosine (Mannherz et Goody, 1976).

Le rôle du complexe tropomyosine-troponines est essentiel dans la régulation de la sensibilité au calcium de la MgATPase de l'actomyosine, en particulier lors de l'augmentation de la concentration intracellulaire en calcium intervenant au cours de la stimulation. Si l'on en juge par des critères tels que la composition en acides aminés, la mobilité électrophorétique et les études de séquences, la troponine I (Cole et Perry, 1975; Cummins et Perry, 1978 ; Wilkinson et Grand, 1978), la troponine T (Perry et Cole, 1974 ; Wilkinson, 1978 ; Wilkinson et al., 1984), la troponine $C$ (Weeds et McLachlan, 1974 ; Wilson et al., 1978) et la tropomyosine (Cummins et Perry, 1973, 1974; Roy et al., 1979a) existent dans les muscles selon des formes polymorphiques. Plusieurs formes de troponine I se trouvent dans les muscles squelettiques lent, rapide et cardiaque. Et bien que moins étudiée, la troponine T existerait aussi sous différentes formes dans chaque type de muscle strié (Briggs et al., 1984). De plus, deux types de troponine C ont été isolés à partir du muscle squelettique humain et on a montré que la troponine $\mathrm{C}$ cardiaque diffère de la forme présente dans le muscle rapide (Dhoot et Perry, 1979). Par ailleurs, la tropomyosine est constituée de sous-unités dont deux types $\alpha$ et $\beta$ ont été décrits. La forme $\alpha$ migre plus rapidement que la forme $\beta$ en gel d'électrophorèse en présence de sodium dodécyl sulfate. On pensait que la proportion des tropomyosines $\alpha$ et $\beta$ dans le muscle squelettique était en rapport avec la vitesse de contraction des muscles, les chaînes $\alpha$ étant mises en évidence dans les mucles rapides et les chaînes $\beta$ dans les muscles lents. En fait, des travaux plus récents (Bronson et Schachat, 1982 ; Kardami et al., 1983) ont montré que dans les muscles squelettiques lents et rapides coexistent les formes $\alpha$ et $\beta$ de la tropomyosine (voir la revue de Perry, 1985).

- Conclusion. - Les muscles rapides et les muscles lents sont donc constitués d'isozymes distinctes de protéines myofibrillaires expliquant partiellement leurs propriétés contractiles. De récents travaux sur la myosine isolée ont montré que l'activité ATPasique de l'actomyosine est déterminée par la structure de la chaîne lourde du fragment $S_{1}$ et ne dépend pas des chaînes légères. Cependant, dans les conditions physiologiques in vivo, le degré de phosphorylation des chaînes légères et l'ensemble des protéines régulatrices troponine-tropomyosine modulent l'activité enzymatique de l'actomyosine. Par ailleurs, la relation qui existe entre vitesse de contraction des fibres et activité ATPasique 
de leur actomyosine - fonction clé de la protéine puisqu'elle procure l'énergie nécessaire à la contraction - a permis de classer les fibres selon leurs caractéristiques fonctionnelles (Barany, 1967). Associée à la mise en évidence des activités métaboliques des muscles squelettiques, les propriétés histochimiques de l'ATPase myofibrillaire - donc de la vitesse de contraction - ont été utilisées pour distinguer les fibres musculaires en plusieurs types dont nous allons décrire les caractéristiques essentielles.

\section{III) Types de fibres: classification et terminologie.}

L'hétérogénéité typologique de la plupart des muscles squelettiques des Vertébrés supérieurs a amené les chercheurs, et particulièrement les cliniciens, à proposer différentes classifications des fibres musculaires extrafusales. Depuis 1958, date à laquelle Ogata publie la première nomenclature des fibres, toutes les classifications utilisent soit les niveaux d'activité des enzymes du métabolisme intermédiaire, soit les propriétés de l'ATPase myofibrillaire, soit une combinaison des deux (Close, 1972; Barnard et al., 1971).

Depuis une dizaine d'année, à la classification histochimique communément utilisée, s'ajoutent des travaux faisant intervenir les propriétés immunologiques des constituants protéiques des fibres, et particulièrement de la myosine : ces techniques, utilisant l'immunofluorescence, ne bouleversent pas les classifications histochimiques classiques, mais permettent, grâce à leur spécificité et à leur sensibilité, de mieux différencier les problèmes évolutifs liés soit à la pathologie, soit au développement des fibres musculaires au cours de l'embryogenèse.

\section{Classification et terminologie.}

Les critères métaboliques, essentiellement enzymatiques, ont été les premiers utilisés pour différencier les types de fibres musculaires. D'après la seule intensité de l'activité succinate déshydrogénase (SDH), Ogata (1958) mettait en évidence trois types de fibres qu'il appelait « rouges " (petit diamètre, activité SDH élevée), «blanches" (grand diamètre, activité SDH faible) et « intermédiaires » (de taille et d'activité SDH moyennes). En utilisant la même technique, Stein et Padykula (1962) proposent de nommer ces fibres $A, B$ et $C$ : fibres $A$ pauvres en SDH, fibres $B$ riches en $\mathrm{SDH}$ et fibres $C$ riches en $\mathrm{SDH}$ mais présentant une plus forte coloration à la périphérie qu'au centre des fibres.

En montrant qu'il existait dans le tissu musculaire humain une relation inversement proportionnelle entre la teneur en enzymes oxydatives et en phosphorylases, Dubowitz et Pearse (1960a et b) ont introduit une classification mieux adaptée en particulier aux études cliniques (Fardeau, 1973; TelermanToppet et Coers, 1973). Cette relation aboutit à la caractérisation de deux types principaux de fibres : I (riche en SDH, pauvre en phosphorylase) et II (pauvre en $\mathrm{SDH}$, riche en phosphorylase). Chez l'animal, des fibres de propriétés intermédiaires étaient décrites et en utilisant une gamme plus étendue d'activités d'enzymes oxydatives, glycolytiques et estérasiques, Romanul (1964) proposait une classification en huit types de fibres. 
Les techniques utilisées au cours de ces travaux, l'activité estérasique exclue, permettaient de classer les divers types de fibres par leurs activités métaboliques oxydatives ou glycolytiques. Si, fondamentalement, l'usage de tels critères est justifié puisque les fibres musculaires ont des propriétés métaboliques très différentes, voire opposées, le faible contraste et l'existence de colorations intermédiaires rend leur interprétation histologique délicate et criticable (Eckner et al., 1968 ; Eckner, 1971). Par exemple, les enzymes oxydatives possèdent dans les mitochondries un support structural cellulaire et donnent des colorations fiables - encore que dépendant de l'intensité d'utilisation des muscles (Edgerton et al., 1980 ; Booth et al., 1980). La mise en évidence d'enzymes glycolytiques est beaucoup plus aléatoire: ces enzymes, qui existent à l'état soluble dans le cytoplasme ont tendance à diffuser lors de la préparation histochimique (Khan, 1976).

L'application systématique de la coloration de l'ATPase "myofibrillaire " (Padykula et Herman, 1955a, b), apporta la plupart des informations nécessaires à l'étude histoenzymologique des muscles striés, en complétant celles obtenues par l'intermédiaire des enzymes oxydatives. Dans un premier temps, la révélation de la seule activité ATPasique « $\mathrm{Ca}^{+}{ }^{+}$dépendante " a permis à Engel (1962) de revenir à une classification en deux types de fibres : les types I ont une coloration plus faible que les fibres de type II après une préincubation à $\mathrm{pH} 9,4$. Si les fibres I identifiées par cette dernière méthode correspondent généralement au type $\mid$ de Dubowitz et Pearse (activités oxydatives élevées, phosphorylase faible), les fibres II présentent une forte hétérogénéité pour les enzymes du métabolisme intermédiaire. En approfondissant l'observation de Drews et Engel (1966) sur I'inversion de la réaction ATPasique par une préincubation à $\mathrm{pH}$ acide, Guth et Samaha (1969) devaient montrer que les activités de I'ATPase myofibrillaire des fibres musculaires n'avaient pas toutes la même sensibilité aux $\mathrm{pH}$ acides et alcalins (Planche 1 A-D) : celle des fibres dites $\alpha$ (II) était « acide-sensible » (à $\mathrm{pH} 4,35)$ et alcali-résistante, celle des fibres $\beta$ (I) était alcali-sensible (à $\mathrm{pH} 10,4)$ et acide-résistante. Brooke et Kaiser $(1969,1970)$ ont poursuivi l'analyse des différents types de fibres selon la même orientation, en explorant la sensibilité de I'ATPase aux variations de $\mathrm{pH}$ acides $(3,8$ à 5,5$)$. Ils ont ainsi défini, en s'inspirant de Engel, à côté des fibres de type I, trois sous-groupes de fibres II : fibres IIA inhibées chez l'homme par une préincubation à $\mathrm{pH}<4,9$, IIB inhibées à $\mathrm{pH}<4,30$ et IIC partiellement résistantes à ce dernier $\mathrm{pH}$.

Ces derniers exemples montrent la confusion qui a entouré les essais de classification reposant sur l'activité de l'ATPase myofibrillaire. Bien que celle-ci soit caractéristique de la fibre musculaire, il était difficile d'établir des corrélations physiologiques satisfaisantes permettant de comprendre les fonctions des différents types de fibres ainsi révélés dans la contraction musculaire (Guth, 1973 ; Maxwell et al., 1982). De plus, l'origine de la sensibilité différentielle de la myosine de différents types de fibres aux préincubations acides ou alcalines reste inexpliquée.

Edgerton et Simpson (1969) montrent clairement que l'activité ATPasique ne permet pas de distinguer les fibres rouges des fibres blanches chez le rat et le cobaye adultes. Ils ont les premiers classé les fibres selon trois types en

Reproduction, Nutrition, Développement, $n^{\circ} 6 \mathrm{~A} / 88-2$ 


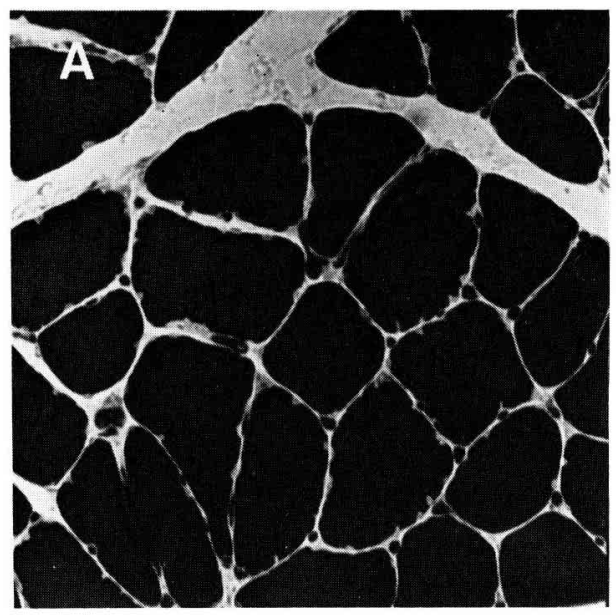

B
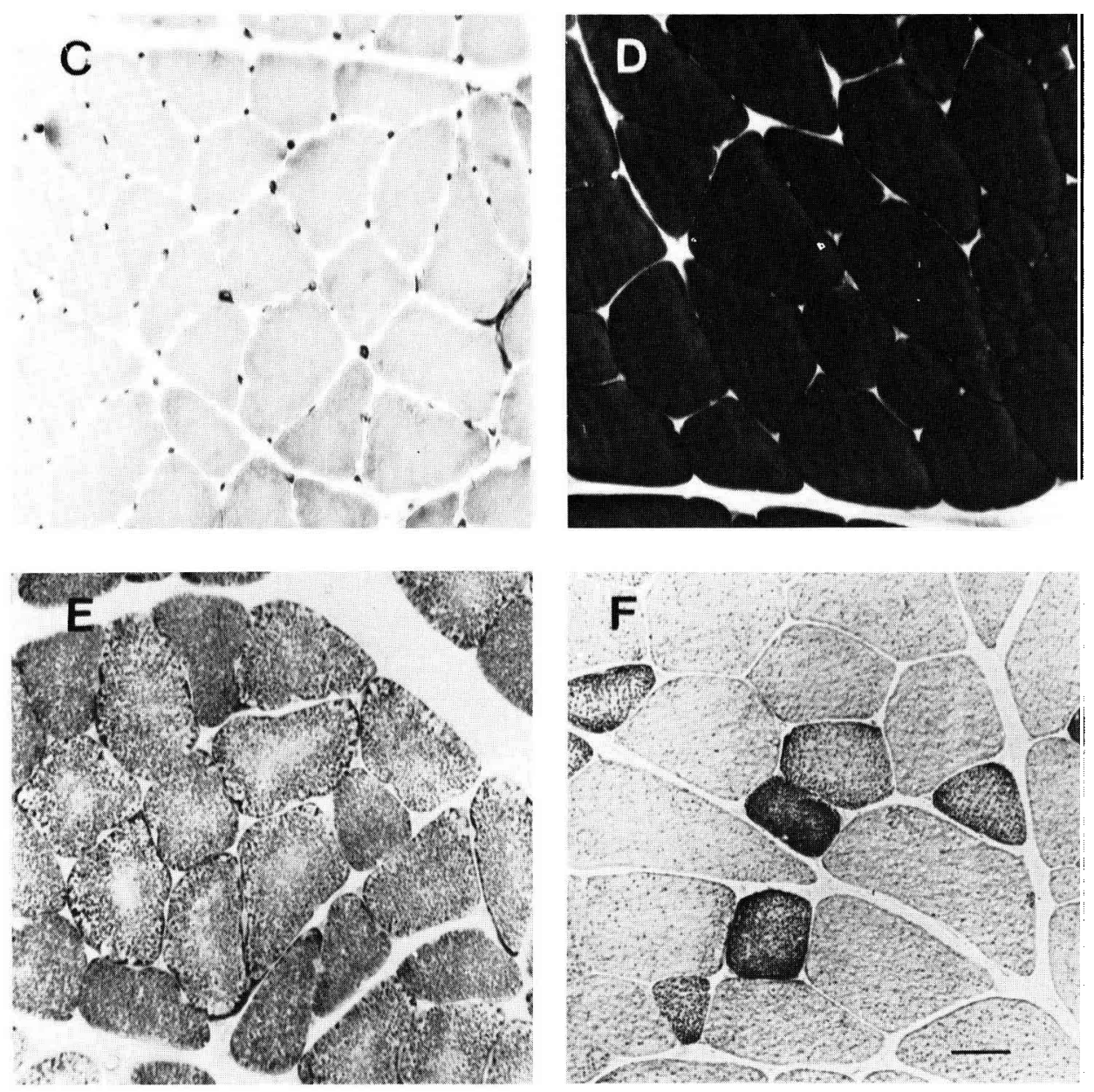
conjuguant l'utilisation d'enzymes oxydatives (SDH, MDH et NADH diaphorase) et l'activité ATPasique : fibres blanches (ATPase élevée, activité oxydative basse), intermédiaires (ATPase basse, activité oxydative intermédiaire) et rouges (ATPase élevée, activité oxydative élevée - Planche 1E-F). Par la suite, diverses nomenclatures basées sur la double révélation activité ATPasique/activité oxydative ont été publiées. Parmi celles-ci, nous retiendrons la classification de Ashmore et Doerr (1971), particulièrement utilisée dans les études appliquées à certains animaux domestiques : $\alpha \mathrm{W}$ (ATPase acido-labile, métabolisme glycolytique), $\alpha \mathrm{R}$ (ATPase acido-labile, métabolisme oxydatif élevé) et $\beta \mathrm{R}$ (ATPase acido-résistante,métabolisme oxydatif élevé), et la classification de Peter et al. (1972), juxtaposant l'activité contractile et la nature du métabolisme producteur d'énergie: FG (contraction rapide, métabolisme glycolytique), FOG (contraction rapide, métabolisme oxydoglycolytique) et SO (contraction lente, métabolisme oxydatif).

La classification selon trois types de fibres a trouvé une confirmation élégante dans les expériences de Edström et Kugelberg (1968) et de Burke et al. (1971). En explorant les propriétés contractiles d'unités motrices (cf. Chapitre II) isolées de chat par stimulation du motoneurone correspondant, ces auteurs ont montré que toutes les fibres musculaires appartenant à une unité motrice avaient le même profil histoenzymologique et des propriétés contractiles caractéristiques de ce profil. Deux paramètres ont permis de subdiviser les unités motrices en trois groupes parfaitement distincts : la sensibilité à la fatigue (mesurée par l'appauvrissement relatif en glycogène) au cours d'une stimulation répétitive prolongée, et la forme de la courbe de tension développée au cours d'un tétanos incomplet. Burke et ses collaborateurs distinguaient ainsi trois types de fibres: les fibres FF (Fast, Fatigable) à contraction puissante, rapides mais fatigables, les fibres FR (Fast, Résistantes à la fatigue) à contraction rapide et résistantes à la fatigue, et les fibres $S$ (slow) à contraction lente, non fatigables (Nemeth et al., 1981). Par la suite, un quatrième type mineur d'unité motrice $(F)$ a été déterminé, de propriétés intermédiaires entre les types FF et FR (Burke et al., 1973; Burke et Tsairis, 1974).

II existe une excellente corrélation entre les types physiologiques de Burke et les profils histochimiques des fibres de l'unité motrice, comme le montre le tableau 3 qui récapitule également les différences structurales entre les types de fibres ainsi déterminés. Si trois types principaux de fibres sont généralement proposés, certains auteurs ont décrit plusieurs types supplémentaires de fibres afin d'affiner leur classification. Ces types de fibres, aux propriétés intermédiaires peuvent être liés à des caractéristiques d'espèces (Suzuki, 1970; Suzuki et Tamate, 1974 ; Suzuki et Cassens, 1980 ; Wirtz et al., 1983; Hintz et al., 1984),

PLANCHE 1. - Caractérisation par l'ATPase myofibrillaire après préincubation acide (A, B) ou alcaline (C, D) et par l'activité de la succinate déshydrogénase ( $\mathrm{E}, \mathrm{F})$ des fibres musculaires de lapin :- de type I du muscle Semimembranosus proprius (A, C, E) : - de type IIA et IIB du muscle Semimembranosus accessorius (B, D, F). Les fibres de type IIA et IIB possèdent les mêmes propriétés ATPasiques, mais l'activité de la succinate déshydrogénase est plus importante dans les fibres IIA que dans les fibres IIB.

Echelle $=50 \mu \mathrm{m}(\mathrm{F})$. 
à diverses conditions physiologiques (Engel, 1970 ; Guth et Samaha, 1972) ou encore à la propriété de conversion des types contractiles de fibres (Brown et al., 1983; Seedorf et al., 1983) déjà mentionnée par Ashmore (1974). Ceci sous-entend la coexistence de différentes protéines contractiles et isoenzymes à l'intérieur d'une même fibre et conduit à une multitude de types possibles, avec des problèmes de limites entre classes non résolus (Kugelberg et Lindegren, 1979 ; Lefaucheur, 1985).

\section{Propriétés immunologiques des types de fibres.}

C'est pour répondre aux questions posées lors de recherches liées à l'établissement des structures et des propriétés de divers types de fibres musculaires au cours de l'embryogenèse, qu'ont été abordées les études des caractéristiques immunologiques des isoformes des principales protéines contractiles, en particulier de la myosine (revues de Gröshel-Stewart et Drenckhahn, 1982). Après une série de travaux préliminaires attestant l'existence de différences immunologiques entre les myosines extraites de muscles squelettiques homogènes lents et rapides (Lowey et Steiner, 1972; Gröshel-Stewart et al., 1973 ; Mazaki, 1974 ; Arndt et Pepe, 1975 ; Bruggmann et Jenny, 1975), Gauthier et Lowey, 1977) montraient par immunofluorescence que plus d'une isoenzyme de la myosine existait à l'intérieur d'un même muscle et que les types de fibre pouvaient être reconnus par les différences immunologiques de leurs myosines.

A l'aide d'anticorps contre la myosine entière de Pectoralis de poulet (muscle blanc, rapide), ces auteurs déterminent, en les comparant aux résultats obtenus avec les activités ATPase/SDH, quatre types de fibres dans le diaphragme de rat: trois d'entre eux réagissent avec l'anticorps (types de fibres blanc, intermédiaire et rouge), le quatrième ne réagissant pas (rouge). Ces auteurs font correspondre ces quatre types de fibre aux quatre types d'unité motrice décrits par Burke et al. (1973), c'est-à-dire respectivement FF, F (intermédiaire), FR et $S$. Des résultats semblables ont été obtenus à partir d'anticorps contre les têtes (fragment $S_{1}$ ), la queue, ainsi que les chaînes alcalines $\left(L C_{1}, L C_{3}\right)$ et « régulatrices" $\left(L C_{2}\right)$ de la myosine (Gauthier et Lowey, 1979 ; Lowey, 1980). Les anticorps contre la tête et la queue de la molécule réagissent sur les trois types de fibres marqués avec les anticorps contre la myosine entière, indiquant que l'homologie entre les myosines inclut à la fois les fragments $S_{1}$ et la queue de la molécule. Des différences apparaissent toutefois dans l'intensité de réponse de certains types de fibres, en particulier au niveau du fragment $S_{1}$ : les fibres rouges FR qui réagissent contre la myosine entière sont marquées plus faiblement avec l'anticorps anti- $S_{1}$ que ne le sont les fibres blanches ou intermédiaires. Les déterminants antigéniques localisés dans la tête de la molécule seraient distribués de façon hétérogène dans les divers types de fibres. Par contre, aucune différence de coloration n'est observée avec les anticorps contre la queue de la myosine. Les anticorps obtenus contre les chaînes légères réagissent avec autant de spécificité que ceux obtenus contre la molécule de myosine entière. Une variation de l'intensité de la réponse des anticorps contre les chaînes légères $L_{3}$ est toutefois observée au niveau des fibres rouges $F R$, analogue à celle mentionnée avec les anticorps $S_{1}$, ce qui 
suggère que les chaînes $\mathrm{LC}_{1}$ et $\mathrm{LC}_{3}$ ne sont pas distribuées uniformément parmi les types de fibres. Les homologies de séquence entre les myosines blanches, intermédiaires et rouges $\mathrm{FR}$ ne sont donc pas réduites à une partie limitée de la molécule, mais incluent la tête, la queue et toutes les classes de chaînes légères. Enfin, en utilisant des anticorps contre la myosine du muscle Latissimus dorsi anterior (ALD lent, oxydatif) de poulet, Gauthier et Lowey (1979) obtiennent des résultats inverses : pas de marquage des fibres constituant les muscles rapides tels le Latissimus dorsi posterior (PLD) et le Pectoralis de poulet, marquage intense des fibres lentes que ce soit sur I'ALD de poulet ou le Soléaire de rat (Gauthier, 1980). L'ensemble de ces données a amené les auteurs à suggérer l'existence de trois types de myosine chez l'adulte: un type blanc-rapide, un type rouge-lent, et un troisième type rouge-rapide diffèrent des myosines de type blanc-rapide par leurs faibles marquages avec les anticorps anti $S_{1}$ et anti $L_{3}$ (tabl. 4).

\section{TABLEAU 4}

Caractéristiques ultrastructurales et cytochimiques des fibres musculaires en relation avec les propriétés des unités motrices.

\section{Caractères}

\section{Physiologie}

Unité motrice

Vitesse de contraction

Résistance à la fatigue

\section{Morphologie}

Surface plaque motrice

Réticulum sarcoplasmique

Tubules transverses

Couleur

Myoglobine

Densité capillaire

Nombre de mitochondries

Epaisseur de la strie Z

Richesse en collagène

Aire de section

Métabolites

Glycogène

Lipides

Propriétés enzymatiques

ATPase myofibrillaire

Hexokinase

Phosphorylase

Enzymes de la glycolyse anaérobie

Enzymes oxydatives

Propriétés immunologiques de la myosine (poulet)

Myosine anti-Pectoralis

Myosine anti-ALD

Types Références

\begin{tabular}{|c|c|c|c|}
\hline & \\
\hline I & IIA & IIB & \\
\hline $\begin{array}{c}S \\
\text { lente } \\
+++\end{array}$ & $\begin{array}{c}\text { FR } \\
\text { rapide } \\
++\end{array}$ & $\begin{array}{c}\text { FF } \\
\text { rapide } \\
+\end{array}$ & Gauthier, 1980 \\
\hline+ & +++ & +++ & Ogata et Murata, 1969 \\
\hline+ & +++ & +++ & Schmalbruch, 1979 \\
\hline $\begin{array}{c}+ \\
\text { rouge }\end{array}$ & $\begin{array}{l}+++ \\
\text { rouge }\end{array}$ & $\begin{array}{c}+++ \\
\text { blanche }\end{array}$ & Cullen et a/., 1984 \\
\hline$+t+$ & $+t+$ & + & Morita et al., 1970 \\
\hline+++ & ++ & + & Romanul, 1965 \\
\hline+++ & $+t+$ & + & Pelissier, 1982 \\
\hline+++ & ++ & + & Friden et al., 1984 \\
\hline$++t$ & ++ & ++ & Kovanen et al., 1984 \\
\hline+ & +++ & +++ & Kiessling et Hanson, 1983 \\
\hline $\begin{array}{c}+ \\
++\end{array}$ & $\begin{array}{l}+t+ \\
++t\end{array}$ & $\begin{array}{c}++ \\
+\end{array}$ & $\begin{array}{l}\text { Peter et al., } 1972 \\
\text { Reitman et al., } 1973\end{array}$ \\
\hline+ & +++ & +++ & Barany, 1967 \\
\hline+++ & ++ & + & Bass et al., 1969 \\
\hline+ & ++ & +++ & Bass et al., 1969, 1970 \\
\hline+ & ++ & +++ & Essen et al., 1975 \\
\hline+++ & $+t$ & + & Reichmann et Pette, 1982 \\
\hline- & \pm & + & Gauthier, 1980 \\
\hline+ & $\overline{ \pm}$ & - & \\
\hline
\end{tabular}


L'ensemble des données obtenues à ce jour soit chez l'adulte, soit au cours de l'embryogenèse conduisent aux conclusions suivantes:

a) les myosines, et particulièrement leurs chaînes lourdes, isolées à partir de muscles homogènes rapides ou lents adultes, ont des propriétés antigéniques différentes permettant de séparer les types de fibres rapide ou lent. Ces résultats ont été obtenus soit à partir d'anticorps polyclonaux (Lutz et al., 1978 ; Billeter et al., 1980; Gauthier et Lowey, 1977, 1979; Gauthier, 1980), soit à partir d'anticorps monoclonaux (Bader et al., 1982 ; Crow et Stockdale, 1984 ; Moore et al., 1984 ; Shafiq $e t$ al., 1984) et sont en relation avec la vitesse de contraction des muscles (Gauthier et al., 1982);

b) les types de fibres ainsi mis en évidence sont semblables à ceux obtenus en utilisant les techniques histochimiques classiques. Toutefois, des sousgroupes peuvent apparaître permettant de différencier les fibres phasiques à contraction lente des mammifères (Pierobon-Bormioli et al., 1980), des fibres toniques à contraction lente des oiseaux (Shafiq et al., 1984) ;

c) au cours du développement embryonnaire, toutes les fibres réagissent aussi bien avec les antimyosines rapides que lentes (Gauthier et al., 1978 ; Lowey et al., 1982 ; Stockdale et al., 1982). De nombreux auteurs ont montré que ces myosines sont, sur le plan biochimique, distinctes des formes rapides ou lentes adultes (Winkelmann et al., 1983; Sweeney et al., 1984). Elles correspondent à des formes embryonnaires et néonatales (Gambke et Rubinstein, 1984) qui apparaissent successivement puis disparaissent séparément avant que les chaînes adultes ne les remplacent (Whalen et al., 1979, 1981; Sartore et al., 1982; Butler-Browne et Whalen, 1984).

- Conclusion. - L'ensemble des résultats obtenus en utilisant soit des techniques histochimiques (enzymes métaboliques et ATPase), morphologiques, fonctionnelles (vitesse de contraction), neurophysiologiques (unités motrices) et immunologiques, montre la difficulté d'établir un consensus dans la classification des fibres (Nemeth et al., 1979; Nemeth et Pette, 1981a, b ; Spurway, 1981 ; Reichmann, 1985). Malgré les différences liées soit à des cas d'espèces (Barnard et al., 1982; Green et al., 1984), soit aux propriétés neurophysiologiques (Kugelberg, 1973; Burke et al., 1974 ; Hennig et Lømo, 1985), la nomenclature la plus utilisée à l'heure actuelle est dérivée de celle proposée par Brooke et Kaiser (1974) qui combine l'activité ATPasique myofibrillaire et l'activité métabolique oxydative mitochondriale de la SDH : type I (activité ATPase faible, SDH élevée), type IIA (ATPase élevée, SDH élevée), type IIB (ATPase élevée, SDH faible), et IIC (ATPase élevée, SDH élevée) présente dans la période embryonnaire et néonatale. C'est cette nomenclature que nous utiliserons dans cette revue.

\section{B) Innervation motrice et matrice extracellulaire des fibres musculaires squelettiques}

Comme l'ont montré les travaux effectués au cours des vingt-cinq dernières années, les propriétés contractiles et métaboliques des muscles squelettiques sont sous la dépendance de la nature de l'innervation motrice. La deuxième partie de 
cette revue sur la biologie de la fibre musculaire squelettique sera donc consacrée à l'importance de l'innervation motrice dans l'acquisition des caractéristiques des fibres au cours de l'embryogenèse, et dans le maintien de ces propriétés chez l'adulte. Nous nous intéresserons, en outre, à la matrice extracellulaire qui enveloppe chacune des fibres musculaires et s'étend entre les digitations synaptiques au niveau de la jonction neuromusculaire. De nombreuses expériences ont montré, en effet, que les zones synaptiques et extrasynaptiques de la matrice extracellulaire possédaient des propriétés immunologiques différentes et que celles-ci guidaient, dans une certaine mesure, la mise en place de l'innervation motrice au cours de la réinnervation expérimentale. L'existence de cette structure, dont le rôle et les constituants biochimiques sont mieux connus, nous ont amené à lui consacrer un chapitre particulier.

\section{1) L'unité motrice : module de base du fonctionnement musculaire.}

A l'échelle de l'organisme, chaque muscle constitue l'unité tissulaire permettant la mise en mouvement des articulations. Sur le plan fonctionnel, l'organisation de la contraction musculaire se situe au niveau de l'unité motrice. Telle qu'elle a été définie par Sherrington, l'unité motrice consiste en un motoneurone localisé dans la corne ventrale de la moelle épinière, son axone moteur, et l'ensemble des fibres musculaires motrices qu'il innerve : I'excitation du motoneurone entraîne la contraction de toutes les fibres de l'unité motrice ; sur un plan global, la régulation de l'amplitude de la contraction musculaire s'effectue par le nombre de motoneurones recrutés.

Le nombre d'unités motrices (donc le nombre de motoneurones) varie selon les muscles et peut atteindre plusieurs centaines pour les plus gros d'entre eux (Mommaerts, 1970 ; Sica et al., 1974). De même, le nombre de fibres musculaires de chaque unité motrice est variable à l'intérieur d'un même muscle et d'un muscle à l'autre : le nombre de fibres musculaires d'une unité motrice est peu important (de l'ordre de la dizaine) dans les muscles commandant des mouvements rapides et précis, comme les muscles extrinsèques de l'œil (Buchtal et Schmalbruch, $1980)$; inversement, les unités motrices contenant le plus grand nombre de fibres musculaires se trouvent dans les muscles actionnant les masses corporelles les plus importantes: plus de 1700 fibres sont ainsi innervées par le même motoneurone dans le muscle Gastrocnemius medius chez l'homme (voir les revues de Buchtal et Schmalbruch, 1980, et de Pette et Vrbova, 1985). Par ailleurs, nous avons vu dans le chapitre précédent que les unités motrices possèdent des propriétés morphologiques, biochimiques et physiologiques différentes à l'intérieur d'un même muscle, les fibres d'une unité motrice donnée ayant les mêmes caractéristiques physiologiques et histochimiques (Close, 1967 ; Dum et Kennedy, 1980).

Pour expliquer la spécificité d'association neurone-fibres d'un même type, deux hypothèses peuvent être avancées: soit les caractéristiques des fibres musculaires sont génétiquement différentes et les neurones reconnaissent respectivement chacun des types de fibre; soit toutes les fibres sont génétiquement équipotentielles et leur spécificité n’est déterminée que par la nature du motoneurone qui les innerve. Bien que ces deux hypothèses ne soient pas 
exclusives, la plupart des travaux réalisés sur le système neuromusculaire montre les étroites interactions existant entre muscle et nerf moteur, en particulier dans l'établissement de la typologie et le maintien des caractéristiques contractiles et métaboliques des fibres musculaires. L'importance de ces relations a été surtout étudiée chez l'adulte : pour certains, le nerf agirait sur la détermination du type de fibre musculaire par un hypothétique facteur trophique; pour d'autres, le nerf agirait par l'intermédiaire du type d'activité motrice qu'il impose. Plusieurs auteurs ont extrapolé les résultats expérimentaux obtenus chez l'adulte à la mise en place de l'innervation motrice au cours de l'embryogenèse (Buller et al., 1960b). Bien que de nombreuses analogies expérimentales se retrouvent entre ces deux stades, le tissu musculaire en différenciation montre, cependant, une certaine indépendance vis-à-vis de l'innervation motrice, apportant des arguments aux tenants de I'hypothèse «myogène » de la différenciation des fibres (Rubinstein et Kelly, 1978).

\section{II) Rôle de l'innervation motrice.}

1. Rôle de l'innervation motrice dans l'acquisition des propriétés de la fibre musculaire au cours de l'embryogenèse.

1.1. Etablissement des contacts neuromusculaires. - Parmi les faits marquants des relations neuromusculaires, la synaptogenèse est sans nul doute celui qui revêt l'importance la plus grande : il représente la différenciation d'une structure spécialisée, la plaque motrice, impliquant la reconnaissance réciproque du neurone et de la fibre musculaire.

La formation des synapses neuromusculaires commence très tôt au cours du développement, les myotubes étant innervés par plusieurs motoneurones dans les deux jours qui suivent leur formation (Bennett, 1983). Ainsi dans les bourgeons des membres du poulet, la stimulation neurale provoque des contractions avant même que les masses musculaires ne soient clivées en muscles distincts (Landmesser et Morris, 1975). En dépit de sa précocité, la synaptogenèse est très étalée dans le temps, les synapses n'acquérant leurs caractéristiques adultes qu'après plusieurs semaines de développement postnatal (Kelly et Zacks, 1969b ; Rees et al., 1976 ; Kelly, 1978; Dennis et al., 1981). Un des aspects les plus étudiés de la synaptogenèse neuromusculaire concerne la distribution des récepteurs de l'acétylcholine $(A C h R)$. Les fibres musculaires sont initialement sensibles à l'acétylcholine (ACh) sur toute leur longueur (Diamond et Miledi, 1962 ; Burden, 1977a, b; Weinberg et al., 1981); après 16 jours de gestation chez le rat, des amas d'AChR apparaissent aux sites synaptiques, bien que la sensibilité extrajonctionnelle à l'ACh soit encore importante (Bevan et Steinbach, 1977 ; Steinbach, 1981). La spécialisation postsynaptique rudimentaire s'accroît progressivement, la plaque motrice devient plus complexe, les AChR s'accumulent à la zone synaptique définitive, et les récepteurs extrajonctionnels disparaissent dans le premier mois de la vie (Gutmann et Hanzlikova, 1965 ; Nystron, 1968a, b ; Teravainen, 1968 ; Reiness et Weinberg, 1981 ; Hall et al., 1985).

L'étude de la distribution, du métabolisme et de la fonction des AChR a servi de base d'étude aux questions soulevées par la synaptogenèse (Purves et 
Lichtman, 1985) : existe-t-il des régions spécialisées destinées à devenir site postsynaptique à la surface des cellules cibles avant l'arrivée de l'innervation, ou bien les zones synaptiques sont-elles induites par celle-ci ? Dans quelle limite les cellules postsynaptiques induisent-elles une différenciation des éléments présynaptiques? La discussion relative à cette dernière question sera abordée dans le troisième volet de ce chapitre, consacré à la matrice extracellulaire.

Les réponses aux premières questions ont été établies essentiellement en étudiant la distribution des AChR sur des cellules musculaires différenciées in vitro ou en co-culture nerf-muscle de Vertébrés. Dans des conditions de culture aneurale, l'existence de zones de haute densité d'AChR ( myotubes (Fischbach et Cohen, 1973 ; Sytkowsky et al., 1973 ; Fischbach et al., 1979; Frank et Fischbach, 1979), co-localisées avec des digitations de la membrane musculaire dans les cultures de mammifères, avec des concentrations d'acétylcholinestérase ( $\mathrm{AChE}$ ) et de certains antigènes synaptiques (MoodyCorbett et Cohen, 1981 ; Sanes et al., 1984), laissait penser à une préspécialisation de certains sites de la fibre musculaire. En utilisant des co-cultures nerf-muscle, il apparut en fait que les terminaisons nerveuses n'innervent pas les " hotspots » pré-existants, mais qu'au contraire le contact nerf-muscle réorganise les récepteurs membranaires qui s'agrègent au point de contact et disparaissent ailleurs (Anderson et Cohen, 1977 ; Anderson et al., 1977 ; Cohen et al., 1979 ; Moody-Corbett et Cohen, 1982 ; Role et al., 1985). De même, l'accumulation de l'AChE en régions de fortes concentrations paraît être sous la dépendance de l'innervation (Fischbach et al., 1979) et est stimulée comme celle des AChR, par des extraits de nerf (Davey et al., 1979). Toutefois, alors que le phénomène d'agrégation des AChR s'effectue sur des fibres paralysées, l'accumulation de l'AChE à la plaque motrice ne se fait pas en présence de curare (Rubin et al., 1980 ; voir cependant Moody-Corbett et al., 1982 ; Cohen et al., 1984 ainsi que Lømo et Slater, 1980a).

Ainsi, le contact synaptique initial s'établit probablement au hasard avec les myotubes qui reçoivent transitoirement une innervation polyneurale. L'ensemble des changements qui interviennent au cours de la formation des synapses montre que les axones présynaptiques ont une forte influence sur la différenciation des structures spécialisées postsynaptiques (Korneliussen et Sommerschild, 1976). L'agrégation des $A C h R$, par exemple, suggère que certains aspects postsynaptiques de la jonction neuromusculaire sont induits par une information provenant de la cellule présynaptique et qu'il n'existe pas de zone prédéterminées sur les myotubes. Les données actuelles ne permettent pas de déterminer l'agent responsable des transformations observées. Cependant, l'agrégation des AChRs ne paraît pas influencée par l'absence d'activité in vitro, résultat analogue à celui observé après ténotomie du muscle adulte. Au contraire, l'accumulation d'AChE dépend à la fois de l'action nerveuse trophique et de l'activité des fibres musculaires, ce qui laisse penser que ces deux facteurs agissent indépendamment sur les différents constituants de la jonction neuromusculaire (voir toutefois, Wallace et al., 1985).

La majorité des fibres musculaires des mammifères adultes possède une seule plaque motrice occupant environ $0,1 \%$ de la surface membranaire, mais sur 
certaines longues fibres, deux ou trois synapses peuvent cohabiter (Bennett et Pettigrew, 1976). Cette situation contraste avec le type d'innervation des fibres au cours du développement. Dès le début du siècle, Tello (1917) avait observé que contrairement aux adultes, les fibres des muscles d'animaux nouveau-nés étaient innervées au même endroit par plusieurs axones différents, observation confirmée par Redfern en 1970. De nombreuses études morphologiques, électrophysiologiques et pharmacologiques montrèrent que ces contacts synaptiques étaient localisés approximativement à la même place que le site de la plaque motrice adulte. Cette constatation implique l'élimination de certaines synapses initiales (Bennett et Pettigrew, 1974; Brown et al., 1976; Korneliussen et Jansen, 1976; Riley, 1976, 1977a, b, 1981) et se déroule en deux phases: premièrement, une phase de mort cellulaire se déroulant au cours de la période périnatale, pendant laquelle le nombre de neurones innervant la cible diminue pratiquement de moitié (Pittman et Oppenheim, 1978; Oppenheim et Nunez, 1982 ; Oppenheim, 1984). Deuxièmement, une phase d'élimination synaptique se déroulant après la précédente au cours de laquelle les neurones survivants réduisent le nombre de leurs axones, perdant de ce fait le contact avec certaines de leurs cellules cibles (voir la revue de Bennett, 1983). Ces phénomènes ont été abondamment étudiés, et il semble que l'activité musculaire ait une grande influence sur le réaménagement synaptique néonatal. Ainsi, la paralysie chronique du nerf par un anesthésique local ou la ténotomie diminuent la vitesse d'élimination synaptique (Benoit et Changeux, 1975, 1978 ; Riley, 1978 ; Srihari et Vrbova, 1978 ; Thompson et al., 1979 ; Brown et al., 1982 ; Caldwell et Ridge, 1983). Au contraire, l'augmentation de l'activité des axones par stimulation chronique accélère ce processus (O'Brien et al., 1978; Thompson, 1983; Bourgeois et al., 1986).

Ainsi, la construction du schéma synaptique adulte implique non seulement la formation, mais aussi la disparition de nombreuses synapses. La polyinnervation des fibres musculaires est un aspect général de la synaptogenèse: elle disparaît chez le rat, le chat et le lapin entre la première et la troisième semaine de développement postnatal (Bagust et al., 1973; Bennett et Pettigrew, 1974; Rosenthal et Taraskevich, 1977 ; Bixby et Van Essen, 1979).

1.2. Développement des fibres musculaires et importance de linnervation motrice. - Les différentes étapes de l'évolution des cellules myogéniques ne sont pas synchronisées dans le développement du tissu musculaire in vitro. Ainsi, au même moment, en un même endroit, il est possible d'observer à la fois des cellules mononuclées indifférenciées, des myoblastes fusiformes, des myotubes plurinuclées à noyaux centraux et des fibres immatures. De nombreuses études ont rapporté l'apparition de générations successives de myotubes chez l'embryon de souris (Wirsen et Larsson, 1964), de rat (Kelly et Zacks, 1969a), d'agneau (Ashmore et al., 1972b), de porc (Ashmore et al., 1973a ; Swatland et Cassens, 1973) et de poulet (Ashmore et al., 1973b; McLennan, 1983a; Crow et Stockdale, 1986). Afin de clarifier la présentation, nous décrirons la morphogenèse du muscle intercostal de rat (Kelly et Zacks, 1969a), chez lequel l'établissement des relations neuromusculaires a été étudié parallèlement (Kelly et Zacks, 
1969b), les événements décrits ci-dessous étant qualitativement représentatifs de ceux observés dans d'autres muscles et chez d'autres espèces animales (Touraine, 1981 ).

A seize jours de gestation (fig. 2A), le muscle en différenciation comprend de nombreux groupes de cellules séparés les uns des autres par de larges espaces intercellulaires. Les cellules les plus différenciées, petites, possèdent des noyaux centraux et de nombreuses myofibrilles périphériques. Les cellules, longues de 100 à $300 \mu \mathrm{m}$, ont été nommées «myotubes primaires». La composition de différents groupes de cellules est variable, mais il y a souvent plusieurs myotubes primaires adjacents entourés de cellules mononucléées indifférenciées en contact étroit avec les myotubes.

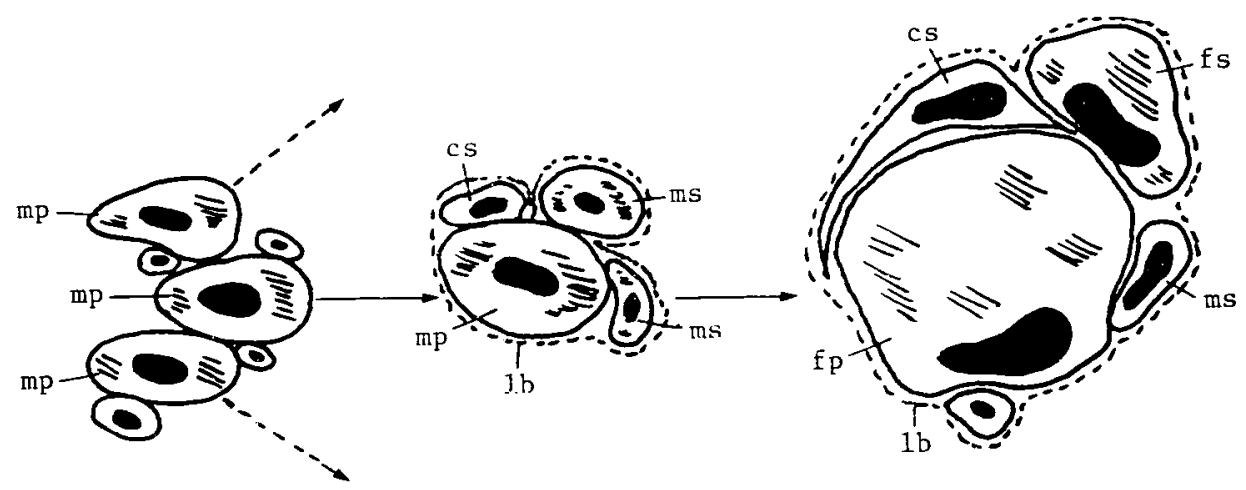

A B

FIG. 2. - Différenciation des cellules myogéniques en un groupe de cellules musculaires. A: les myotubes primaires ( $\mathrm{mp}$ ), accompagnés de cellules indifférenciées, sont séparés des ensembles de myotubes nouvellement formés. $B$ : des amas de cellules se forment autour des mp ; tous sont enveloppés dans une lame basale (lb) commune. Ces cellules sont constituées de myotubes secondaires ( $\mathrm{ms}$ ) et de cellules satellites (cs). C : les $\mathrm{mp}$ se différencient en fibres musculaires primaires $(\mathrm{fp})$, et les $\mathrm{ms}$ se différencient en fibres musculaires secondaires ( $\mathrm{fs}$ ) ; les cs et $\mathrm{ms}$ sont encore localisés à l'intérieur de la lb commune (modifié d'après Bennett, 1983).

A dix-huit jours de gestation (fig. 2B), les groupes de cellules sont plus petits et plus organisés. Ils sont dominés par un ou plusieurs myotubes primaires bien différenciés. Ces myotubes sont entourés par des cellules mononucléées ou plurinucléées possédant quelques myofilaments et quelques grains de glycogène. Ces cellules plurinucléées sont considérées comme une génération secondaire de myotubes formés par fusion des myoblastes qui se trouvent en contact étroit avec les myotubes primaires au stade 16 jours. Chaque groupe de cellules est entouré par une lame basale rudimentaire qui ne pénètre pas à l'intérieur de celui-ci. 
A la naissance, soit après 21 jours de gestation (fig. $2 \mathrm{C}$ ), la plupart des fibres sont individualisées et entourées d'une lame basale, mais il reste encore quelques groupes de cellules à l'intérieur d'une même matrice extracellulaire (Ontell et Dunn, 1978).

Les techniques histochimiques et immunocytochimiques utilisées chez l'adulte ont été appliquées pour déterminer à quel moment de la myogenèse débute la différenciation des types de fibres musculaires. Les muscles des animaux nouveau-nés se contractent lentement quel que soit leur type chez l'adulte (Denny-Brown, 1929; Buller et al., 1960a; Drachman et Johnston, 1973). Paradoxalement, les travaux d'Ashmore et al., (1972b, 1973a), de Butler et Cosmos $(1981 \mathrm{a}, \mathrm{b})$ mettent en évidence une différenciation très précoce d'une activité ATPasique, aux $60^{\mathrm{e}}$ jour de gestation chez le mouton, $75^{\mathrm{e}}$ jour chez le porc (durées respectives de gestation : 147 et 115 jours) et à la fin de la première semaine d'incubation chez le poulet: l'activité ATPasique myofibrillaire des myotubes primaires résiste à la pré-incubation acide, propriété des fibres de type I; les myotubes secondaires montrent un schéma réactionnel inverse, qui correspond aux caractéristiques des fibres de type II. Sur le plan biochimique et immunochimique, ces données sont encore controversées. Les premiers travaux suggéraient que le muscle en développement contenait essentiellement de la myosine de type lent, en particulier dans les myotubes primaires (Brevet et Whalen, 1978 ; Gauthier et al., 1978 ; Cantini et al., 1980; Kelly et Rubinstein, 1980), tandis que d'autres montraient la présence de myosine rapide, en particulier dans les myotubes secondaires (Rubinstein et al., 1977 ; Rubinstein et Kelly, 1978 ; Rubinstein et Holtzer, 1979 ; Kelly et Rubinstein, 1980). Toutefois, et depuis les travaux de l'équipe de Whalen, il est acquis que la myosine existe sous deux formes embryonnaire et fœtale au cours du développement, deux formes différentes des myosines rapide et lente. A l'heure actuelle, on ne sait pas si la myosine lente détectée par immunocytochimie dans les myotubes primaires correspond à la même protéine lente adulte, ou s'il s'agit d'une isoenzyme différente (Rubinstein et Kelly, 1981 ; Kelly et Rubinstein, 1985).

Contrairement aux propriétés de la myosine, les caractéristiques métaboliques de chaque type de fibres se mettent en place plus tardivement. Pendant la vie embryonnaire et fœtale, ainsi que dans les jours qui suivent la naissance ou l'éclosion, toutes les fibres possèdent un métabolisme de type aérobie. Par la suite, les activités enzymatiques n'évoluent pratiquement pas dans les futures fibres I ; par contre, le métabolisme des futures fibres II se transforme progressivement par l'acquisition d'activités glycolytiques.

Un parallèle est souvent établi entre les interactions neuromusculaires chez l'adulte, et les mécanismes intervenant dans la différenciation des fibres au cours du développement. Toutefois, la situation des muscles dans la période néonatale n'est pas aussi simple, les fibres musculaires étant différenciées en deux types (I et II) malgré la présence de la polyinnervation. Cette observation indique, soit que les motoneurones polyinnervent les fibres au hasard et que l'expression phénotypique des fibres I et II n'est pas déterminée par l'innervation motrice, soit que l'innervation polyneurale s'installe de façon à ce que chaque fibre reçoive des informations précises et convergentes pour sa différenciation. Les travaux récents 
de Thompson et al. (1984) et de Gordon et Van Essen (1985) (voir cependant Jones et al., 1985) montrent que dans la période périnatale, chaque motoneurone polyinnerve un seul des deux types de fibres présents dans le muscle étudié : ces auteurs suggèrent donc que, au cours du développement précoce, les motoneurones sont différenciés en types spécifiques innervant préférentiellement des types de fibres de mêmes propriétés contractiles (McLennan, 1983b).

La question importante sous-jacente à ces mécanismes est de savoir jusqu'à quel degré la différenciation des fibres musculaires est due à des influences « myogènes » (Nougues et Bacou, 1977 ; Bacou et Nougues, 1980), c'est-à-dire intrinsèques, ou «neurogènes», résultant d'actions inductrices du nerf sur le muscle (Rubinstein et Kelly, 1978 ; Peirone et Filogamo, 1980). Si chez l'adulte, le nerf moteur exerce une influence importante sur les propriétés contractiles des muscles, la différenciation des types de fibres lent et rapide du poussin peut se faire en l'absence d'influx nerveux (Laing et Lamb, 1983), mais n'évolue que jusqu' au stade myotube en absence totale d'innervation motrice (Popiela, 1976 , 1977 ; Sohal et Holt, 1980 ; Creazzo et Sohal, 1983). Butler et al. (1982) ont ainsi montré que le muscle ALD (type I), mais non le muscle PLD (type II), d'embryon de poulet survit à un état aneural au-delà du stade 32 ( 7,5 jours) de Hamburger et Hamilton (1951); ces résultats sont à rapprocher de ceux obtenus par McLennan (1983c) chez le poulet et Harris (1981a) chez le rat, montrant que la paralysie au cours du développement empêche le développement des myotubes secondaires.

Au cours de l'embryogenèse, la régulation du développement musculaire pourrait donc s'effectuer selon deux phases (Kelly et Rubinstein, 1985 ; voir aussi Eccles, 1963) : une phase primaire de formation des éléments musculaires, au cours de laquelle les myotubes primaires se développent en l'absence d'innervation motrice; une phase secondaire au cours de laquelle la structure de base des fibres se diversifie, en relation étroite avec l'innervation et l'activité motrice (Renaud et al., 1978, 1983 ; Toutant et al., 1979, 1980; Bloom et al., 1985).

Après la naissance ou l'éclosion, l'influence neurale est indispensable à la différenciation musculaire et au maintien de cette différenciation chez l'adulte (Hanzlikova et Schiaffino, 1973; Gordon et al., 1977 ; Betz et al., 1980 ; Okada et al., 1984). Cependant, les expériences de dénervation et de réinnervation néonatale, comme les résultats obtenus au cours de l'embryogenèse, ont montré la plus grande dépendance des fibres de type II vis-à-vis de l'innervation motrice (Curless, 1977 ; Engel et Karpati, 1968 ; Lowrie et al., 1982 ; Lowrie et Vrbova, 1984). Ces données qui suggèrent que l'influence neurale, via l'activité motrice ou trophique (Tomanek, 1976 ; Jones, 1981), agit surtout sur la différenciation des propriétés des fibres de type II, sont à rapprocher de celles obtenues par Close (1964) : pour cet auteur, la différence des vitesses de contraction entre les muscles rapides et lents est essentiellement due à une augmentation néonatale de la vitesse de contraction des muscles de type rapide, celle des muscles de type lent étant peu modifiée. Cette conception est cependant controversée. Ainsi, Huizar et al. (1975) ont montré que la vitesse de conduction axonale des motoneurones des muscles gastrocnémien (prédominance rapide) et soléaire (lent) chez le chat augmentait de façon monotone après la naissance, sans corrélation avec les 
changements postnatals de la vitesse de contraction des muscles. Ces auteurs concluent que l'activité musculaire agit aussi sur les propriétés des motoneurones, la différenciation des tissus nerveux moteurs et musculaires étant le résultat d'échanges permanents d'informations dans les sens antérograde et rétrograde (Czeh et al., 1978; Bacou et al., 1985).

Conc/usion. - Les fibres des muscles squelettiques sont initialement formées à partir d'une population de cellules de première génération, innervées précocement par les axones primitifs (Bennett et Pettigrew, 1974). Autour et à partir de ces myotubes primaires, une génération de myotubes secondaires se développe par un mécanisme dépendant de l'innervation. Les études par histochimie et immunocytochimie montrent que les propriétés de la myosine des myotubes primaires et secondaires sont différentes, et que la génération primaire de myotubes est destinée à donner les fibres de type I, les fibres de type II se développant à partir des myotubes secondaires. Malgré l'existence de ces deux types de fibres, l'ensemble des muscles possède à la naissance des caractéristiques contractiles analogues à celles des muscles lents, les différences métaboliques et fonctionnelles caractérisant les muscles rapides et lents ne se développant qu'après la naissance, lorsque l'innervation fonctionnelle s'établit. Les études faites sur des muscles embryonnaires paralysés ou aneuraux, et les résultats obtenus après dénervation néonatale montrent que l'innervation motrice est indispensable à l'acquisition et au développement des propriétés des fibres à contraction rapide, contrairement aux fibres à contraction lente relativement indépendantes des interactions trophiques ou motrices nerveuses au cours de cette période.

Ces conclusions, qui se réfèrent à des travaux effectués sur des tissus musculaires en formation, ont souvent été étayées par les résultats de nombreuses expériences réalisées chez l'adulte. Le chapitre suivant essaie d'apporter quelques éléments de réponse aux questions suivantes: les propriétés des fibres musculaires adultes sont-elles définitivement fixées ou dépendent-elles de l'innervation motrice? Les différents types de fibres ont-ils, à ce stade, une même dépendance vis-à-vis du neurone moteur? Quels sont les facteurs qui expliquent I'influence nerveuse et quels sont leurs limites?

2. Rôle de l'innervation motrice dans le maintien des propriétés de la fibre musculaire chez l'adulte.

2.1. Résultats expérimentaux. - Parmi les travaux étudiant l'influence du nerf moteur sur le muscle, on peut distinguer ceux dont le but est de vérifier l'effet de la privation d'activité motrice (par dénervation, immobilisation, ténotomie des muscles, blocage du transport axonal par la colchicine ou de la transmission synaptique par la $\alpha$-bungarotoxine ou la tétrodotoxine) et ceux visant à modifier l'activité contractile, soit par réinnervation homologue ou étrangère (réinnervation croisée), soit par stimulation du nerf ou du muscle.

2.1.1. Effets de la dénervation. - La dénervation des muscles squelettiques des Vertébrés adultes provoque une série de modifications drastiques de la structure et des propriétés biochimiques des fibres musculaires. Chez les 
mammifères adultes, la dénervation est suivie d'une atrophie générale des muscles plus prononcée pour les fibres de type II que pour les fibres de type I (Karpati et Engel, 1968 ; Asmussen et Kiessling, 1975 ; Pulliam et April, 1979b). Cependant, certains muscles particuliers comme le diaphragme, ou le muscle Latissimus dorsi anterior (ALD) des oiseaux présentent une hypertrophie transitoire ou permanente (Feng et al., 1962 ; Kikida et Bock, 1972 ; Stewart et al., 1972 ; Turner et Manchester, 1973 ; Yellin, 1974 ; Trout et al., 1981).

La dénervation stimule la prolifération cellulaire, en particulier celle des cellules satellites (McGeachie et Allbrook, 1978; Murray et Robbins, 1982; Snow, 1983 ; McGeachie, 1985). Des phénomènes de dégénérescence affectant à la fois le métabolisme, la structure des myofilaments et des terminaisons nerveuses apparaissent.

Sur le plan métabolique, on observe, après dénervation, une diminution de la synthèse et une augmentation de la dégradation de la majeure partie des protéines intracellulaires (Padieu, 1959 ; Schapira et Dreyfus, 1959; Gutmann, 1962). Ce phénomène se manifeste, en particulier au niveau des enzymes du métabolisme intermédiaire, par une dédifférenciation des propriétés métaboliques respectives des fibres, excepté dans l'hémidiaphragme dénervé chez le rat (Turner et Manchester, 1972a, b) : chute rapide des activités glycolytiques dans les fibres des muscles fonctionnant essentiellement en anaérobiose, diminution des activités oxydatives dans le muscle soléaire (Hogan et al., 1965 ; Romanul et Hogan, 1965 ; Pichey et Blaise Smith, 1979; Shackelford et Lebherz, 1981).

Au niveau de la structure des fibres musculaires, on observe une augmentation du nombre de lysosomes, de ribosomes et de globules lipidiques ainsi qu'un accroissement du réticulum sarcoplasmique (Gauthier et Dunn, 1973; Gauthier et Schaeffer, 1974). Par ailleurs, les myofilaments perdent progressivement leur striation régulière et s'orientent à la fois longitudinalement et transversalement (voir la revue de Tipnis et Malhotra, 1978). Ces modifications structurales sont associées avec la perte de coordination de la synthèse des protéines myofibrillaires : myosines lente et rapide sont exprimées dans les mêmes fibres (Gauthier et Hobbs, 1982 ; Carraro et al., 1985), tropomyosine, troponine et chaînes légères de la myosine évoluent vers des configurations embryonnaires (Dhoot et Perry, 1982 ; Matsuda et al., 1984a ; Obinata et al., 1984 ; Shimizu et Shimada, 1985).

Les terminaisons nerveuses subissent, après dénervation, une dégénérescence rapide affectant la partie présynaptique; des modifications du nombre et de la dimension des digitations postsynaptiques se produisent pendant plusieurs semaines après l'opération (Pulliam et April, 1979a). A ces modifications de la structure des membranes synaptiques s'ajoutent des changements dans la synthèse de certaines protéines concentrées à la jonction neuromusculaire: l'acétylcholinestérase (AChE) et les récepteurs de l'acétylcholine (AChR). Alors que l'on dénombre de 12000 à 46000 molécules d'AChR/ $\mu^{2}$ selon les muscles à la jonction neuromusculaire de fibres normales (Fambrough et Hartzell, 1972 ; Porter et al., 1973; Fertuck et Salpeter, 1974), on ne compte qu'une dizaine de molécules d'AChR/ $\mu^{2}$ au niveau de la membrane extrajonctionnelle (Hartzell et Fambrough, 1972). Après dénervation, la densité des AChR extrasynaptiques 
atteint plus de 600 molécules d'AChR $/ \mu^{2}$ (voir les revues de Edwards, 1979 et de Fambrough, 1979), et le niveau des ARN messagers correspondants augmente de près de 100 fois 3 jours après dénervation (Merlie et al., 1984). Cette synthèse de novo des récepteurs (Devreotes et Fambrough, 1976), biochimiquement identiques aux AChR jonctionnels et embryonnaires (Sumikawa et al., 1982a, b), est responsable de la sensibilité extrajonctionnelle à l'acétylcholine qui caractérise les fibres musculaires privées d'innervation motrice (Albuquerque et Mclsaac, 1970). Enfin, la matrice extracellulaire qui enveloppe chaque fibre n'est pas affectée dans un premier temps par la dénervation. Par contre, des modifications rapides des glycoprotéines de la membrane plasmique apparaissent (Leung et al., 1982; Covault et Sanes, 1985).

2.1.2. Effets de la ténotomie et de l'immobilisation. - Ténotomie et immobilisation par plâtre des articulations complètent les études réalisées par dénervation des muscles. Elles permettent de dissocier la privation d'activité motrice de la suppression d'activité contractile, tout en maintenant une éventuelle influence trophique nerveuse. De nombreux travaux réalisés chez le jeune et chez l'adulte montrent que la ténotomie entraîne des perturbations musculaires proches de celles observées après dénervation : atrophie, dégénérescence structurale, modification du métabolisme intermédiaire, des protéines contractiles et des propriétés membranaires. L'atrophie générale des muscles observée après ténotomie affecte plus sévèrement les muscles de type lent que les muscles de type rapide (Eccles, 1944; McMinn et Vrbova, 1964 ; McLachlan, 1981), et l'apparition de la dégénérescence graisseuse des fibres musculaires est même plus rapide qu'après dénervation (Bacou, observation personnelle). Après immobilisation ou ténotomie, les différences entre les voies du métabolisme énergétique des différents types de fibres s'atténuent, avec une diminution générale de l'activité de leurs enzymes, en particulier celles des métabolismes prépondérants (Booth et Kelso, 1973 ; Jozsa et al., 1978, 1979 ; Edes et al., 1980). Parallèlement, la vitesse de contraction des muscles (Vrbova, 1963; Buller et Lewis, 1965a) et les propriétés des protéines contractiles tendent à s'uniformiser (Bagust, 1979; Davis et Montgomery, 1977; Steinbach et al., 1980). Ces modifications peuvent être la conséquence des perturbations observées au niveau des plaques motrices (Vincent-Ablazey et al., 1978; Dias, 1979; McLachlan, 1983) ou des modifications de la vitesse de conduction des axones innervant les fibres affectées (Russel, 1980). Enfin, contrairement à la dénervation, on n'observe pas de sensibilité extrajonctionnelle à l'acétylcholine, ce phénomène n'apparaissant que de façon transitoire dans les fibres ténotomisées (Fischbach et Robbins, 1971).

2.1.3. Effets de la réinnervation croisée. - Dénervation, ténotomie, immobilisation attestent l'importance de l'innervation et de l'activité motrice dans le maintien des propriétés des muscles. Innervation croisée et stimulation électrique à fréquences lente ou rapide montrent que ces propriétés dépendent aussi du type de motoneurone innervant les fibres musculaires. Buller, Eccles et leurs collaborateurs montrèrent les premiers, par une série d'expériences chez le chat, que le croisement de l'innervation des muscles à contraction lente et rapide inversait les propriétés contractiles des fibres musculaires: la réinnervation du muscle Flexor 
digitorum longus - à contraction rapide - par le nerf moteur du muscle Soleus - à contraction lente - modifie la vitesse de contraction du muscle réinnervé vers les valeurs du muscle lent (et vice versa, Buller et al., 1960a, b ; Buller et Lewis, 1965b; Eccles, 1967). Afin de vérifier si les observations faites par ces auteurs étaient généralisables à l'ensemble des propriétés métaboliques et fonctionnelles qui différencient les fibres musculaires, de nombreux travaux ont été entrepris par la suite, comparant muscles normaux à ceux recevant une innervation croisée. Les résultats obtenus montrent que l'innervation croisée:

a) tend à inverser les propriétés métaboliques oxydatives et glycolytiques des muscles opérés, observations faites soit par histochimie (Dubowitz, 1967a, b ; Robbins et al., 1969; Prewitt et Salafsky, 1970; Romanul, 1971 ; Koenig et Fardeau, 1973), soit par biochimie quantitative ou qualitative (Prewitt et Salafsky, 1967 ; Romanul et Van der Meulen, 1967 ; Mommaerts et al., 1969 ; Golish et al., 1970; Mommaerts et al., 1977). Les propriétés contractiles et celles de la résistance à la fatigue des différents types d'unités motrices sont également inversées (Bagust et al., 1981 ; Chan et al., 1982 ; Lewis et al., 1982) ;

b) transforme l'activité ATPasique des fibres (Buller et al., 1969; Barany et Close, 1971 ; Müntener et Srihari, 1984), la composition isozymique relative de leur myosine (Sreter et al., 1974; Weeds et al., 1974; Hoh, 1975; Hoh et al., 1980 ; Gauthier et al., 1983), de leur troponine (Amphlett et al., 1975) et de leur tropomyosine (Heeley et al., 1983) selon la nature de l'activité spontanée des motoneurones responsables de la réinnervation;

c) modifie la morphologie des synapses néoformées sur les fibres rapides et lentes d'oiseaux et de mammifères (Koenig, 1967, 1970; Zelena et al., 1967 ; Bennett et al., 1973 ; Jirmanova et Zelena, 1973 ; Zelena et Jirmanova, 1973 ; Dias et Simpson, 1974).

Ces études, ainsi que de nombreuses autres (Close, 1965, 1969 ; revues de Buller et Pope, 1977 et de Jolesz et Sreter, 1981) ont essentiellement confirmé les observations originales de Buller et de ses collègues sur la transformation des propriétés musculaires après innervation croisée. Cependant, la plupart des caractéristiques des muscles ainsi réinnervés diffère de celles des muscles originaux ou encore de celles des muscles réinnervés par leur propre nerf (Ip and Vrbova, 1983). En particulier, il est notable que la conversion muscle lent $\rightarrow$ muscle rapide est beaucoup moins importante - inférieure souvent à $25 \%$ - que celle observée dans le sens muscle rapide $\rightarrow$ muscle lent, et ce quels que soient les critères fonctionnels ou métaboliques considérés (Mommaerts, 1974 ; Dum et al., 1985a, b). Certains travaux montrent que la transformation est plus importante et plus stable lorsque l'opération est effectuée chez le jeune (Dubowitz, 1967a). II est donc tentant de penser que les fibres I acquièrent, au cours de leur développement postnatal, certaines propriétés qui les rendent plus réfractaires que les fibres II à l'innervation étrangère: soit que ces propriétés fassent partie de l'expression postnatale du patrimoine génétique des fibres I, soit qu'elles soient le résultat d'informations (nerveuses?) reçues par ces fibres formées à partir de la première génération de myotubes au cours de l'embryogenèse (Ashmore et al., 1972b; Rubinstein et Kelly, 1981). Les raisons de la résistance des fibres I à la réinnervation étrangère demeurent donc hypothétiques.

Reproduction, Nutrition, Développement, $n^{\circ} 6 \mathrm{~A} / 88-3$ 
Si la réinnervation croisée expérimentale suggère une souplesse considérable du développement neural et des interactions neuromusculaires, elle montre par ailleurs que la plasticité permise par le potentiel génétique des fibres n'est pas illimitée.

2.2. Importance relative des facteurs neuromoteurs et neurotrophiques. De nombreuses revues ont été consacrées à l'influence trophique du nerf sur le muscle, par exemple celles de Guth (1968) et Gutmann (1976). Ces auteurs font la distinction entre le rôle des facteurs trophiques ou chimiques, et celui de l'activité motrice dans le maintien des propriétés des muscles squelettiques. II est toutefois nécessaire de remarquer, comme le fait à juste raison McArdle (1983), que dans les conditions physiologiques, activité motrice et fonction trophique sont toutes deux le résultat de l'activité nerveuse et doivent donc être, à ce titre, considérées comme neurotrophiques. Avant d'établir les rôles relatifs des facteurs trophiques et de l'activité motrice imposés par le nerf, il est donc important de signaler que la séparation des deux fonctions nerveuses est artificielle et ne sert qu'à distinguer la prépondérance de l'une par rapport à l'autre dans un contexte physiologique donné.

2.2.1. Facteurs neuromoteurs. - Les changements qui suivent l'innervation croisée des muscles rapides et lents des mammifères et des oiseaux reflètent une capacité d'adaptation certaine des muscles squelettiques à différentes nécessités fonctionnelles. En conclusion de leurs premiers articles, Buller et ses collaborateurs attribuaient les propriétés des muscles lents et rapides à des influences trophiques libérées par leurs nerfs moteurs respectifs: les nerfs expérimentalement croisés transporteraient les substances trophiques aux muscles de types opposés et seraient responsables de leur transformation. Ces auteurs n'étaient pas convaincus de l'importance des modifications du schéma d'activité nerveuse atteignant les muscles. Eccles et al. (1958) avaient, cependant, montré que chez les mammifères adultes, les motoneurones innervant les muscles lents ont un régime d'activité soutenue, de faible fréquence $(20 \mathrm{~Hz})$ alors que les motoneurones innervant les muscles rapides les soumettent à des bouffées intermittentes de stimulation, à fréquence plus élevée (60 à $90 \mathrm{~Hz}$, voir aussi Hennig et Lømo, 1985).

Adoptant l'hypothèse neuromotrice, Salmons et Vrbova (1969) démontraient les premiers que la stimulation électrique — via le nerf moteur - à long terme (plus de 3 semaines) et à basse fréquence (de l'ordre de $10 \mathrm{~Hz}$ ) ralentissait significativement le temps de contraction des muscles rapides de lapin et de chat. Ces expériences attestaient l'importance du schéma de décharge de l'influx nerveux sur l'établissement et le maintien des propriétés contractiles des muscles. Ces résultats furent largement confirmés par la suite, en particulier grâce aux travaux effectués par Lømo et ses collaborateurs. Ces derniers, au cours d'une longue série d'expériences, montrèrent que la stimulation directe du muscle dénervé contrôlait :

a) la sensibilité extrajonctionnelle de la fibre à l'acétylcholine (Lømo et Rosenthal, 1972 ; Lømo et Westgaard, 1975, 1976) ; 
b) les propriétés contractiles lentes et rapides des muscles (Lømo et al., 1974);

c) la formation de synapses ectopiques par un nerf étranger supplémentaire (Jansen et al., 1973; Lømo et Slater, 1978) ;

d) le maintien de l'AChE jonctionnelle musculaire et certaines de ses propriétés polymorphiques (Lømo et Slater, 1980b; Lømo et al., 1985).

De nombreuses études ont été effectuées parallèlement, le plus souvent par stimulation directe du nerf. Comparée à la technique de Lømo, qui stimule l'ensemble du muscle dénervé et ne peut opérer que sur des muscles de petite taille, la stimulation du nerf offre l'avantage d'atteindre la quasi totalité des fibres musculaires. Elle présente, toutefois, l'inconvénient de ne pouvoir être utilisée que sur des nerfs de type rapide, la décharge soutenue de trains d'influx par les nerfs lents interférant avec la stimulation expérimentale de type rapide (Eisenberg et al., 1984). Peu de résultats, et souvent contradictoires, ayant été obtenus au cours de stimulation à fréquence élevée de motoneurone lent (Sreter et al., 1982 ; Hudlika et Tyler, 1984 ; Hudlika et al., 1984 ; voir aussi Brown et al., 1976), la majeure partie des données concerne la transformation morphologique, métabolique et fonctionnelle du muscle rapide en muscle lent après stimulation à fréquence lente de leurs nerfs moteurs:

- Sur le plan morphologique, le système tubulaire des muscles rapides (tubules $T$, cisternae terminales et réticulum sarcoplasmique) diminue et atteint en deux semaines le niveau des muscles lents témoins (Ramirez et Pette, 1974 ; Eisenberg et Salmons, 1981 ; Sarzala et al., 1982). Parallèlement, la densité de capillaires, le nombre, ainsi que la taille des mitochondries, augmentent (Cotter et al., 1973; Salmons et al., 1978 ; Reichmann et al., 1985).

- Les données obtenues sur le métabolisme des muscles (Romanul et al., 1974 ; Pette et al., 1973 ; Brown et al., 1974 ; Buchegger et al., 1984 ; Reichmann et al., 1985) confirment les modifications morphologiques observées : augmentation du métabolisme oxydatif, diminution du métabolisme glycolytique. Parallèlement, ces transformations affectent la vitesse de contraction des muscles ainsi que la distribution isozymique des protéines contractiles qui évoluent vers le type lent (Sreter et al., 1975 ; Pette et al., 1976 ; Roy et al., 1979b ; Brown et al., 1983 ; Pluskal et Sreter, 1983 ; Hoffman et al., 1985).

- Enfin, une série d'expériences complémentaires après réinnervation croisée a été effectuée par Salmons et Sreter (1976) sur le soleus, muscle lent réinnervé par les nerfs Tibialis anterior et Extensor digitorum longus (types rapides). Ces auteurs stimulent à faible fréquence ces nerfs croisés et comparent les caractéristiques contractiles des muscles Soleus correspondant, soit à celles de Soleus dont l'innervation croisée n'est pas stimulée soit à celles de muscles Soleus témoins. L'analyse des résultats montre que les muscles Soleus dont l'innervation croisée est stimulée à faible fréquence ont des propriétés contractiles identiques à celles des témoins ; par contre, les propriétés du muscle Soleus dont l'innervation croisée n'est pas stimulée évoluent vers le type rapide. Ces résultats permettent donc de penser que les effets de l'activité neuromotrice et ceux de l'innervation croisée sont modulés par les mêmes mécanismes. Ils montrent l'importance peut-être prépondérante de l'activité dans la régulation des proprié- 
tés morphologiques, fonctionnelles et métaboliques des muscles, par rapport à l'influence du(des) facteur(s) trophique(s) nerveux dont l'existence a été postulée depuis longtemps et étayée par des travaux actuels, en particulier sur la synaptogenèse (Lømo, 1983).

2.2.2. Facteurs neurotrophiques. - L'influence nerveuse trophique sur le muscle a été suggérée par les expériences de Luco et Eyzaguirre (1955) (voir Emmelin et Malm, 1965) montrant que le temps d'apparition de la sensibilité généralisée des fibres musculaires à l'ACh est inversement proportionnel à la longueur du fragment de nerf demeurant attaché au muscle dénervé. Dans le même ordre d'idée, Albuquerque et al. (1971) montraient que la longueur de l'innervation intramusculaire était aussi importante, les fibres situées le plus loin du point de pénétration du nerf dans le muscle étant dépolarisées plus tard que les fibres les plus proches. On pouvait donc supposer qu'un long fragment nerveux contenait davantage de substances trophiques susceptibles d'agir pendant une période plus longue d'autant que les nerfs en dégénérescence contiennent des substances à activité trophique (Jones et Vrbova, 1974; Cangianno et Lutzemberger, 1977, 1980; Brown et al., 1978; Oh et al., 1980). L'utilisation de la colchicine qui bloque le transport axonal sans modifier l'activité nerveuse apporte un argument supplémentaire à la thèse de la médiation neutrophique (Hoffmann et Thesleff, 1972; Albuquerque et al., 1972). En détruisant le système microtubulaire des axones, la colchicine appliquée sur les nerfs moteurs provoque indirectement des modifications musculaires caractéristiques de la dénervation: au cours de ces expériences, les fibres nerveuses propagent normalement des potentiels d'action, et les effets de la colchicine sur le muscle ne sont donc pas produits par une paralysie (Warnick et al., 1977). L'explication la plus simple est qu'il existe des composés chimiques neurotrophiques transportés par le nerf (Younkin et al., 1978). Cet effet est supprimé à la fois par la dénervation et après blocage par la colchicine. De nombreuses tentatives ont été faites pour déterminer la nature du(des) facteur(s) trophique(s) nerveux. On a successivement attribué le rôle à :

a) I'acétylcholine (Thesleff, 1960 ; Drachman, 1967, 1974 ; voir cependant Gutmann, 1969) ;

b) une protéine dérivée du cerveau de rat (Lentz, 1971, 1974);

c) la sciatine (Markelonis et al., 1982a). Cette dernière substance, une glycoprotéine de 84000 daltons, isolée par Markelonis et al. (1980a) à partir du nerf sciatique de poulet, stimule la synthèse de protéines, en particulier la synthèse d'AChE et d'AChR (Oh et Markelonis, 1978 ; Markelonis et Oh, 1979 ; Markelonis et al., 1980b; Markelonis et al., 1982a). Cependant, les études sur les propriétés physicochimiques de la molécule, sa composition et sa séquence partielle en acides aminés, montrèrent une ressemblance frappante avec la transferrine, protéine impliquée dans la régulation du transport et de la concentration en fer dans les cellules, très répandue chez les Vertébrés. En fait, plusieurs études successives ont montré que la transferrine purifiée de poulet mime tous les effets de la sciatine (Markelonis et al., 1982b; Oh et Markelonis, 1982), et permettent de se demander si les molécules de type transferrine sont un exemple de facteur neurotrophique spécifique (Kimura et al., 1981 ; Beach et al., 1983; 
Davis, 1985 ; voir cependant Davis et Heinicke, 1984 ; Beach et al., 1985).

En fait, l'ambiguité de nombre de ces expériences qui sont généralement réalisées sur des cultures de cellules musculaires, réside dans le rôle réel des molécules à action trophique. Est-ce que l'effet induit par l'agent supposé trophique est spécifique et physiologiquement significatif ? Une molécule a-t-elle une action trophique lorsqu'elle agit sur des mécanismes généraux : différenciation (Oh et Markelonis, 1980), synthèse protéique (Davis et Kiernan, 1980, 1981 ; Matsuda et al., 1984b) ? Tout au plus peut-on dire qu'elle a un rôle important dans le fonctionnement cellulaire, mais décider de son action trophique réelle est délicat en raison de son absence de spécificité.

Ceci conduit à se demander comment les influences neurales au sens large, exercent leurs effets sur le muscle. Les facteurs neurochimiques et l'activité agissent par des voies biochimiques dont certaines étapes sont encore inconnues. Le fait que ces deux facteurs contrôlent les mêmes propriétés musculaires peut s'expliquer de différentes façons: leurs effets peuvent passer par des étapes communes, comme par exemple par certains intermédiaires des régulations chimiques et de l'activité mécanique. Parmi ces intermédiaires, on trouve le calcium et les nucléotides. En particulier, on sait que l'AMP cyclique (AMPC) facilite la différenciation des myoblastes (Curtis et Zalin, 1981 ; voir cependant Schutzle et al., 1984), maintient la morphologie des plaques motrices (Lentz, 1972) et augmente la synthèse des AChR du muscle (Betz et Changeux, 1979), observation que l'on peut relier à l'élévation de la concentration en AMPc musculaire après dénervation (Carlsen, 1975). Par ailleurs, le GMP cyclique (GMPc) semble être dans certains cas le second messager intracellulaire de certaines actions de I'ACh. La stimulation du muscle squelettique adulte provoque une augmentation très importante de la concentration en GMPc musculaire (Nestler et al., 1978). De même, l'addition de GMPc à des cultures de muscle mime les effets de l'activité sur l'AChE synaptique (Rubin et al., 1980). II est important de noter que dans ces deux dernières séries d'expériences, on n'observe aucun effet au niveau de l'AMPc. Ce qui laisse penser à un rôle distinct des deux nucléotides dans la régulation des propriétés fonctionnelles musculaires et suggère des sites multiples pour les diverses influences neutrophiques (voir aussi Schwartz et Truman, 1984).

Conclusion. - L'ensemble de ces résultats atteste le rôle de l'innervation motrice dans l'acquisition, le développement et le maintien des propriétés métaboliques et fonctionnelles des fibres musculaires. Si la période initiale de la différenciation du tissu musculaire montre une certaine indépendance vis-à-vis de l'innervation (voir, en particulier, les travaux réalisés en culture), la différenciation des fibres musculaires adultes ne peut se faire en l'absence des facteurs trophiques et/ou moteurs de l'innervation motrice.

L'innervation est essentielle au maintien des propriétés des fibres musculaires adultes. De fait, elle détermine souvent la survie de ses cellules cibles, comme le montre la dégénérescence adipeuse de la majorité des muscles dénervés. II est plus complexe de savoir si le mécanisme d'action nerveuse est d'origine chimique 
ou neuromotrice. Cependant, le fait que la paralysie musculaire entraîne des effets analogues à la dénervation et que la stimulation directe contrôle la récupération ou l'inversion des propriétés des muscles, montrent l'importance particulière de l'activité neurale. La controverse activité motrice/facteurs trophiques permet de mettre en avant deux points fondamentaux : d'une part, elle introduit la notion d'information chimique opérant en direction antérograde pour contrôler les propriétés de la cellule postsynaptique; d'autre part, elle montre que les influences présynaptiques dont on pense qu'elles agissent par médiation chimique doivent être rigoureusement distinguées des effets importants dus à l'activité électrique (Purves et Lichtman, 1985).

L'information nerveuse est transmise à la cellule musculaire par l'intermédiaire d'une structure commune hautement différenciée, la plaque motrice. A son niveau, entre les parties pré et postsynaptiques, séparées d'environ $100 \mathrm{~nm}$, une zone constituée d'éléments spécifiques retient depuis les dix dernières années l'attention des chercheurs par ses propriétés particulières : la matrice extracellulaire (m.e.c.) qui enveloppe chaque fibre musculaire, et dont la lame basale pénètre entre les digitations jonctionnelles au niveau de la synapse nerf-muscle (revue de Mayne et Sanderson, 1985). Cette matrice, et particulièrement sa lame basale, possède une structure, des propriétés antigéniques, des constituants moléculaires spécifiques - comme le collagène IV et certaines formes de l'AChE - qui lui confèrent un rôle particulièrement important dans l'établissement des relations neuromusculaires. Le troisième et dernier volet de cette revue est donc consacré à l'étude des caractéristiques et du rôle de la m.e.c. dans l'établissement et le maintien des interactions nerf-muscle.

\section{Rôle de la matrice extracellulaire dans l'établissement et le maintien des relations neuromusculaires.}

La plupart des cellules des organismes multicellulaires sont en contact avec un réseau filamenteux complexe de macromolécules extracellulaires interactives qui constitue la matrice extracellulaire (Hay, 1981). On peut séparer les différentes zones de la m.e.c. des cellules musculaires selon le schéma décrit dans le tableau 5 (Toutant et Arpagaus, 1984).

TABLEAU 5

\section{Cellule}

Membrane cytoplasmique

Lame basale

Zone réticulée

Zone conjonctive

$$
\left.\begin{array}{l}
\text { (a) } \\
\text { (b) } \\
\text { (c) }
\end{array}\right\}
$$

$\left.\begin{array}{l}\text { Zone } 1 \\ 50-100 \mathrm{~nm} \\ \text { Zone } 2 \\ 100 \mathrm{~nm} \\ \text { Zone } 3\end{array}\right\}$

Matrice extra-cellulaire 
Deux familles principales de macromolécules constituent la m.e.c. et sont sécrétées localement, en particulier par les fibroblastes. Ce sont:

a) les collagènes (Kieny et Mauger, 1984),

b) les glycosaminoglycanes, généralement liés par covalence à des protéines pour former les protéoglycanes (Alberts et al., 1983). Glycosaminoglycanes et protéoglycanes forment une substance fondamentale enrobant les fibres de collagènes. Alors que les longues fibres de collagènes renforcent et structurent la matrice, la phase aqueuse de gel polysaccharidique permet la diffusion des nutriments, métabolites et hormones entre le milieu intérieur et les cellules. Deux glycoprotéines figurent parmi les constituants majeurs des m.e.c. (Yamada, 1983) :

a) la fibronectine (Yamada et Olden, 1978; Madri et al., 1980; Pearlstein et al., 1980 ; Sanes, 1982 ; Yamada et al., 1985) abondamment distribuée dans le tissu conjonctif ;

b) la laminine (Rohde et al., 1979 ; Timpl et al., 1979 ; Kleinman et al., 1984, 1985) détectée seulement dans la lame basale (L.B.).

De nombreux composants de ce type ont été décrits : entactine (Carlin et al., 1981), ligatine (Carbonetto, 1984), nidogène (Timpl et al., 1983, 1984 ; Dziadek et Timpl, 1985), cytotactine (Grumet et al., 1985) et de nombreux autres demeurent à découvrir, en relation en particulier avec la spécificité qui caractérise certaines zones cellulaires différenciées, telle la jonction neuromusculaire (fig. 3).

\section{Caractéristiques de la matrice extracellulaire des fibres musculaires.}

Chaque fibre musculaire est enveloppée par une gaine de m.e.c. contenant une L.B., elle-même subdivisée en une zone dense ou Lamina densa de $20 \mathrm{~nm}$ d'épaisseur, séparée de la membrane cytoplasmique par une zone riche en glycoprotéine de $10 \mathrm{~nm}$ (Nitkin et al., 1984). La lame basale - et non la zone réticulée - s'étend entre nerf et muscle à la jonction neuromusculaire (j.n.m.) et ne représente à ce niveau que $0,1 \%$ de la totalité de la L.B. de la fibre musculaire (Bennett et Pettigrew, 1976). La lame basale constitue une fraction importante du matériel synaptique de la j.n.m., sous une forme très structurée, morphologiquement identifiable et susceptible d'analyses expérimentales, essentiellement par immunofluorescence. Ainsi, Chiu et Sanes (1984) divisent en trois classes les anticorps susceptibles de marquer des zones synaptiques et extrasynaptiques des fibres musculaires adultes:

a) des anticorps contre plusieurs antigènes non identifiés (par exemple: JS1-3, $C_{1}$ et $C_{4} \ldots$ ) marquent plus spécifiquement la L.B. synaptique que la L.B. extrasynaptique, définissant ainsi des déterminants antigéniques synaptiques;

b) des anticorps contre le collagène IV, entactine, fibronectine, un héparane sulfate protéoglycane, la laminine... (Planche $2 a, b, c, d$ ) qui marquent à la fois les L.B. synaptique et extrasynaptique;

c) des anticorps contre le collagène $V$, les anticorps monoclonaux C21-22 marquant les zones extrasynaptiques et non la synapse, définissant des propriétés antigéniques extrasynaptiques. 


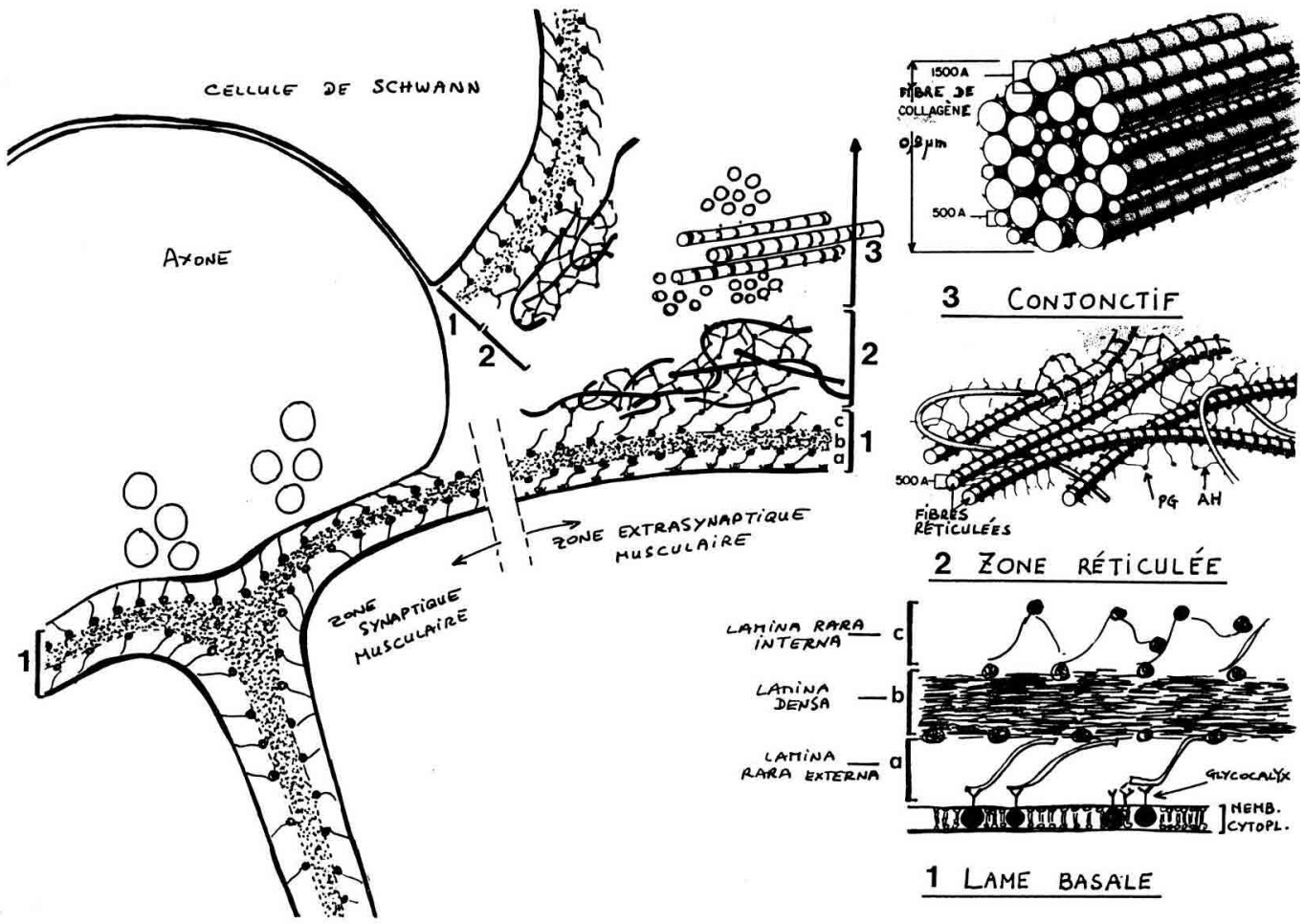

FIG. 3. - Schéma d'organisation de la matrice extracellulaire de la fibre musculaire au niveau synaptique et extrasynaptique. $\mathrm{PG}=$ Protéoglycanes; $\mathrm{AH}=$ Acide hyaluronique; Memb. cytopl. $=$ Membrane cytoplasmique. (D'après Toutant et Arpagaus, 1984).

Ces résultats, ainsi que ceux acquis par ailleurs, attestent la spécificité immunologique des zones jonctionnelles et extrajonctionnelles de la L.B. (Sanes et Hall, 1979 ; Anderson et Fambrough, 1983 ; Sanes et Chiu, 1983). Enfin, une partie importante de l'AChE jonctionnelle est associée à la L.B. synaptique (McMahan et al., 1978 ; Vigny et al., 1983 ; Nicolet et al., 1986 - Planche 2e et $f$ ). Cette enzyme, indétectable par histochimie dans les régions extrasynaptiques, demeure fixée à la L.B. synaptique pendant plusieurs semaines après disparition

PLANCHE 2. - Marquage de la matrice extracellulaire des fibres musculaires par des anticorps monoclonaux anti-laminine (A) et anti-héparane protéoglycane (B); l'anti-acéty/cholinestérase (C) ne marque que des molécules situées au niveau de la jonction neuromusculaire. $\mathrm{D}, \mathrm{E}$ et $\mathrm{F}$ correspondent aux récepteurs de l'acéty/choline, localisés au niveau de la plaque motrice, marqués par $I^{\prime} \alpha$-Bungarotoxine rhodaminée.

Les anticorps anti-laminine et anti-héparane sulfate protéoglycane nous ont été aimablement fourni par J. R. Sanes (Washington University, School of Medicine, St-Louis, USA) ; S. Brimijoin (Mayo Clinic, Rochester, USA) nous a donné les anticorps monoclonaux anti-acétylcholinestérase.

$A$ à $D$ même échelle $=30 \mu \mathrm{m}(D)$

$E$ et $F$ même échelle $=10 \mu \mathrm{m}$ (F). 

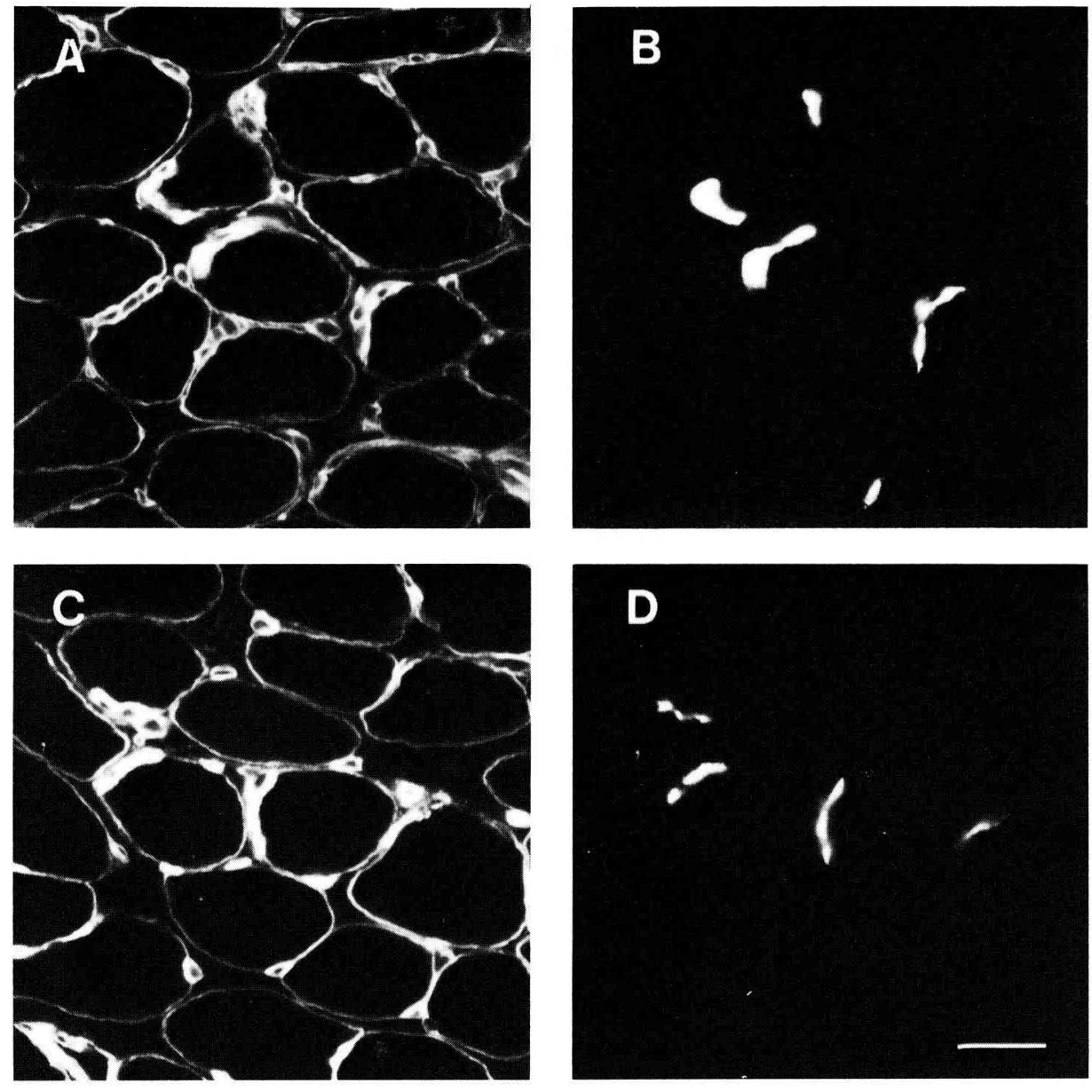

$E$

$=$ 
à la fois des fibres musculaires et des axones qui les innervent. Cette propriété a été utilisée par McMahan et ses collaborateurs dans leur série d'expériences montrant le rôle chimiotropique de la L.B. synaptique dans la réinnervation des fibres musculaires par leur neurone.

\section{Rôle de la matrice extracel/ulaire dans la régénération des jonctions} neuromusculaires.

Bien que les axones embryonnaires forment les synapses probablement au hasard le long des myotubes, les axones en régénérescence reconnaissent et réinnervent les anciens sites des plaques motrices avec une extraordinaire précision, généralement supérieure à $95 \%$ (Saito et Zachs, 1969; Bennett et Pettigrew, 1976 ; Letinsky et al., 1976). Ce résultat est d'autant plus remarquable que le muscle dénervé est capable, par ailleurs, de former des synapses additionnelles hors de la zone neurale originale (synapses ectopiques).

Les expériences de McMahan et de ses collaborateurs sur le muscle Cutaneus pectoris de grenouille attestent le rôle de la L.B. dans la précision topographique de la réinnervation. La figure 4 montre le principe chirurgical de leurs expérimentations : deux rectangles de tissu musculaire sont découpés de part et d'autre du rameau innervant les fibres musculaires ; cette opération laisse en place une bande ( " bridge ») de fibres lésées dont l'innervation est sectionnée et laissée en place. Deux semaines après l'opération, le tissu musculaire régénère à l'intérieur de la L.B., ainsi que les axones, qui forment aux anciens sites synaptiques de la L.B. de nouvelles jonctions semblables aux originales. Cette première série d'expériences, due à Marshall et al. (1977), montre que ni les cellules musculaires, ni les terminaisons axonales originales ne sont nécessaires à la régénération des j.n.m. aux sites synaptiques originaux de la L.B. des fibres musculaires (Glicksman et Sanes, 1983).

Pour étudier la réinnervation en absence de fibres musculaires, Sanes et al. (1978) utilisèrent le même schéma expérimental mais irradièrent les animaux aux rayons $X$, empêchant la prolifération des myoblastes et donc la régénération des fibres musculaires. Sur ces muscles lésés, dénervés et irradiés, plus de $95 \%$ des axones réoccupent les sites synaptiques originaux - la moitié d'entre eux présentant des spécialisations, telles les zones actives - même si leurs cellules cibles, les fibres musculaires, sont absentes. Ces résultats montrent que les molécules qui orientent la morphogenèse des terminaisons nerveuses en régénération sont associées avec la portion synaptique de la L.B. musculaire. Ces constituants persistent dans la lame basale pendant plusieurs jours en l'absence de cellules pré et postsynaptiques, les axones en régénération n'atteignant leur cible qu'une semaine après l'opération. Toutefois, le nombre des terminaisons nerveuses qui se différencient dans ces conditions sur la seule L.B. aux anciens sites synaptiques diminue progressivement après 4 et 5 semaines de dénervation (Sanes et al., 1978) : aucune étude n'a été réalisée pour savoir si les terminaisons ainsi formées disparaissent au-delà de cette période. Le site synaptique original de la L.B. possède des propriétés d'attraction des neurones au cours de la réinnervation, mais la m.e.c. n'a peut-être pas les capacités nécessaires au maintien des j.n.m. lorsque celles-ci sont formées. 
A

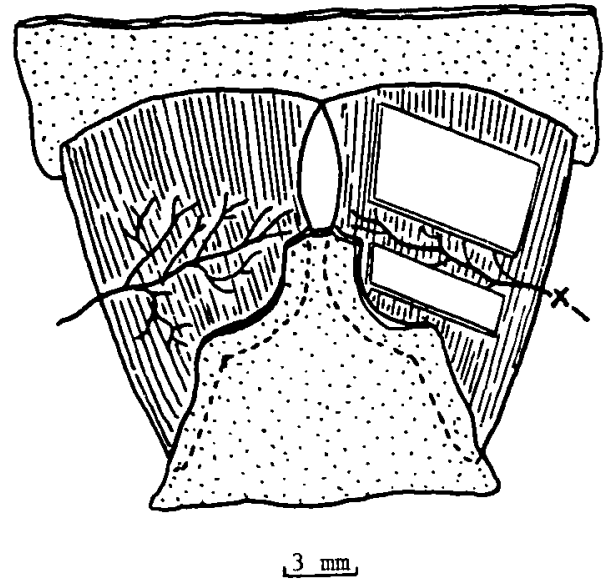

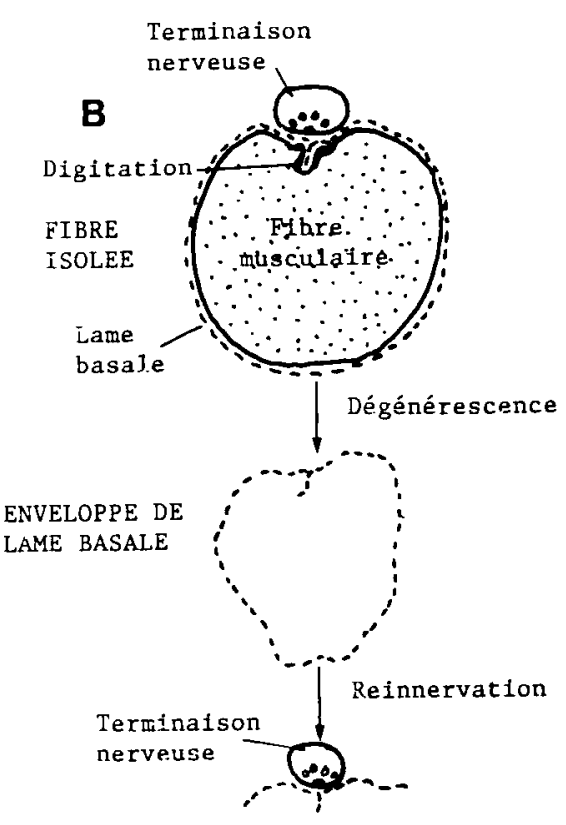

FIG. 4. - A) Schéma du m. Cutaneus pectoralis normal (à gauche) et de son contralatéral dans lequel une bande ("bridge ") centrale a été découpée chirurgicalement (Sanes et al., 1978).

B) Les fibres musculaires de te/s bridges dégénèrent, laissant l'enveloppe ("Ghost ") de lame basale (Sanes, 1983). Si le nerf est sectionné au même instant (voir $X$ en $A$ ), les axones en régénération se dirigent vers l'enveloppe de lame basale. Comme l'ancien site de la j.n.m. peut encore être identifié par la présence de cholinestérase et les invaginations de la lame basale, il est possible de vérifier si les axones réinnervent les sites synaptiques originaux. L'expérience montre que, même en l'absence de cellules musculaires, les axones en croissance réoccupent les sites synaptiques primitifs avec une précision remarquable. Ce qui sous-entend la présence, dans la lame basale jonctionnelie, de molécules reconnues par les axones en régénération. (D'après Purves et Lichtman, 1985).

Les études de Burden etal. (1979) ont montré parallèlement que le développement de l'appareil sous-neural des fibres musculaires en régénération est indépendant de la présence des axones. En utilisant le schéma expérimental de Marshall et al. (1977) mais dans lequel on empêche la réinnervation, ces auteurs observent qu'en dépit de l'absence de terminaisons nerveuses, les AChR s'accumulent préférentiellement aux endroits où la membrane plasmique des fibres musculaires nouvellement régénérées est apposée aux anciennes zones de la L.B. synaptique (McMahan et Slater, 1984) et que l'AChE néosynthétisée est incorporée dans la L.B. des mêmes régions (Anglister et McMahan, 1985).

A l'heure actuelle, les recherches en cours, en particulier dans l'équipe de McMahan, visent à identifier les constituants moléculaires responsables de la morphogenèse synaptique: Godfrey et al. (1983, 1984), Nitkin et al. (1983, 1984) ont ainsi isolé à partir de L.B. d'organe électrique de Torpille (Torpedo 
californica) un facteur, appelé "Agrin» (Nitkin et al., 1987 ; Reist et al., 1987), provoquant l'agrégation des AChR (Fallon et al., 1985) et la formation d'amas d'AChE (Wallace et al., 1985; Wallace, 1986) sur des myotubes de poulet différenciés en culture.

3. Rôle de la matrice extracellulaire dans l'établissement des jonctions neuromusculaires chez l'embryon.

Les expériences de régénération neuromusculaire chez l'adulte suggèrent que les constituants associés à la L.B. pourraient être impliqués dans le développement neural des jonctions au cours de l'embryogenèse (voir la revue de Sanes, 1983). Toutefois, les relations entre nerf et muscle, et la constitution de la L.B. sont fondamentalement différentes chez l'adulte et l'embryon. Chez l'adulte, les axones et les fibres musculaires au cours de leur régénération entrent en contact et sont influencés par une gaine de L.B. déjà différenciée en région synaptique et extrasynaptique; au cours du développement, les cellules musculaires doivent assembler de novo une m.e.c. : les interactions neuromusculaires chez l'embryon doivent à la fois moduler et être modulées par la L.B. Plusieurs données expérimentales montrent que les rôles de la m.e.c. chez l'adulte et au cours de l'embryogenèse ne peuvent être confondus :

a) les synapses se forment au hasard sur les muscles en différenciation et c'est l'allongement des myotubes par ses deux extrémités qui amènerait la position centrale des synapses sur les fibres musculaires adultes (Williams et Goldspink, 1971 ; Bennett et Pettigrew, 1974, 1976) ;

b) bien que les myotubes différenciés en culture aneurale puissent élaborer des antigènes de L.B. synaptique et présentent des spécialisations postsynaptiques (Sanes et Chiu, 1983), les nerfs ont vraisemblablement un rôle actif, en déterminant où de telles spécialisations se forment, et en divisant la surface des myotubes en domaines synaptique et extrasynaptique biochimiquement distincts (Anderson et Cohen, 1977; Frank et Fischbach, 1979) ;

c) au moins deux marqueurs de la L.B. synaptique, l'AChE et l'antigène $C_{1}$, s'accumulent au niveau de la zone jonctionnelle après que les synapses se soient formées et les AChRs agrégés (Weinberg et al., 1981; Sanes et Chiu, 1983);

d) des études en microscopie électronique de muscles de plusieurs espèces montrent que les j.n.m. se forment avant que les myotubes n'aient acquis une enveloppe complète de L.B., la formation des L.B. et la maturation synaptique s'effectuant parallèlement au cours d'une période étalée dans le temps (Kelly et Zacks, 1969b; Kullber et al., 1977).

Ainsi, en l'état actuel des connaissances, il ne paraît pas exister des molécules particulières de la $L$. B. qui prédétermineraient la topographie synaptique. $D^{\prime}$ après Burrage et Lentz (1982), les molécules «trophiques » solubles sécrétées par le nerf et/ou le muscle pourraient se fixer et se concentrer au niveau de la L.B. de la région au premier contact synaptique. Vogel et al. (1983), Daniels et al. (1984) et Bayne et al. (1984), suggèrent qu'un facteur neural d'agrégation des AChRs se lierait à la laminine ou à un Héparane Sulfate Protéoglycane (HSPG), hypothèse 
confirmée par la présence d'antigènes mixtes (jonctionnels et extrajonctionnels, dont la laminine et le HSPG) au niveau des agrégats d'AChRs nouvellement formés in vivo.

La lame basale pourrait encore intervenir dans l'établissement et l'élimination de la polyinnervation caractérisant les myotubes embryonnaires. La synthèse de L. $B$. synaptique au niveau de la première synapse rendrait ce site particulièrement réceptif aux nouveaux axones; la formation sur les autres parties de la fibre de L.B. pauvre en antigène synaptique et/ou riche en antigène extrasynaptique serait une des voies par laquelle la zone extrajonctionnelle de la L.B. deviendrait réfractaire à l'innervation. Si au cours du développement, comme pendant la régénération, la L.B. confine la terminaison nerveuse à une zone très limitée de la fibre, elle pourrait alors avoir un rôle très important dans la régulation des interactions compétitives aboutissant à l'établissement du schéma mono-innervé caractéristique des fibres musculaires (Purves et Lichtman, 1980).

\section{Conclusion et résumé.}

L'utilisation des techniques histochimiques révélant à la fois l'activité ATPasique de l'actomyosine et de la succinate déshydrogénase a permis de mettre schématiquement en évidence trois types de fibres musculaires squelettiques chez l'adulte.

A de rares exceptions près, les muscles des vertébrés supérieurs sont hétérogènes et sont ainsi constitués de fibres à mode de contraction lente à métabolisme oxydatif ( $\mathrm{l}$ ou $\beta \mathrm{R}$ ), de fibres à mode de contraction rapide et à métabolisme oxydo-glycolytique (IIA ou $\alpha \mathrm{R}$ ) et de fibres à mode de contraction rapide et à métabolisme glycolytique (IIB ou $\alpha \mathrm{W}$ ). L'apparition des techniques immunocytochimiques, et en particulier l'utilisation d'anticorps monoclonaux antimyosine lente ou rapide, confirme et affine cette classification en type de fibres lente ou rapide, et précise les modifications des propriétés de la myosine au cours du développement (myosine embryonnaire et néonatale).

Contrairement à certains muscles de batraciens, de poissons ou d'oiseaux, les fibres musculaires des mammifères sont innervées par un seul neurone moteur se terminant en une plaque motrice, structure différenciée assurant la libération du neuromédiateur, l'acétylcholine, et la transmission de l'influx nerveux depuis le corps cellulaire du neurone situé dans la corne ventrale de la moelle épinière, jusqu'aux systèmes membranaires de la fibre musculaire. L'importance de l'innervation motrice dans la différenciation, le développement et le maintien des propriétés des fibres musculaires squelettiques a été clairement établie. Les expériences de dénervation, d'innervation croisée, de ténotomie et de stimulation des muscles ou de leurs nerfs moteurs à des fréquences déterminées ont montré le rôle prépondérant du nerf sur les propriétés des fibres musculaires, en particulier par l'intermédiaire du type d'activité motrice qu'il impose au muscle.

Si l'activité neuromotrice représente le facteur essentiel du développement et du maintien des caractéristiques des différents types de fibres musculaires, d'autres facteurs ont une importance non négligeable. Parmi ces derniers, 
certaines hormones sont impliquées dans la différenciation neuromusculaire (lanuzzo et al., 1977 ; Bacou et al., 1980 ; Johnson et al., 1980 ; Goldberg, 1980 ; Winder et al., 1980), dont nous avons abordé l'importance dans la deuxième partie de cette revue consacrée aux propriétés des fibres musculaires squelettiques et à leur différenciation (Vigneron et al., 1989).

Reçu en décembre 1987.

Accepté en septembre 1988.

\section{Références}

ADELSTEIN R.S., EISENBERG E., 1980. Regulation and kinetics of the actin-myosin-ATP interaction. Ann. Rev. Biochem., 49, 921-956.

ALBERTS B., BRAY D., LEWIS J., RAFF M., ROBERTS K., WATSON J. D., 1983. Molecular biology of the cell. Garlang Publ. Inc. New-York/London.

ALBIS A. d', PANTALONI C., BECHET J. J., 1979. An electrophoretic study of native myosin isozymes and of their subunit content. Eur. J. Biochem., 99, 261-272.

ALBUOUERQUE E. X., Mc ISAAC R. J., 1970. Fast and slow mammalian muscles after denervation. Exp. Neurol., 26, 183-202.

ALBUQUERQUE E. X., SCHUH F. Y., KAUFFMAN F. C., 1971. Early membrane depolanization of the fast mammalian muscle after denervation. Pflugers Arch., 328, 36-50.

ALBUQUERQUE E. X., WARNICK J. E., TASSE J. R., SANSONE F. M., 1972. Effects of vinblastine and colchicine on neural regulation of the fast and slow skeletal muscles of the rat. Exp. Neurol., 37, 607-634.

AMPHLETT G. W., PERRY S. V., SYSKA H., BROWN M. D., VRBOVA G., 1975. Cross-innervation and the regulatory protein system of rabbit soleus muscle. Nature, 257, 602-604.

ANDERSON M. J., COHEN M.W., 1977. Nerve-induced and spontaneous redistribution of acetylcholine receptors on cultured muscle cells. J. Physiol., 268, 757-773.

ANDERSON M. J., COHEN M. W., ZORYCHTA E., 1977. Effects of innervation on the distribution of acetylcholine receptors on cultured muscle cells. J. Physiol., 268, 731-756.

ANDERSON M. J., FAMBROUGH D. M., 1983. Aggregates of acetylcholine receptor are associated with plaques of basal lamina heparan sulphate proteoglycan on the surface of skeletal muscle fibers. J. Cell. Biol., 97, 1396-1411.

ANGLISTER L., McMAHAN U. J., 1985. Basal lamina directs acetyl-cholinesterase accumulation at synaptic sites in regenerating muscle. J. Cell Biol., 101, 735-743.

ANSAY M., 1974. Individualité musculaire chez le bovin : étude de l'équipement enzymatique de quelques muscles. Ann. Biol. anim. Bioch. Biophys., 14, 471-486.

APPEL H. J., 1984. Variability in microvascular pattern dependent upon muscle fiber composition. Prog. appl. Microcirc., 5, 15-29.

ARNDT I., PEPE F. A., 1975. Antigenic specificity of red and white muscle myosin. J. Histochem. Cytochem., 23, 159-168.

ASHMORE C. R., DOERR L., 1971. Comparative aspects of muscle fiber types in different species. Exp. Neurol., 31, 408-418.

ASHMORE C. R., TOMPKINS G., DOERR L., 1972a. Comparative aspects of mitochondria isolated from W, R and R muscle fibers of the chick. Exp. Neurol., 35, 413-420.

ASHMORE C. R., ROBINSON D. W., RATTRAY P., DOERR L., 1972b. Biphasic development of muscle fibers in the fetal lamb. Exp. Neurol., 37, 241-255.

ASHMORE C. R., ADDIS P. B., DOERR L., 1973a. Development of muscle fibers in the fetal pig. $J$. anim. Sci, 36, 1088-1093.

ASHMORE C. R., ADDIS P. B., DOERR L., STOCKES H., 1973b. Development of muscle fibers in the complexus muscle of normal and dystrophic chicks. J. Histochem. Cytochem., 21, 266-278.

ASHMORE C. R., 1974. Phenotypic expression of muscle fiber types and some implications to meat quality. J. anim. Sci., 38, 1158-1164. 
ASMUSSEN G., KIESSLING A., 1975. Hypertrophy and atrophy of mammalian extraocular muscle fibres following denervation. Experientia, 31, 1186-1187.

BACOU F., 1972. Evolution quantitative de l'aldolase, de l'aspartate aminotransférase, de la succinate déshydrogénase et de l'acétylcholinestérase dans les muscles blancs et rouges de lapin au cours de la période postnatale. C. R. Soc. Biol., 166, 1037-1042.

BACOU F., VIGNERON P., 1976. Evolution périnatale des voies métaboliques glycolytique et oxydative de divers types de muscles squelettiques du lapin et du poulet. Ann. Biol. anim. Bioch. Biophys., 16, 675-686.

BACOU F., JALLAGEAS M., NOUGUES J., VIGNERON P., 1980. Influence of experimental hypothyroidism on chick myogenesis. Reprod. Nutr. Dévelop., 20, 217-224.

BACOU F., NOUGUES J., 1980. Alterations of enzymatic activities during red and white muscle differentiation in vitro. Exp. Cell Res., 129, 455-460.

BACOU F., VIGNERON P., COURAUD J.Y., 1985. Retrograde effect of muscle on forms of acetylcholinesterase in peripheral nerves. J. Neurochem., 45, 1178-1185.

BADER D., MASAKI T., FISCHMAN D. A., 1982. Immunochemical analysis of myosin heavy chain during avian myogenesis in vivo and in vitro. J. Cell Biol., 95, 763-770.

BAGUST J., LEWIS D. M., WESTERMAN R. A., 1973. Polyneuronal innervation of kitten skeletal muscle. J. Physiol., 229, 241-255.

BAGUST J., 1979. The effects of tenotomy upon the contraction characteristics of motor units in rabbit soleus muscle. J. Physiol., 290, 1-10.

BAGUST J., LEWIS D.M., WESTERMAN R. A., 1981. Motor units in cross-reinnervated fast and slow twitch muscle of the cat. J. Physiol., 314, 223-235.

BALDWIN K. M., HOOKER A. M., HERNICK R. E., 1978. Lactate oxidative capacity in different types of muscle. Biochem. Biophys. Res. Commun., 83, 151-157.

BARANY M., BARANY K., RECKARD T., VOLPE A., 1965. Myosin of fast and slow muscles of the rabbit. Arch. Biochem. Biophys., 109, 185-191.

BARANY M., 1967. ATPase activity of myosin correlated with speed of muscle shortening. J. gen Physiol., 50, suppl. part 2, 197-218.

BARANY M., CLOSE R. I., 1971. The transformation of myosin in cross-innervated rat muscles. J. Physiol., 213, 455-474.

BARNARD E. A., LYLES J. M., PIZZE J. A., 1982. Fibre types in chicken skeletal muscles and their changes in muscular dystrophy. J. Physiol., 331, 333-354.

BARNARD R. J., EDGERTON V. R., FURUKAWA T., PETER J. B., 1971. Histochemical, biochemical and contractile properties of red, white and intermediate fibers. Am. J. Physiol., 220. 410-414.

BARTON P. J. R., BUCKINGHAM M. E., 1985. The myosin alkali light chains proteins and their genes. Biochem. J., 231, 249-261.

BARTON P. J. R., COHEN A., ROBERT B., FISZMAN M. Y., BONHOMME F., GUENET J. L., LEADER D. P., BUCKINGHAM M. E., 1985. The myosin alkali light chains of mouse ventricular and slow skeletal muscle are indistinguishable and are encoded by the same gene. J. biol. Chem., 260, 8578-8584.

BASS A., BRDICZKA D., EYER P., HOFER S., PETTE D., 1969. Metabolic differentiation of distinct muscle types at the level of enzymatic organization. Eur. J. Biochem., 10, 198-206

BASS A., LUSCH G., PETTE D., 1970. Postnatal differentiation of the enzyme activity pattern of energy-supplying metabolism in slow (red) and fast (white) muscles of chicken. Eur. J. Biochem., 13, 289-292.

BASS A., GUTMANN E., MELICHNA J., SYROVY I., 1973. Contractile and enzymatic properties of fast and slow muscles of rabbit and hare. Physiol. Bohemoslov., 22, 477-486.

BAYNE E. K., ANDERSON M. J., FAMBROUGH D.M., 1984. Extracellular matrix organization in developing muscle: correlation with acetylcholine receptor aggregates. J. Cell Biol., 99, 1486-1501.

BEACH R. L., POPIELA H., FESTOFF B. W., 1983. The identification of neurotrophic factor as a transferrin. FEBS Lett., 156, 151-156.

BEACH R. L., POPIELA H., FESTOFF B. W., 1985. Specificity of chicken and mammalian transferrins in myogenesis. Cell. Diff., 16, 93-100 
BEATTY C. H., PETERSON R. D., BOCEK R.M., 1963. Metabolism of red and white muscle fiber groups. Am. J. Physiol., 204, 939-942.

BEATTY C. H., BOCEK R. M., 1970. Biochemistry of the red and white muscle. In E. J. BRISKEY, R. G. CASSENS, B. B. MARSH, Physiology and biochemistry of muscle as a food, 2, 155-191. Kingsport Press, Tennessee.

BEATTY C. H., BOCEK R. M., 1971. Interrelation of carbohydrate and palmitate metabolism in skeletal muscle. Am. J. Physiol., 220, 1928-1934.

BEATTY C. H., YOUNG M. K., DWYER D., BOCEK R. M., 1972. Glucose utilisation of cardiac and skeletal muscle homogenates from fetal and adult rhesus monkey. Pediat. Res., 6, 813-821.

BENNETT M. R., PETTIGREW A. G., TAYLOR R. S., 1973. The formation of synapses in reinnervated and cross reinnervated adult avian muscle. J. Physiol., 230, 331-357.

BENNETT M. R., PETTIGREW A. G., 1974. The formation of synapses in striated muscle during development. J.Physiol., 241, 515-545.

BENNETT M. R., PETTIGREW A. G., 1976. The formation of neuromuscular synapses. Cold Spring Harb. Symp. Quant. Biol., 40, 409-424.

BENNETT M. R., 1983. Development of neuromuscular synapses. Physiol. Rev., 63, 915-1048.

BENOIT P., CHANGEUX J. P., 1975. Consequences of tenotomy on the evolution of multiinnervation in developing rat soleus muscle. Brain Res., 99, 354-358.

BENOIT P., CHANGEUX J. P., 1978. Consequences of blocking the nerve with a local anaesthetic on the evolution of multi-innervation at the regenerating neuromuscular junction of the rat. Brain. Res., 149, 89-96.

BERGSTRÖM J., HERMANSEN L., HOLTMAN E., SALTIN B., 1967. Diet, muscle glycogen and physical performance. Acta. physiol. scand., 71, 140-150.

BETZ M., CHANGEUX J.P., 1979. Regulation of muscle acetylcholine receptor synthesis in vitro by cyclic nucleotide derivatives. Nature, 278, 749-752.

BETZ W. J., CALDWELL J. H., RIBCHESTER R. R., 1980. The effects of partial denervation at birth on the development of muscle fibres and motor units in rat lumbrical muscle. J. Physiol., 303, 265-279.

BEVAN S., STEINBACH J. H., 1977. The distribution of $\alpha$-bungarotoxin binding sites on mammalian skeletal muscle developing in vivo. J. Physiol., 267, 195-213.

BILLETER R., WEBER H., LUTZ H., HOWALD H., EPPENBERGER H. M., JENNY E., 1980. Myosin types in human skeletal muscle fibers. Histochemistry, 65, 249-259.

BILLETER R., HEIZMANN C. W., HOWALD H., JENNY E., 1981. Analysis of myosin light and heavy chain types in single human skeletal muscle fibers. Eur. J. Biochem., 116, 389-395.

BIXBY J. L., VAN ESSEN D. C., 1979. Regional differences in the timing of synapse elimination in skeletal muscles of the neonatal rabbit. Brain Res., 169, 275-286.

BLANCHAER M. C., VAN WIJHE M., MOZERSKY D., 1963. The oxydation of lactate and -glycerophosphate by red and white skeletal muscle: I. Quantitative studies. J. Histochem. Cytochem., 11, 500-504.

BLOOM J. W., BUTLER J., BRIERLEY J., COSMOS E., 1985. Direct electrical stimulation promotes growth and enhances survival of aneurogenic muscles of the chick embryo. J. Neurosci., $\mathbf{5}$, 414-420.

BOCEK R. M., PETERSON R. D., BEATTY C. H., 1966. Glycogen metabolism in red and white muscles. Am. J. Physiol., 210, 1101-1107.

BOOTH F. W., KELSO J. R., 1973. Effect of hind-limb immobilization on contractile and histochemical properties of skeletal muscle. Pf/ügers Arch., 342, 231-238.

BOOTH F. W., SEIDER M. J., HUGMAN G. R., 1980. Effects of disuse by limb immobilization on different muscle fiber types, 373-383. In D. PETTE, Plasticity of muscle, Walter de Gruyter. Berlin.

BOURGEOIS J. P., TOUTANT M., GOUZE J. L., CHANGEUX J. P., 1986. Effect of activity on the selective stabilization of the motor innervation of fast muscle posterior latissimus dorsi from chick embryo. Int. J. dev. Neurosci., 45, 415-431.

BREVET A., WHALEN R. G., 1978. Comparative structural analysis of myosin after limited tryptic hydrolysis by use of two-dimensional gel electrophoresis. Biochimie, 60, 459-466. 
BRIAND M., TALMANT A., BRIAND Y., MONIN G., DURAND R., 1981. Metabolic types of muscle in the sheep : II. Lactate dehydrogenase activity and LDH isoenzyme distribution. Eur. $J$. appl. Physiol., 46, 359-365.

BRIGGS M. M., KLEVIT R. E., SCHACHAT F. H., 1984. Heterogeneity of contractile proteins. Purification and characterization of two species of troponin $T$ from rabbit fast skeletal muscle. J. biol. Chem., 259, 10369-10375.

BRONSON D. D., SCHACHAT F. H., 1982. Heterogeneity of contractile proteins. Differences in tropomyosin in fast, mixed and slow skeletal muscles of the rabbit. J. biol. Chem., 257. 3937-3944.

BROOKE M. H., KAISER K. K., 1969. Some comments on the histochemical characterization of muscle adenosine triphosphatase. J. Histochem. Cytochem., 17, 431-432.

BROOKE M. H., KAISER K. K., 1970. Muscle fiber types : how many and what kind? Arch. Neurol., 23, 369-379.

BROOKE M. H., KAISER K. K., 1974. The use and abuse of muscle histochemistry. Ann. N. Y. Acad. Sci., 228, $121-144$.

BROWN M. C., JANSEN J. K. S., VAN ESSEN D., 1976. Polyneuronal innervation of skeletal muscle in new-born rats and its elimination during maturation. J. Physio/., 261, 387-422.

BROWN M. C., HOLLAND R. L., TRONTON R., 1978. Degenerating nerve products affect innervated muscle fibres. Nature, 275, 652-654.

BROWN M. C., HOPKINS W. G., KEYNES R. J., 1982. Short- and long-term effects of paralysis on the motor innervation of two different neonatal mouse muscles. J. Physiol., 329, 439-450.

BROWN M. C., BOOTH C. M., 1983. Postnatal development of the adult pattern of motor axon distribution in rat muscle. Nature, 304, 741-742.

BROWN M. D., COTTER M., HUDLICKA O., SMITH M. E., VRBOVA G., 1974. The effect of long-term stimulation of fast muscles on their ability to withstand fatigue. J. Physiol., 238, 47P-48P.

BROWN M. D., COTTER M., HUDLICKA O., VRBOVA G., 1976. The effects of different patterns of muscle activity on capillary density, mechanical properties and structure of slow and fast rabbit muscles. Pflügers Arch., 361, 241-250.

BROWN W. E., SALMONS S., WHALEN R. G., 1983. The sequential replacement of myosin subunit isoforms during muscle type transformation induced by long term electrical stimulation. $J$. biol. Chem., 258, 14686-14692.

BRUGGMANN S., JENNY E., 1975. The immunological specificity of myosin from cross-striated muscles as revealed by quantitative microcomplement fixation and enzyme inhibition by antisera. Biochim. Biophys. Acta, 412, 39-50.

BUCHEGGER A., NEMETH P. M., PETTE D., REICHMANN H., 1984. Effects of chronic stimulation on the metabolic heterogeneity of the fibre population in rabbit tibialis anterior muscle. $J$. Physiol., 350, 109-119.

BUCHTAL F., SCHMALBRUCH H., 1980. Motor unit of mammalian muscle. Physio/. Rev., 60 , 90-142.

BUCKINGHAM M. E., 1985. Actin and myosin multigen families: their expression during the formation of skeletal muscle. Assays biochem., 20, 77-109.

BULLARD H. H., 1919. Histological as related to physiological and chemical differences in certain muscles of the rat. The John Hopkins Hosp. Rep., 18, 323-328.

BULLER A. J., ECCLES J. C., ECCLES R. M., 1960a. Differentiation of fast and slow muscles in the cat hind limb. J. Physiol., 150, 399-416.

BULLER A. J., ECCLES J. C., ECCLES R. M., 1960b. Interactions between motoneurones and muscles in respect of the characteristic speeds of their responses. J. Physiol., 150, 417-439.

BULLER A. J., LEWIS D. M., 1965a. Some observations on the effect of tenotomy in the rabbit. $J$. Physiol., 178, 326-342.

BULLER A. J., LEWIS D. M., 1965b. Further observations on mammalian cross-innervated skeletal muscle. J. Physiol., 178, 343-358.

BULLER A. J., MOMMAERTS W. F. H. M., SERAYDARIAN K., 1969. Enzymic properties of myosin in fast and slow twitch muscles of the cat following cross-innervation. J. Physiol., 205, $581-597$. 
BULLER A. J., POPE R., 1977. Plasticity in mammalian skeletal muscle. Philos. Trans. roy. Soc. Lond. B. Biol. Sci., 278, 295-305.

BURDEN S., 1977a. Development of neuromuscular junction in the chick embryo: the number, distribution and stability of acetylcholine receptors. Develop. Biol., 57, 317-329.

BURDEN S., 1977b. Acetylcholine receptors at the neuromuscular junction : developmental change in receptor turnover. Develop. Biol., 61, 79-85.

BURDEN S., SARGENT P., MCMAHAN U. J., 1979. Acetylcholine receptors in regenerating muscle accumulate at original synaptic sites in the absence of the nerve. J. Cell Biol., 82, 412-425.

BURKE R. E., LEVINE D. N., ZAJAC F. E., TSAIRIS P., ENGELW. K., 1971. Mammalian motor units : Physiological, histochemical correlation in three types in cat gastrocnemius. Science, 174, 709-712.

BURKE R. E., LEVINE D. N., TSAIRIS P., ZAJAC F. E., 1973. Physiological types and histochemical profiles in motor units of the cat gastrocnemius. J. Physiol., 234, 723-748.

BURKE R. E., LEVINE D. N., SALEMAN M., TSAIRIS P., 1974. Motor units in cat soleus muscle: physiological, histochemical and morphological characteristics. J. Physio/., 238, 503-514.

BURKE R. E., TSAIRIS P., 1974. The correlation of physiological properties with histochemical characteristics in single muscle units. Ann. N. Y. Acad. Sci., 228, 145-159.

BURLEIGH I. G., SCHIMKE R. T., 1968. On the activities of some enzymes concerned with glycolysis and glycogenolysis in extracts of rabbit skeletal muscles. Biochem. Biophys. Res. Commun., 31, 831-836.

BURRAGE T. G., LENTZ T. L., 1982. Distribution of cell surface saccharides and fibrorectin on cultured chick myotubes : relationships to acetylcholine receptor clusters. Dev. Neurosci., $\mathbf{5}$, 533-545.

BUTLER J., COSMOS E., 1981a. Enzymic markers to identify muscle-nerve formation during embryogenesis : modified myosin ATPase and silver-cholinesterase histochemical reactions. Exp. Neurol., 73, $831-836$.

BUTLER J., COSMOS E., 1981 b. Differentiation of the avian latissimus dorsi primordium : analysis of fiber type expression using the myosin ATPase histochemical reaction. J. exp. Zool., 218. 219-232.

BUTLER J., COSMOS E., BRIERLEY J., 1982. Differentiation of muscle fiber types in aneurogenic brachial muscles of the chick embryo. J. exp. Zool., 224, 65-80.

BUTLER-BROWNE G. S., WHALEN R. G., 1984. Myosin isozyme transitions occuring during the postnatal development of the rat soleus muscle. Develop. Biol., 102, 324-334.

CALDWELL J. H., RIDGE R. M. A. P., 1983. The effects of differentiation and spinal cord transection on synapse elimination in developing rat muscles. J. Physio/., 339, 145-159.

CANGIANO A., LUTZEMBERGER L., 1977. Partial denervation affects both denervated and innervated fibers in mammalian skeletal muscle. Science, 196, 542-545.

CANGIANO A., LUTZEMBERGER L., 1980. Partial denervation in inactive muscle affects innervated and denervated fibres equally. Nature, 285, 233-235.

CANTINI M., SARTORE S., SCHIAFFINO S., 1980. Myosin types in cultured muscle cells. J. Cell Biol., 85, 903-909.

CARBONETTO S., 1984. The extracellular matrix of the nervous system. Trend Neurosci., 384-387.

CARLIN B., JAFFE R., BENDER B., CHUNG A. E., 1981. Entactin a novel basal lamina-associated sulfated glycoprotein. J. biol. Chem., 256, 5209-5214.

CARLSEN R. C., 1975. The possible role of cyclic AMP in the neurotrophic control of skeletal muscle. J. Physiol., 247, 343-361.

CARRARO U., MORALE D., MUSSINI I., LUCKE S., CANTINI M., BETTO R., CATANI C., DALLA LIBERA L., DANIELI BETTO D., NOVENTA D., 1985. Chronic denervation of rat hemidiaphragm : maintenance of fiber heterogeneity with associated increasing uniformity of myosin isoform. J. Cell Biol, 100, $161-174$.

CHAN A. K., EDGERTON V. R., GOSLOW G. E. Jr., KURATA H., RASMISSEN S. A., SPECTOR S. A., 1982. Histochemical and physiological properties of cat motor units after self- and cross-reinnervation. J. Physiol., 332, 343-361.

CHIU A. Y., SANES J. R., 1984. Development of basal lamina in synaptic and extrasynaptic portions of embryonic rat muscle. Develop. Biol., 103, 456-467. 
CIACCIO C. G., 1898. La scoperta dei muscoli rossi et bianchi del coniglio revendicata a Stefano Lorenzini. Rend. Sess. Acad. Sci. Inst. Bologna; Nuov. Ser., 2, 115-117.

CLOSE R., 1964. Dynamic properties of fast and slow skeletal muscles of the rat during development. J. Physiol., 173, 74-95.

CLOSE R., 1965. Effects of cross-union of motor nerves to fast and slow skeletal muscles. Nature, 206, $831-832$.

CLOSE R., 1967. Properties of motor units in fast and slow skeletal muscles of the rat. J. Physiol., 193, 45-55.

CLOSE R., 1969. Dynamic properties of fast and slow skeletal muscles of the rat after nerve cross-union. J. Physiol., 204, $331-346$.

CLOSE R., 1972. Dynamic properties of mammalian skeletal muscles. Physiol. Rev., 52, 129-197.

COHEN M. W., ANDERSON M. J., ZORYCHTA E., WELDON P.R., 1979. Accumulation of acetylcholine receptors at nerve-muscle contacts in culture. Prog. Brain. Res., 49, 335-349.

COHEN M. W., GRESCHNER M., TUCCI M., 1984. In vivo development of cholinesterase at a neuromuscular junction in the absence of motor activity in Xenopus leavis. J. Physiol., 348, 57-66.

COHEN P., 1983. Protein phosphorylation and the control of glycogen metabolism in skeletal muscle. Phil. Trans. roy. Soc. Lond. B, 302, 13-25.

COLE H. A., PERRY S. V., 1975. The phosphorylation of Troponine I from cardiac muscle. Biochem. J., 149, 525-533.

COLLINS P. L., YOUNKIN S. G., 1982. Effect of denervation on the molecular forms of actylcholinesterase in rat diaphragm. J. biol. Chem., 257, 13638-13644.

CORSI A., MIDRIO M., GRANATA A. L., 1969. In situ utilization of glycogen and blood glucose by skeletal muscle during tetanus. Am. J. Physiol., 216, 1534-1541.

COTTER M., HUDLICKA O., PETTE D., STAUDTE H., VRBOVA G., 1973. Changes of capillary density and enzyme pattern in fast rabbit muscles during long-term stimulation. J. Physiol., 230, 34P-35P.

COVAULT J., SANES J. R., 1985. Neural cell adhesion molecule (N-CAM) accumulates in denervated and paralyzed skeletal muscles. Proc. nat. Acad. Sci., USA, 82, 4544-4548.

CRABTREE B., NEWSHOLME E. A., 1972a. The activities of phosphorylase, hexokinase, phosphofructokinase, lactate dehydrogenase and the glycerol 3-Phosphate dehydrogenases in muscles from vertebrates and invertebrates. Biochem. J., 126, 49-58.

CRABTREE B., NEWSHOLME E. A., 1972b. The activities of lipases and carnitine palmitoyltransferase in muscles from vertebrates and invertebrates. Biochem. J., 130, 697-705.

CREAZZO T. L., SOHAL G. S., 1983. Neural control of embryonic acetylcholine receptor and skeletal muscle. Cell Tissue Res., 228, 1-12.

CROW M. T., STOCKDALE F. E., 1984. Myosin isoforms and the cellular basis of skeletal muscle development. Exp. Biol. Med., 9, 165-174.

CROW M. T., STOCKDALE F. E., 1986. Myosin expression and specialization along the earliest muscle fibers of the developing avian limb. Develop. Biol., 113, 238-254.

CULLEN M. J., HOLLINGWORTH S., MARSHALL M. W., 1984. A comparative study of the transverse tubular system of the rat extensor digitorum longus and soleus muscles. $J$. Anat., 138, 297-308.

CUMMINS P., PERRY S. V., 1973. The subunits and biological activity of polymorphic forms of tropomyosins. Biochem. J., 133, 765-777.

CUMMINS P., PERRY S. V., 1974. Chemical and immunochemical characteristics of tropomyosins from striated and smooth muscle. Biochem. J., 141, 43-49.

CUMMINS P., PERRY S. V., 1978. Troponin I from human skeletal and cardiac muscles. Biochem. $J ., 171,251-259$.

CURLESS R. G., 1977. Developmental patterns of peripheral nerve, myoneural junction and muscle a review. Progr. Neurobiol., 9, 197-209.

CURTIS D. H., ZALIN R., 1981. Regulation of muscle differentiation : stimulation of myoblast fusion in vitro by catecholamines. Science, 214, 1355-1357.

CZEH G., GALLEGO R., KUDO N., KUNO M., 1978. Evidence for the maintenance of motoneurone properties by muscle activity. J. Physiol., 281, 239-252. 
DANIELS M. P., VIGNY M., SONDEREGGER P., BAUER H. C., VOGEL Z., 1984 . Association of lamina and other basement membrane components with regions of high acetylcholine receptor density on cultured myotubes. Int. J. Dev. Neurosci., 2, 87-99.

DAVEY B., YOUNKIN L. H., YOUNKIN S. G., 1979. Neural control of skeletal muscle cholinesterase : a study using organ-cultured rat muscle. J. Physial., 289, 501-515.

DAVIS C. J. F., MONTGOMERY A., 1977. The effect of prolonged inactivity upon the contraction characteristics of fast and slow mammalian twitch muscle. J. Physiol., 270, $581-594$.

DAVIS H. L., KIERNAN J. A., 1980. Neurotrophic effects of sciatic nerve extract on denervated Extensor digitorum longus muscle in the rat. Exp. Neurol., 69, 124-134.

DAVIS H. L., KIERNAN J. A., 1981. Effect of nerve extract on atrophy of denervated or immobilized muscles. Exp. Neurol., 72, 582-591.

DAVIS H. L., HEINICKE E. A., 1984. Prevention of denervation atrophy in muscle: mammalian neurotrophic factor is not transferrin. Brain Res., 309, 293-298.

DAVIS H. L., 1985. Myotrophic effects on denervation atrophy of hind limb muscles of mice with systemic administration of nerve extract. Brain Res., 343, 176-179.

DAWSON D. M., ROMANUL F. C. A., 1964. Enzymes in muscle. II. Histochemical and quantitative studies. Arch. Neurol., 11, 369-378.

DENNIS M. J., ZISKIND-CONHAIM L., HARRIS A. J., 1981, Development of neuromuscular junctions in rat embryos. Develop. Biol., 81, 266-279.

DENNY-BROWN D., 1929. The histological features of striped muscle in relation to its functional activity. Proc. roy. Soc. B, 104, 371-411.

DEVREOTES P. N., FAMBROUGH D. M., 1976. Turnover of acetylcholine receptors in skeletal muscle. Cold Spring Harb. Symp. Quant. Biol., 40, 237-251.

DHOOT G. K., PERRY S. V., 1979. Distribution of polymorphic forms of troponin components and tropomyosin in skeletal muscle. Nature, 278, 714-718.

DHOOT G. K., PERRY S. V., 1982. The effect of denervation on the distribution of the polymorphic forms of troponin components in fast and slow muscles of the adult rat. Cell Tissue Res., 225. $201-215$.

DIAMOND J., MILEDI R., 1962. A study of fetal and newborn rat muscle fibres. J. Physiol., 162. 393-408.

DIAS P. L. R., SIMPSON J. A., 1974. Effects of cross innervation on the motor endplates of fast-and-slow twitch muscles of the rabbit. Quant. J. Exp. Physiol., 59, 213-223.

DIAS P. L. R., 1979. Effects of tenotomy on the motor endplates of fast and slow twitch muscles of the rabbit. $J$. Anat., 129, 399-404.

DOMONKOS J., 1961. The metabolism of the tonic and tetanic muscles. I. Glycolytic metabolism. Arch. Biochem. Biophys., 95, 138-143.

DOMONKOS J., LATZKOVITS L., 1961. The metabolism of the tonic and tetanic muscles. II. Oxidative metabolism. Arch. Biochem. Biophys., 95, 144-146.

DRACHMAN D. B., 1967. Is acetylcholine the trophic neuromuscular transmitter? Arch. Neurol., 17, 206-218.

DRACHMAN D. B., 1974. The role of acetylcholine as a neurotrophic transmitter. Ann. N. Y. Acad. Sci, 228, 160-175.

DRACHMAN D. B., JOHNSTON D. M., 1973. Development of a mammalian fast muscle : dynamic and biochemical properties correlated. J. Physio/., 234, 29-42.

DREWS G. A., ENGEL W. K., 1966. Reversal of the ATPase reaction in muscle fibers by E.D.T.A. Nature, 212, $1551-1553$.

DUBOWITZ V., PEARSE A. G. E., 1960a. Reciprocal relationships of phosphorylase and oxydative enzymes in skeletal muscles. Nature, 185, 701-702.

DUBOWITZ V., PEARSE A. G. E., 1960b. A comparative histochemical study of oxydative enzyme and phosphorylase activity in skeletal muscle. Histochimie, 2, 105-117.

DUBOWITZ V., 1967a. Cross innervated mammalian skeletal muscle : histochemical, physiological and biochemical observations. J. Physiol., 193, 481-496.

DUBOWITZV., 1967b. Cross innervation of fast and slow muscle : histochemical, physiological and biochemical studies, 164-167. In A.T. MILHORAT, Exploratory concepts in muscular dystrophy and related disorders, Excerpta med. Found. Amsterdam. 
DUM R. P., KENNEDY T. T., 1980. Physiological and histochemical characteristics of motor units in cat Tibialis anterior and Extensor digitorum longus muscle. J. Neurophysiol., 43. 1615-1630.

DUM R. P., O'DONOVAN M. J., TOOP J., BURKE R. E., 1985a. Cross-reinnervated motor units in cat muscle. I. Flexor digitorum longus muscle units reinnervated by soleus motoneurons. $J$. Neurophysiol., 54, 818-836.

DUM R. P., O'DONOVAN M. J., TOOP J., TSAIRIS P., PINTER M. J., BURKE R. E., 1985b. Crossreinnervated motor units in cat muscle. II. Soleus muscle reinnervated by Flexor digitorum longus motoneurons. J. Neurophysiol., 54, 837-851.

DUNN R. B., CRITZ J. B., 1975. Uptake of lactate by dog skeletal muscle in vivo and the effect of free fatty acids. Am. J. Physiol., 229, 255-259.

DZIADEK M., TIMPL R., 1985. Expression of nidogen and laminin in basement membranes during mouse embryogenesis and in teratocarcinoma cells. Develop. Biol., 111, 372-382.

EBASHI S., 1963. Third component participating in the superprecipitation of natural actomyosin. Nature, 22, 1010-1012.

EBASHI S., ENDO M., 1968. Calcium ion and muscle contraction. Progr. Biophys. molec. Biol., 18, 123-183

EBASHI S., ENDO M., OHTSUKI I., 1969. Control of muscle contraction. Q. Rev. Biophys., 2, $351-384$

EBASHI S., WAKABAYASHI T., EBASHI F., 1971. Troponin and its components. J. Biochem., 69, $441-445$.

EBASHI S., 1980. The Croonian Lecture 1979. Regulation of muscle contraction. Proc. roy. Soc. Lond. B, 207, 259-286.

ECCLES J. C., 1944. Investigations on muscle atrophies arising from disuse and tenotomy. $J$. Physiol., 103, 253-266.

ECCLES J. C., ECCLES R. M., LUNDBERG A., 1958. The action potentials of the alpha motoneurons supplying fast and slow muscles. J. Physiol., 142, 275-291.

ECCLES J. C., 1963. Specificity of neural influence on speed of muscle contraction, 111-128. In E. GUTMAN, P. HNIK, The effect of use and disuse on neuromuscular functions. Publ. House Czechosl. Acad. Sci., Prague.

ECCLES J. C., 1967. The effects of nerve cross-union on muscle contraction, 151-160. In A.T. MILHORAT, Exploratory concepts in muscular dystrophy and related disorders. Excerpta med. Found., Amsterdam.

ECKNER F. A. O., RIEBE B. H., MOULDER P. V., BLACKSTONE E. H., 1968. Histochemical study of enzyme systems in frozen dried tissue. Histochemie, 13, 283-288.

ECKNER F. A. O., 1971. Demonstration of phosphorylase and uridine diphosphate glucose-glucosyl transferase activities. J. Histochem. Cytochem., 19, 133.

EDES I., SOHAR I., MAZAREAN H., TAKACS O., GUBA F., 1980. Changes in the aerobic and anaerobic metabolism of skeletal muscle subjected to plasted cast immobilization. Acta. Biochim. Biophys. Acad. Sci. Hung., 15, 305-311.

EDGERTON V. R., SIMPSON D. R., 1969. The intermediate fiber of rats and guinea pigs. $J$. Histochem. Cytochem., 17, 828-838.

EDGERTON V. R., SMITH J. L., SIMPSON D. R., 1975. Muscle fiber type populations of human leg muscles. Histochem. J., 7, 259-266.

EDGERTON V. R., SMITH L. A., ELDRED E., COPE T. C., MENDELL L. M., 1980. Muscle and motor unit properties of exercised and non-exercised chronic spinal cats, 355-371. In D. PETTE. Plasticity of musc/e. Walter de Gruyter, Berlin.

EDSTRÖM L., KUGELBERG E., 1968. Histochemical composition, distribution of fibres and fatiguability of single motor units. J. Neurol. Neurosurg. Psychiat., 31, 424-433.

EDWARDS C., 1979. The effect of innervation on the properties of acetylcholine receptors in muscle. Neuroscience, 4, 565-584.

EISENBERG B. R., SALMONS S., 1981. The reoganization of subcellular structure in muscle undergoing fast-to-slow type transformation. Cell Tissue Res., 220, 449-471.

EISENBERG B. R., BROWN J. M. C., SALMONS S., 1984. Restoration of fast muscle characteristics following cessation of chronic stimulation. The ultrastructure of slow-to-fast transformation. Cell Tissue Res., 238, 221-230. 
EMMELIN N., MALM L., 1965. Development of supersensitivity as dependent on the length of degenerating nerve fibres. Quart. J. exp. Physiol., 50, 142-145.

ENGEL W. K., 1962. The essentiality of histo-and cytochemical studies of skeletal muscle in the investigation of neuromuscular diseases. Neurology, 12, 778-784.

ENGEL W. K., KARPATI G., 1968. Impaired skeletal muscle maturation following neonatal neurectomy. Develop. Biol., 17, 713-723.

ENGEL W. K., 1970. Selective and non selective susceptibility of muscle fiber types. A new approach to human neuromuscular diseases. Arch. Neurol., 22, 97-117.

ESSEN B., JANSSON E., HENRIKSSON J., TAYLOR A. W., SALTIN B., 1975. Metabolic characteristics of fibre types in human skeletal muscle. Acta. physiol. scand., 95, 153-165.

FALLON J. R., NITKIN R. M., REIST N. E., WALLACE B. G., McMAHAN U. J., 1985. Acetylcholine receptor-aggregating factor is similar to molecules concentrated at neuromuscular junctions. Nature, 315, $571-574$.

FAMBROUGH D. M., HARTZELL H. C., 1972. Acetylcholine receptors : number and distribution at neuromuscular junctions in rat diaphragm. Science, 176, 189-191.

FAMBROUGH D. M., 1979. Control of acetylcholine receptors in skeletal muscle. Physiol. Rev., 59, 165-226.

FARDEAU M., 1973. Caractéristiques cytochimiques et ultrastructurales des différents types de fibres musculaires squelettiques extrafusales (chez l'homme et quelques mammifères). Ann. Anat. path. Paris, 18, 7-34.

FENG T. P., JUNG H. W., WU W. Y., 1962. The contrasting trophic changes of the anterior and posterior latissimus dorsi of the chick following denervation. Acta. physiol. sini., 25, 304-311.

FERTUCK H. C., SALPETER M. M., 1974. Localisation of acetylcholine receptor by 1125-labelled - Bungarotoxin binding at mouse motor endplates. Proc. nat. Acad. Sci. USA, 71, 1376-1378.

FISCHBACH G. D., ROBBINS N., 1971. Effect of chronic disuse of rat soleus neuromuscular junctions on postsynaptic membrane. J. Neurophysiol., 34, 562-569.

FISCHBACH G. D., COHEN S. A., 1973. The distribution of acetylcholine sensitivity over uninnervated and innervated muscle fibers grown in cell culture. Develop. Biol., 31, 147-162.

FISCHBACH G. D., FRANK E., JESSEL T.M., RUBIN L. L., SCHUETZE S. M., 1979. Accumulation of acetylcholine receptors and acetylcholinesterase at newly formed nerve-muscle synapses. Pharmacol. Rev., 30, 411-428.

FRANK E., FISCHBACH G. D., 1979. Early events in neuromuscular junction formation in vitro: induction of acetylcholine receptor clusters in the postsynaptic membrane and morphology of newly formed synapses. J. Ce/l Biol., 83, 143-158.

FRANZINI-ARMSTRONG C., PEACHEY L. D., 1981. Striated muscle. Contractile and control mechanisms. J. Cell Biol., 91, 166S-186S.

FRIDEN J., SJÖSTROM M., EKBLOM B., 1984. Muscle fibre type characteristics in endurance trained and untrained individuals. Eur. J. applied. Physiol., 52, 266-271.

GAMBKE B., RUBINSTEIN N. A., 1984. A monoclonal antibody to the embryonic myosin heavy chain in rat skeletal muscle. J. biol. Chem., 259, 12092-12100.

GAUTHIER G. F., 1970. The ultrastructure of three fiber types in mammalian skeletal muscle, 2, 103-130. In E. J. BRISKY, R. G. CASSENS, B. B. MARSH, The physiology and biochemistry of muscle as a food. Kingsport Press, Tennessee.

GAUTHIER G. F., DUNN R. A., 1973. Ultrastructure and cytochemical features of mammalian skeletal muscle fibres following denervation. J. Cell Sci, 12, 525-547.

GAUTHIER G. F., SCHAEFFER S. F., 1974. Ultrastructure and cytochemical manifestations of protein synthesis in the peripheral sarcoplasm of denervated and newborn skeletal muscle fibres. J. Cell Sci., 14, 113-137.

GAUTHIER G. F., LOWEY S., 1977. Polymorphism of myosin among skeletal muscle fiber types. $J$. Cell Biol., 74, 760-779.

GAUTHIER G. F., LOWEY S., HOBBS A. W., 1978. Fast and slow myosin in developing muscle fibres. Nature, 274, 25-29.

GAUTHIER G. F., LOWEY S., 1979. Distribution of myosin isoenzymes among skeletal muscle fiber types. J. Cell Biol., 81, 10-25. 
GAUTHIER G. F., 1980. Distribution of myosin isoenzymes in adult and developing muscle fibers, 83-95. In D. PETTE, Plasticity of muscle. Walter de Gruyter, Berlin.

GAUTHIER G. F., HOBBS A. W., 1982. Effects of denervation on the distribution of myosin isoenzymes in skeletal muscle fibers. Exp. Neurol., 76, 331-346.

GAUTHIER G. F., LOWEY S., BENFIELD P. A., HOBBS A. W., 1982. Distribution and properties of myosin isozymes in developing avian and mammalian skeletal muscle fibers. J. Cel/ Biol., 92. $471-484$.

GAUTHIER G. F., BURKE R. E., LOWEY S., HOBBS A. W., 1983. Myosin isozymes in normal and cross-reinnervated cat skeletal muscle fibers. J. Cell Biol., 97, 756-771.

GEORGE J. C., BERGER A. J., 1966. Avian myology. Acad. Press, New York.

GLICKSMAN M. A., SANES J. R., 1983. Differentiation of motor nerve terminals formed in the absence of muscle fibres. J. Neurocytol., 12,661-671.

GODFREY E. W., NITKIN R. M., WALLACE B. G., McMAHAN U. J., 1983. Identifying components of extracellular matrix that organize $\mathrm{ACh}$ receptors at synaptic sites on regenerating muscle cells, 61-70. In Developing and regenerating vertebrate nervous system. Alan R. Liss, New York.

GODFREY E. W., NITKIN R. M., WALLACE B. G., RUBBIN L. L., McMAHAN U. J., 1984. Components of Torpedo electric organ and muscle that cause aggregation of acetylcholine receptors on cultured muscle cells. J. Cell Biol., 99, 615-627.

GOLDBERG A. L., 1980. The regulation of protein turnover by endocrine and nutritional factors, 469-492. In D. PETTE, Plasticity of musc/e. Walter de Gruyter, Berlin.

GOLISH G., PETTE D., PILCHMAIER H., 1970. Metabolic differentiation of rabbit skeletal muscle as induced by specific innervation. Eur. J. Biochem., 16, 110-116.

GORDON T., PERRY R., SRIHARI T., VRBOVA G., 1977. Differentiation of slow and fast muscles in chickens. Cell Tissue Res., 180, 211-222.

GORDON H., VAN ESSEN D. C., 1985 . Specific innervation of muscle fiber types in a developmentally polyinnervated muscle. Develop. Biol., 111, 42-50.

GREEN H. J., REICHMANN H., PETTE D., 1984. Inter- and intraspecies comparisons of fibre type distribution and of succinate dehydrogenase activity in type I, IIA and IIB fibres of mammalian diaphragms. Histochemistry, 81, 67-73.

GRÖSCHEL-STEWART U., MESCHEDE D., LEHR I., 1973. Histochemical and immunochemical studies on mammalian striated muscle fibers. Histochemie, 33, 79-85.

GRÖSCHEL-STEWART U., DRENCKHAHN D., 1982. Muscular and cytoplasmic contractile proteins. Biochemistry, immunology, structural organization. Collagen Rel. Res., 2, 381 -463.

GRUMET M., HOFFMAN S., CROSSIN K. L., EDELMAN G. M., 1985. Cytotactin, an extracellular matrix protein of neural and non-neural tissues that mediates glia-neuron interaction. Proc. nat. Acad. Sci., USA, 82, 8075-8079.

GRÜTZNER P., 1884. Zur Anatomie und Physiologics der quergestreiften Muskeln. Rec. Zool. Suisse, 1, 665-684.

GUTH L., 1968. "Trophic » influences of nerve on muscle. Physiol. Rev., 48, 645-687.

GUTH L., SAMAHA F. J., 1969. Qualitative differences between actomyosin ATPase of slow and fast mammalian muscle. Exp. Neurol., 25, 138-152.

GUTH L., 1972. Regulation of metabolic and functional properties of muscle, 61-75. In GOSS R. J., Regulation of organ and tissue growth. Acad. Press London.

GUTH L., SAMAHA F. J., 1972. Erroneous interpretations which may result from application of the " Myofibrillar ATPase» histochemical procedure to developing muscles. Exp. Neurol., 34, 465-475.

GUTH L., 1973. Fact and artifact in the histochemical procedure for myofibrillar ATPase. Exp. Neurol., 41, 440-450.

GUTMANN E., 1962. The denervated muscle. Publ. House Czechosl. Acad. Sci., Prague, p. 332-333.

GUTMANN E., HANZLIKOVA V., 1965. Age changes of motor endplates in muscle fibers of the rat. Gerontologia, 11, 12-24.

GUTMANN E., 1969. The trophic function of the nerve cell. Scientia, 104, 122-141.

GUTMANN E., 1976. Neurotrophic relations. Annu. Rev. Physiol., 38, 177-216. 
HALL Z. W., GORIN P. D., SILBERSTEIN L., BENNET C., 1985. A postnatal change in the immunological properties of the acetylcholine receptor at rat muscle endplates. J. Neurosci., 5. $730-734$.

HAMBURGER V., HAMILTON H. L., 1951. A serie of normal stages in the development of the chick embryo. J. Morphol., 88, 49-92.

HANZLIKOVA V., SCHIAFFINO J., 1973. Studies on the effect of denervation in developing muscle. III. Diversification of myofibrillar structure and origin of the heterogeneity of muscle fiber types. Z. Zellforsch., 147, 75-85.

HARRIS A. J., 1981 a. Embryonic growth and innervation of rat skeletal muscle. I. Neural regulation of muscle fibre numbers. Phil. Trans. roy. Soc. Lond. B, 293, 258-277.

HARRIS A. J., 1981b. Embryonic growth and innervation of rat skeletal muscle. II. Neural regulation of muscle cholinesterase. Phil. Trans. roy. Soc. Lond. B, 293, 280-286.

HARTZELL H. C., FAMBROUGH D. M., 1972. Acetylcholine receptors. Distribution and extrajunctional density in rat diaphragm after denervation correlated with acetylcholine sensitivity. $J$. gen. Physiol., 60, 248-262.

HAVEL R. J., 1970. Lipid as an energy source, 2, 609-621. In E. J. BRISKEY, R. G. CASSENS, B. B MARSH, The Physiology and biochemistry of muscle as a food. Kingsport Press, Tennessee.

HAY E. D., 1981. Extracellular matrix. J. Cell Biol., 91, 205s-223s.

HEELEY D. H., DHOOT G. K., FREARSON N., PERRY S. V., VRBOVA G., 1983. The effect of cross-innervation on the tropomyosin composition of rabbit skeletal muscle. FEBS Lett., 152. 282-286.

HENNIG R., LØMO T., 1985. Firing patterns of motor units in normal rats. Nature, 314, 164-166.

HIKIDA R. S., BOCK W. J., 1972. Effect of denervation on pigeon slow skeletal muscle. $Z$. Zellforsch., 128, 1-18.

HILTON S. M., 1974. The vasculature of skeletal muscle considered in relation to muscle type and function, 2, 385-388. In A. T. MILHORAT, Exploratory concepts in muscular dystrophy. Excerpta Medica, Amsterdam.

HINTZ C. S., LOWRY C. V., KAISER K. K., McKEE D., LOWRY O. M., 1980. Enzyme levels in individual rat muscle fibers. Am. J. Physiol., 239, C58-C65.

HINTZ C. S., COYLE E. F., KAISER K. K., CHI M. M., LOWRY O. H., 1984. Comparison of muscle fiber typing by quantitative enzyme assays and by myosin ATPase staining. J. Histochem. Cytochem., 32, 655-660.

HOFER S., HOFER H. W., KUHN E., PETTE D., 1971. Change of hexokinase in the enzyme activity pattern of muscle in human myotonia congenita and in experimental myotonia of the rat. Klin. Wshr., 49, 968-971.

HOFMANN E., 1978. Phosphofructokinase - A favourite of enzymologists and of students of metabolic regulation. Trends Biochem. Sci., 3, 145-147.

HOFMANN W. W., THESLEFF S., 1972. Studies on the trophic influence of nerve in skeletal muscle. Eur. J. Pharmacol., 20, 256-260.

HOFMANN R. K., GAMBKE B., STEPHENSON L. W., RUBINSTEIN N. A., 1985. Myosin transitions in chronic stimulation do not involve embryonic isozymes. Muscle Nerve, 8, 796-805.

HOGAN E. L., DAWSON D. M., ROMANUL F. C. A., 1965 . Enzymatic changes in denervated muscle. II. Biochemical studies. Arch. Neurol., 13, 274-282.

$\mathrm{HOH}$ J. F. Y., 1975. Neural regulation of mammalian fast and slow muscle myosins: an electrophoretic analysis. Biochemistry, 14, 742-747.

HOH J. F. Y., McGRATH P. A., WHITE R. I., 1976 . Electrophoretic analysis of multiple forms of myosin in fast twitch and slow-twitch muscles of the chick. Biochem. J., 157, 85-95.

$\mathrm{HOH}$ J. F. Y., 1978. Light chain distribution of chicken skeletal muscle myosin isoenzymes. FEBS Lett., 90, 297-300.

HOH J. F. Y., 1979. Developmental changes in chicken skeletal myosin isoenzymes. FEBS Lett., 98 , 267-270.

HOH J. F. Y., YEOH G. P. S., 1979. Rabbit skeletal myosin isoenzymes from fetal, fast-twitch and slow-twitch muscles. Nature, 280, 321-322.

HOH J. F. Y., KWAN B. T. S., DUNLOP C., KIM B. H., 1980. Effects of nerve cross-union and cordotomy on myosin isoenzymes in fast-twitch and slow-twitch muscles of the rat, 339-352. In D. PETTE, Plasticity of musc/e. Walter de Gruyter, Berlin. 
HOLLOSZY J. O., BOOTH F. W., 1976. Biochemical adaptations to endurance exercise in muscle. Annu. Rev. Physiol., 38, 273-291.

HOOKER A. M., BALDWIN K. M., 1979. Substrate oxidation specificity in different types of mammalian muscle. Am. J. Physiol., 236, C66-C69.

HUDLICKA O., PETTE D., STAUDTE H., 1973. The relation between blood flow and enzymatic activities in slow and fast muscles during development. Pflügers Arch., 343, 341 - 356.

HUDLICKA O., AITMAN T., HEILIG A., LEBERER E., TYLER K. R., PETTE D., 1984. Effects of different patterns of long-term stimulation on blood flow, fuel uptake and enzyme activities in rabbit fast skeletal muscles. Pflügers Arch., 402, 306-311.

HUDLICKA O., TYLER K. R., 1984. The effect of long-term high-frequency stimulation on capillary density and fibre types in rabbit fast muscles. J. Physiol., 353, 435-445.

HUIZAR P., KUNO M., MIYATA Y., 1975. Differentiation of motoneurones and skeletal muscles on kittens. J. Physiol., 252, 465-479.

HUXLEY H. E., HANSON J., 1960. The molecular basis of contraction in cross-striated muscles, 183-227. In G. H. BOURNE, The structure and function of muscle. I. Structure. Acad. Press, New York.

IANUZZO D., PATEL P., CHEN V., O'BRIEN P., WILLIAMS C., 1977. Thyroidal trophic influence on skeletal muscle myosin. Nature, 270,74-76.

IANUZZO D., PATEL P., CHEN V., O'BRIEN P., 1980. A possible thyroidal trophic influence on fast and slow skeletal muscle myosin, 593-605. In D. PETTE, Plasticity of muscle. Walter de Gruyter, Berlin.

IP M. C., VRBOVA G., 1983. Reinnervation of the soleus muscle by its own or by an alien nerve. Neuroscience, 10, 1463-1469.

ISSEKUTZ B. Jr., MILLER H., 1962. Plasma Free Fatty Acids during exercise and the effect of lactic acid. Proc. Soc. exp. Biol. Med., 110, 237-239.

ISSEKUTZ B. Jr., MILLER H. 1., PAUL P., RODAHL K., 1964. Source of fat oxidation in exercising dogs. Amer. J. Physiol., 207, 583-589.

ISSEKUTZ B. Jr., MILLER H. I., PAUL P., RODAHLK., 1965. Effect of lactic acid on Free Fatty Acids and giucose oxidation in dogs. Amer. J. Physiol., 209, 1137-1144

ISSEKUTZ B., 1970. Interrelationships of Free Fatty Acids, lactic acid and glucose in muscle metabolism, 2, 623-643. In E. J. BRISKEY, R. G. CASSENS, B. B. MARSH, Physiology and biochemistry of muscle as a food. Kingsport Press, Tennessee.

JANSEN J. K. S., LØMO T., NICOLAYSEN K., WESTGAARD R. H., 1973. Hyperinnervation of skeletal muscle fibers: dependence on muscle activity. Science, 181, 559-561.

JEAN D. H., ALBERS R. W., GUTH L., ARON H. J., 1975. Differences between the heavy chains of fast and slow muscle myosin. Exp. Neurol., 49, 750-757.

JIRMANOVA I., ZELENA J., 1973. Ultrastructure transformation of fast chicken muscle fibres induced by nerve cross-union. Z. Zellforsch., 146, 103-121.

JOHNSON M. A., MASTAGLIA F. L., MONTGOMERY A., POPE B., WEEDS A. G., 1980. A neurally mediated effect of thyroid hormone deficiency on slow twitch skeletal muscle?, 607-615. In D. PETTE, Plasticity of muscle. Walter de Gruyter, Berlin.

JOLESZ F., SRETER F. A., 1981. Development, innervation, and activity-pattern induced changes in skeletal muscle. Annu. Rev. Physiol., 43, 531-552.

JONES R., VRBOVA G., 1974. Two factors responsible for the development of denervation hypersensitivity. J. Physiol, 236, 517-538.

JONES R., 1981. The influence of electrical activity on the development of newborn innervated rat muscles. Pflügers Arch., 391, 68-73.

JONES S. P., RIDGE R. M. A. P., ROWLERSON A., 1985. Motor units are of mixed types in a fast muscle of neonatal rat. J. Physiol., 358, 28 P.

JOZSA L., BALINT J. B., DEMEL S., 1978. Histochemical and ultrastructural study of human muscles after spontaneous rupture of the tendon. Acta histochem. 63, 61-73.

JOZSA L., BALINT J. B., DEMEL S., REFFY A., SZILAGYI I., 1979. Enzyme histochemical alterations in human skeletal muscles after tenotomy and after spontaneous rupture of the tendon. Folia Histochem. Cytochem., 17, 37-42. 
KAISER C. E., GEORGE J. C., 1973. Interrelationship amongst the avian orders Galliformes, Columbiformes and Anseriformes as evinced by the fiber types in the Pectoralis muscle. Can. J. Zool., 51, 887-892.

KARDAMI E., MONTARRAS D., FISZMAN M., 1983. Fast and slow chicken skeletal muscles contain different and Tropomyosins. Biochem. Biophys. Res. Commun., 110, 147-154.

KARPATI G., ENGEL W. K., 1968. Correlative histochemical study of skeletal muscle after suprasegmental denervation, peripheral nerve section, and skeletal fixation. Neurology, 18, 681-692.

KELLY A. M., ZACKS S. I., 1969a. The histogenesis of rat intercostal muscle. J. Ce/l Biol., 42, $135-153$.

KELLY A. M., ZACKS S. I., 1969b. The fine structure of motor endplate morphogenesis. J. Cel/ Biol.. 42, 154-169.

KELLY A. M., RUBINSTEIN N. A., 1980. Why are fetal muscle slow ? Nature, 288, 266-269.

KELLY A. M., RUBINSTEIN N. A., 1986. Muscle histogenesis and muscle diversity, 77-84. In C. EMERSON, D. FISCHMAN, B. NADAL-GINARD, M. A. Q. SIDDIQUI, Molecular biology of muscle development. Alan R. Liss, New York.

KELLY S. S., 1978. The effect of age on neuromuscular transmission. J. Physiol., 274, 51-62.

KHAN M. A., 1976. Histochemical characteristics of vertebrate striated muscle: a review. Prog. Histochem. Cytochem., 8, 1-48.

KHAN M. A., 1980. A histochemical and ultrastructural study of heterogeneous red fibres of pigeon Pectoralis muscle. Cytobios, 28, 85-93.

KIENY M., MAUGER A., 1984. Immunofluorescent localization of extracellular matrix components during muscle morphogenesis. I. In normal chick embryos. J. exp. Zool., 232, 327-341.

KIESSLING K. H., HANSON I., 1983. Fibre composition and enzyme activities in pig muscles. Swedish J. agric. Res., 13, 257-261.

KIMURA I., HASEGAWA T., MIURA T., OZAWA E., 1981. Muscle trophic factor is identical to transferrin. Proc. Japan Acad., 57 (B), 200-205.

KLEINMAN H. K., MCGARVEY M. L., HASSEL J. R., MARTIN G. R., BARON VAN EVERCOOREN A., DUBOIS-DALCO A, 1984. The role of laminin in basement membranes and in the growth, adhesion, and differentiation of celis, 123-143. In R. L. TRELSTAD, The role of extracellular matrix in development. Alan R. Liss, New York.

KLEINMAN H. K., CANNON F. B., LAURIC G. W., HASSEL J. R., AUMAILLEY M., TERRANOVA V.P., MARTIN G. R., DUBOIS-DALCQ A., 1985. Biological activities of laminin, 117-125. In A. HARI REDDI, Extrace/lular matrix : structure and function. Alan R. Liss New York.

KNOLL P., 1891. Über protoplasmaarme und protoplasmareiche Muskulatur. Denkschr. Kaiserl. Akad. Wiss. Wien, 58, 633-700.

KOENIG J., 1967. Structure et distribution des plaques motrices d'un muscle lent innervé expérimentalement par le nerf moteur d'un muscle rapide. C. R. Soc. Biol., 161, 1276-1279.

KOENIG J., 1970. Contribution à l'étude de la morphologie des plaques motrices des grands dorsaux antérieur et postérieur du poulet après innervation croisée. Arch. Anat. microsc., 59. 403-426.

KOENIG J., FARDEAU M., 1973. Etude histochimique des muscles grands dorsaux antérieur et postérieur du poulet et des modifications observées après dénervation et réinnervation homologue ou croisée. Arch. Anat. micr. Morph. exp., 62, 249-267.

KORNELIUSSEN H., JANSEN J. K. S., 1976. Morphological aspects of the elimination of polyneural innervation of skeletal muscle fibres in newborn rats. J. Neurocytol., 5, 591-604.

KORNELIUSSEN H., SOMMERSCHILD $H_{\text {., }}$ 1976. Ultrastructure of the new neuromuscular junctions formed during reinnervation of rat Soleus muscle by a « foreign » nerve. Ce/l Tissue Res., 167, 439-452.

KOVANEN V., SUOMINEN H., HEIKKINEN E., 1984. Collagen of slow twitch and fast twitch muscle fibres in different types of rat skeletal muscle. Eur. J. applied Physiol., 52, 235-242.

KUGELBERG E., 1973. Histochemical composition, contraction speed and fatigability of rat Soleus motor units. J. Neurol. Sci., 20, 177-198.

KUGELBERG E., LINDEGREN B., 1979. Transmission and contraction fatigue of rat motor units in relation to succinate dehydrogenase activity of motor unit fibres. J. Physiol., 288, 285-300. 
KULLBERG R.W., LENTZT. L., COHEN M. W., 1977. Development of the myotomal neuromuscular junction in Xenopus laevis : an electrophysiological and fine-structural study. Develop. Biol., 60, $101-129$.

KUNZ B., BAUMANN H., SCHAUB M. C., 1985. Myosin heavy chain peptide patterns and histochemical ATPase activities in heart and skeletal muscles of rat and rabbit. 14th Eur. Conf. on Muscle and motility. Uim (RFA), 11-15 September 1985.

LAING N. G., LAMB A. H., 1983. The distribution of muscle fiber types in chick embryo wings transplanted to the pelvic region is normal. J. Embryol. exp. Morphol., 78, 67-82.

LANDMESSER L., MORRIS D. G., 1975. The development of functional innervation in the hind limb of the chick embryo. J. Physiol., 249, $301-326$.

LEBERER E., PETTE D., 1984. Lactate dehydrogenase isozymes in type I, IIA and IIB fibres of rabbit skeletal muscle. Histochemistry. 80, 295-298.

LEFAUCHEUR L., 1985. Differenciation postnatale des types de fibres musculaires chez le porc. Caractérisation des récepteurs de l'insuline dans deux musc/es aux propriétés contractiles et métaboliques différentes. Thèse Dr. Ing. ENSA, Montpellier, $70 \mathrm{pp}$.

LEFAUCHEUR L., VIGNERON P., 1986. Postnatal changes in some histochemical and enzymatic characteristics of three pig muscles. Meat Sci., 16, 199-216.

LENTZ T.L., 1971. Nerve trophic function: in vitro assay of effects of nerve tissue on muscle cholinesterase activity. Science, 171, 187-189.

LENTZ T. L., 1972. A role of cyclic AMP in a neurotrophic process. Nature, 238, 154-155.

LENTZ T. L., 1974. Effect of brain extracts on cholinesterase activity of cultured skeletal muscle. Exp. Neurol., 25, 520-526.

LETINSKY M. S., FISCHBECK K. H., McMAHAN U. J., 1976. Precision of reinnervation of original postsynaptic sites in frog muscle after a nerve crush. J. Neurocytol., 5, 691-718.

LEUNG W. N., JEFFREY P. L., ROSTAS J. A. P., 1982. Denervation exposes cryptic concanavalin A binding sites in skeletal muscle membranes. Neurosci. Lett., 30, 31 -36.

LEWIS D. M., RAVLERSON A., WEBB S. N., 1982. Motor units and immunohistochemistry of cat soleus muscle after long periods of cross reinnervation. J. Physiol., 325, 403-418.

LOMO T., ROSENTHAL J., 1972. Control of ACh sensitivity by muscle activity in the rat. J. Physiol. 221, 493-513.

LOMO T., WESTGAARD R. H., DAHL H. A., 1974. Contractile properties of muscle : control by pattern of muscle activity in the rat. Proc. roy. Soc. Lond. B, 187, 99-103.

LOMO T., WESTGAARD R. H., 1975. Further studies on the control of ACh sensitivity by muscle activity in the rat. J. Physiol., 252, 603-625.

LOMO T., WESTGAARD R. H., 1976. Control of ACh sensitivity in rat muscle fibres. Co/d Spring Harbor Symp. Quant. Biol., 40, 263-274.

LØMO T., SLATER C. R., 1978. Control of Acetylcholine sensitivity and synapse formation by muscle activity. J. Physiol., 275, 391-402.

LOMO T., SLATER C. R., 1980a. Acetylcholine sensitivity of developing ectopic nerve muscle junctions in adult rat soleus muscles. J. Physiol., 303, 173-189.

LOMO T., SLATER C. R., 1980b. Control of junctional acetylcholinesterase by neural and muscular influences in the rat. J. Physiol., 303, 191-202.

LØMO T., 1983. Trophic factors and postsynaptic activity in synapse formation. Nature, 305, 576.

LOMO T., MASSOULIE J., VIGNY M., 1985. Stimulation of denervated rat soleus muscle with fast and slow activity patterns induces different expression of acetylcholinesterase molecular forms. J. Neurosci., 5, 1180-1187.

LOWEY S., SLAYTER H. S., WEEDS A. G., BAKER H., 1969. Substructure of the myosin molecule. I. Subfragments of myosin by enzymic degradation. J. mol. Biol., 42, 1-29.

LOWEY S., RISBY D., 1971. Light chains from fast and slow muscle myosins. Nature, 234, $81-85$.

LOWEY S., STEINER L. A., 1972. An immunochemical approach to the structure of myosin and the thick filament. J. mol. Biol, 65, $111-126$.

LOWEY S., 1980. An immunological approach to the isolation of myosin isoenzyme, 69-81. In D. PETTE, Plasticity of muscle. Walter de Gruyter, Berlin.

LOWEY S., BENFIELD P. A., LE BLANC D. D., WALLER G., WINKELMANN D. A., GAUTHIER G. F., 1982. Characterization of myosins from embryonic and developing chicken Pectoralis 
muscle, 15-24. In Muscle development. Molecular and cellular control. Ed. by M. L. PEARSON and H. F. EPSTEIN. Cold Spring Harbor Laboratory.

LOWRIE M. B., KRISHNAN SUBRAMANIAM, VRBOVA G., 1982. Recovery of slow and fast muscles following nerve injury during early postnatal development in the rat. J. Physiol., 331. $51-66$.

LOWRIE M. B., VRBOVA G., 1984. Different pattern of recovery of fast and slow muscles following nerve injury in the rat. J. Physiol., 349, 397-410.

LOWRY C. V., KIMMEY J. S., FELDER S., CHI M. M. Y., KAISER K. K., PASSONNEAU P. N., KIRK K. A., LOWRY O. M., 1978. Enzyme patterns in single human muscle fibers. J. biol. Chem., 253, 8269-8277.

LOWRY O. H., 1984. The heterogeneity of muscle. Carlsberg Res. Commun., 49, 307-314.

LUCO J. V., EYZAGUIRRE C., 1955. Fibrillation and hypersensitivity to $A C h$ in denervated muscle effect of length of degenerating nerve fibers. J. Neurophysiol., 18, 65-73.

LUTZ H., ERMINI M., JENNY E., BRUGGMANN S., JORIS F., WEBER E., 1978. The size of the fibre populations in rabbit skeletal muscles as revealed by indirect immunofluorescence with antimyosin sera. Histochemistry, 57, 223-235.

MADRI J. A., ROLL F. J., FURTHMAYR H., FOIDART J. M., 1980. Ultrastructural localization of fibronectin and laminin in the basement membranes of the murine kidney. J. Cell Biol., 86, 682-687.

MANNHERZ H. G., GOODY R. S., 1976. Protein of contractile systems. Annu. Rev. Biochem., 45, 427-465.

MARKELONIS G. J., OH T. H., 1979. A sciatic nerve protein has a trophic effect on development and maintenance of skeletal muscle cells in culture. Proc. nat. Acad. Sci. USA, 76, 2470-2474.

MARKELONIS G. J., KEMERER V. F., OH T. H., 1980a. Sciatin : purification and characterization of a myotrophic protein from chicken sciatic nerves. J. biol. Chem., 255, 8967-8970.

MARKELONIS G. J., OHT. H., DERR D., 1980b. Stimulation of protein synthesis in cultured skeletal muscle by a trophic protein from sciatic nerves. Exp. Neurol., 70. 598-612.

MARKELONIS G. J., OH T. H., ELDEFRAWI M. E., GUTH L., 1982a. Sciatin : a myotrophic protein increases the number of acetylcholine receptors and receptor clusters in cultured skeletal muscle. Develop. Biol., 89. 353-361.

MARKELONIS G. J., BRADSHOW R. A., OH T. H., JOHNSON J. L., BATES J. O., 1982b. Sciatin is a transferin-like polypeptide. J. Neurochem., 39, 315-320.

MARSHALL L. M., SANES J. R., MCMAHAN U. J., 1977. Reinnervation of original synaptic sites on muscle fiber basement membrane after disruption of the muscle cells. Proc. Nat. Acad. Sci. USA, 74, 3073-3077.

MARSTON S. B., TAYLOR E. W., 1980. Comparison of the myosin and actomyosin ATPase mechanisms of the four types of vertebrate muscles. J. mol. Biol., 139, 573-600.

MASAKI T., 1974. Immunochemical comparisons of myosins from chicken cardiac, fast white, slow red and smooth muscle. J. Biochem., 76, 441-449.

MATSUDA R., SPECTOR D., STROHMAN R. C., 1984a. Denervated skeletal muscle displays discoordinate regulation for the synthesis of several myofibrillar proteins. Proc. nat. Acad. Sci. USA, 81, 1122-1125.

MATSUDA R., SPECTOR D., STROHMAN R. C., 1984b. There is selective accumulation of a growth factor in chicken skeletal muscle. 1) Transferin accumulation in adult anterior Latissimus dorsi. Develop.Biol., 103, 267-275.

MAXWELL L. C., FAULKNER J. A., MURPHY R. A., 1982. Relationship among fibre type, myosin ATPase activity and contractile properties. Histochem. J., 14, 981 -997.

MAYNE R., SANDERSON R. D., 1985. The extracellular matrix of skeletal muscle. Collagen Rel. Res., 5, 449-468.

MCARDLE B., 1951. Myopathy due to a defect in muscle glycogen breakdown. Clin. Sci., 10, 13-35.

McARDLE J. J., 1983. Molecular aspects of the trophic influence of nerve on muscle. Prog. Neurobiol., 21, 135-198.

McGEACHIE J., ALLBROOK D., 1978. Cell proliferation in skeletal muscle following denervation of tenotomy. A serie of autoradiographic studies. Cell Tissue Res., 193, 259-267. 
McGEACHIE J. K., 1985. The fate of proliferating cells in skeletal muscle after denervation or tenotomy: an autoradiographic study. Neuroscience, 15, 499-506.

MCLACHLAN E. M., 1981. Rapid atrophy of mouse soleus muscles after tenotomy depends on an intact innervation. Neurosci. Lett., 25, 269-274.

McLACHLAN E. M., 1983. Atrophic effects of proximal tendon transection with and without denervation on mouse soleus muscles. Exp. Neurol., 81, 651-668.

McLANE J. A., HOLLOSZY J. O., 1979. Glycogen synthesis from lactate in the three types of skeletal muscle. J. biol. Chem., 254, 6548-6553.

McLENNAN I. S., 1983a. Differentiation of muscle fiber types in the chicken hindlimb. Develop. Biol., 97, 222-228.

McLENNAN I. S., 1983b. The development of the pattern of innervation in chicken hindlimb muscles: evidence for specification of nerve-muscle connections. Develop. Biol., 97 229-238.

McLENNAN I. S., 1983c. Neural dependence and independence of myotube production in chicken hindlimb muscles. Develop. Biol., 98, 287-294.

MCMAHAN U. J., SANES J. R., MARSHALL L. M., 1978. Cholinesterase is associated with the basal lamina at the neuromuscular junction. Nature, 271, 172-174.

McMAHAN U. J., SLATER C. R., 1984. The influence of basal lamina on the accumulation of acetylcholine receptors at synaptic sites in regenerating muscle. J. Cell. Biol., 98, 1453-1473.

MCMINN R. M. H., VRBOVA G., 1964. The effect of tenotomy on the structure of fast and slow muscle in the rabbit. Quart. J. exp. Physiol., 49, 424-429.

MERLIE J. P., ISENBERG K. E., RUSSEL S. D., SANES J. R., 1984 . Denervation supersensitivity in skeletal muscle : analysis with a cloned cDNA probe. J. Cell Biol., 99, 332-335.

MORITA S., COOPER C. C., CASSENS R. G., KASTENSCHMIDT L. L., BRISKEY E. J., 1970. A histological study of myoglobin in developing muscle of the pig. J. anim. Sci, 31, 664-670.

MOMMAERTS W. F. H. M., BULLER A. J., SERAYDARIAN K., 1969. The modification of some biochemical properties of muscle by cross innervation. Proc. nat. Acad. Sci. USA, 64, 128-133.

MOMMAERTS W. F. H. M., 1970. The role of the innervation of the functional differentiation of muscle. In The physiology and biochemistry of muscle as a food. Part. 2, p. 53-66. Ed. by E. J. BRISKEY, R. G. CASSENS and B. B. MARSH. Kingsport Press, Tennessee.

MOMMAERTS W. F. H. M., 1974. Effect of changed activity patterns on the biochemical characteristics of muscle. 331-335. In A. T. MILHORAT, Exploratory concepts in muscular dystrophy II. Excerpta med., Amsterdam.

MOMMAERTS W. F. H. M., SERAYDARIAN K., SUH M., KEAN C. J. C., BULLER A. J., 1977. The conversion of some biochemical properties of mammalian skeletal muscles following cross-reinnervation. Exp. Neurol., 55, 637-653.

MOODY-CORBETT F., COHEN M. W., 1981. Localization of cholinesterase at sites of high acetylcholine receptor density on embryonic amphibian muscle cells cultured without nerve. J. Neurosci., 1, 596-605.

MOODY-CORBETT F., COHEN M. W., 1982. Influence of nerve on the formation and survival of acetylcholine receptor and cholinesterase patches on embryonic Xenopus muscle cells in culture. J. Neurosci, 2, 633-646.

MOODY-CORBETT F., WELDON P. R., COHEN M. W., 1982. Cholinesterase localization at sites of nerve contact on embryonic amphibian muscle cells in culture. J. Neurocytol., 11, $381-394$.

MOORE S. E., HURKO O., WALSH F. S., 1984. Immunocytochemical analysis of fibre type differentiation in developing skeletal muscle. J. Neuroimmun., 7, 137-149.

MÜNTENER M., SRIHARI T., 1984. Changes of myosin and its ATPase in "Neuronally" and "Mechanically» contraiateral muscles after cross-reinnervation in normal and capsaicintreated rats. Expt. Neurol., 86, 134-146.

MURRAY M. A., ROBBINS N., 1982. Cell proliferation in denervated muscle: time course, distribution and relation to disuse. Neuroscience, 7, 1817-1822.

NEEDHAM D. M., 1926. Red and white muscle. Physiol. Rev., 6, 1-27.

NEMETH P., HOFER H. W., PETTE D., 1979. Metabolic heterogeneity of muscle fibers classified by myosin ATPase. Histochemistry, 63, 191-201. 
NEMETH P., PETTE D., 1981a. Succinate dehydrogenase activity in fibers classified by myosin ATPase in three hindlimb muscles of rat. J. Physial., 320, 73-80.

NEMETH P., PETTE D., 1981b. The limited correlation of myosin-based and metabolism-based classifications of skeletal muscle fibers. Authors reply to Dr Spurway. J. Histochem. Cytochem., 29, 89-90.

NEMETH P. M., PETTE D., VRBOVA G., 1981. Comparison of enzyme activities among single muscle fibres within defined motor units. J. Physiol., 311, 489-495.

NESTLER E. J., BEAM K. G., GREENGARD P., 1978. Nicotinic cholinergic stimulation increases cyclic GMP levels in vertebrate skeletal muscle. Nature, 275, $451-453$

NEWSHOLME E. A., RANDLE P. J., 1964. Regulation of glucose uptake by muscle. 7. Effects of fatty acids, ketone bodies and pyruvate and of alloxan-diabetes, starvation, hypophysectomy and adrenalectomy, on the concentrations of hexose phosphates, nucleotides and inorganic phosphate in perfused rat heart. Biochem. J., 93, 641-651.

NEWSHOLME E. A., CRABTREE B., 1976. Substrate cycles in metabolic regulation and in heat generation. Biochem. Soc. Symp., 41, 61-110.

NEWSHOLME E. A., ZAMMIT V. A., CRABTREE B., 1978. The role of glucose and glycogen as fuels for muscle. Biochem. Soc. Trans., 6, 512-520.

NICOLET M., PINCON-RAYMOND M., RIEGER F., 1986. Globular and asymmetric acetylcholinesterase in frog muscle basal lamina sheaths. J. Cel/ Biol., 102, 762-768.

NITKIN R. M., WALLACE B. G., SPIRA M. E., GODFREY E. W., MCMAHAN U. J., 1983. Molecular components of the synaptic basal lamina that direct differentiation of regenerating neuromuscular junctions. Cold Spring Harbor Symp. Quant. Biol., 48, 653-665.

NITKIN R. M., FALLON J. R., GODFREY E. W., WALLACE B. G., McMAHAN U. J., 1984. The role of extracellular matrix in regeneration of the neuromuscular junction. 597-622. In The ro/e of extracellular matrix in development. Alan R. Liss, New York.

NITKIN R. M., SMITH M. A., MAGILL C., FALLON J. R., YAO Y. M. M., WALLACE B. G., MCMAHAN U. J., 1987. Identification of agrin, a synaptic organizing protein from Torpedo electric organ. J. Cell Biol., 105, $2471-2478$.

NOUGUES J., BACOU F., 1977. Enzyme activities of muscie fibres differentiated, in vitro, from pectoralis major (white) and adductor magnus (red) muscles of chick embryos. Experientia, 33, 714-715.

NOUGUES J., 1980. Isozymes de la myosine au cours de la différenciation in vivo et in vitro des muscles de poulet. C. R. Acad. Sci., Paris, 290, 223-226.

NYSTROM B., 1968a. Histochemical studies endplate bound esterases in "slow-red" and " fast-twitch » cat muscles during postnatal development. Acta. neurol. scand., 44, 295-318.

NYSTROM B., 1968b. Postnatal development of motor nerve terminals in "slow-red" and «fast-twitch » rat muscles. Acta. neurol. scand., 44, 363-383.

OBINATA T., MARUYANA K., SUGITA H., KOHAMA K., EBASHI S., 1981. Dynamic aspects of structural proteins in vertebrate skeletal muscle. Muscle Nerve, 4, 456-488.

OBINATA T., SAITOH O., TAKANO-OHMURO H., 1984. Effect of denervation on the isoform transitions of tropomyosin, troponin T, and myosin isozyme in chicken breast muscle. $J$. Biochem., 95, 585-588.

O'BRIEN R. A. D., OSTBERG A. J. C., VRBOVA G., 1978. Observations on the elimination of polyneuronal innervation in developing mammalian skeletal muscle. J. Physiol., 282, $571-582$.

OGATA T., 1958. A histochemical study of the red and white muscle fibers. I. Activity of succinoxydase system in muscle fibers. Acta. med. Okayama, 12, 216-227.

OGATA T., 1960. The differences in some labile constituents and some enzyme activities between the red and the white muscle. J. Biochem. Tokyo, 6, 726-731.

OGATA T., MURATA F., 1969. Fine structure of motor endplate in red, white and intermediate fibers of mammalian fast muscle. Tohoku J. exp. Med., 98, 107-115.

$\mathrm{OH}$ T. H., MARKELONIS G. J., 1978. Neurotrophic protein regulates muscle acetylcholinesterase in culture. Science, 200, 337-339.

$\mathrm{OH}$ T. H., MARKELONIS G. J., 1980. Dependence of in vitro myogenesis on a trophic protein present in chick embryon extract. Proc. nat. Acad. Sci. USA, 77, 6922-6925. 
OH T. H., MARKELONIS G. J., 1982. Chicken serum transferrin duplicates the myotrophic effects of sciatin on cultured muscle cells. J. Neurosci. Res., 8, 535-545.

OH T. H., MARKELONIS G. J., REIER P. J., ZALEWSKY A. A., 1980. Persistence in degenerating sciatic nerve of substances having a trophic influence upon cultured muscle. Exp. Neurol., 67, 646-654.

OKADA S., NOKANA I., CHOU S. M., 1984. Muscle fiber type differentiation and satellite cell populations in normally grown and neonatally denervated muscles in the rat. Acta neuropathol., 65, 90-98.

OKANO G., MATSUZAKA H., SHIMOJO T., 1980. A comparative study of lipids composition of white, intermediate, red and heart muscle in rats. Biochim. Biophys. Acta, 619, 167-175.

OKANO G., SHIMOJO T., 1982. Utilization of long-chain free fatty acids in white and red muscle of rats. Biochim. Biophys. Acta, 710, 122-127.

OPIE L. H., NEWSHOLME E. A., 1967. The activities of fructose 1-6 diphosphatase, phosphofructokinase and phosphoenolpyruvate carboxy-kinase in white muscle and red muscle. Biochem. J., 103, $391-399$.

OPIE L. H., 1969. Metabolism of the heart in health and disease. Part II. Amer. Heart J., 77, 100-122.

OPPENHEIM R. W., NUNEZ R., 1982. Electrical stimulation of hindlimb increases neuronal cell death in chick embryo. Nature, 295, 57-59.

OPPENHEIM R. W., 1984. Cell death of motoneurons in the chick embryo spinal cord. VIII. Motoneurons prevented from dying in the embryo persist after hatching. Develop. Biol., 101, 35-39.

ONTELL M., DUNN R. F., 1978. Neonatal muscle growth : a quantitative study. Am. J. Anat., 152. 539-556.

PADIEU P., 1959. Biosynthèse des protéines musculaires et section du nerf moteur. Bull. Soc. Chim. biol. Paris, 41, 57-68.

PADYKULA H. A., HERMAN E., 1955a. Factors affecthy the activity of adenosine triphosphatase and other phosphatases as measured by histochemical techniques. J. Histochem. Cytochem. 3, $161-169$.

PADYKULA H. A., HERMAN E., 1955b. The specificity of the histochemical method for adenosine triphosphatase. J. Histochem. Cytochem., 3, 170-183.

PANDE S. V., BLANCHAER M. C., 1971. Carbohydrate and fat in energy metabolism of red and white muscle. Am. J. Physiol., 220, 549-553.

PARKER G. H., GEORGE J. C., 1972. Histochemical demonstration of glycogen utilization and resynthesis in pigeon pectoralis during exercise. 4th int. Congr. Histochem. Cytochem. Kyoto, 249-250.

PEARLSTEIN E., GOLD L. I., GARCIA-PARDO A., 1980. Fibronectin : a review of its structure and biological activity. Mol. cell. Biochem., 29, 103-128.

PEIRONE S., FILOGAMO G., 1980. Non-neural influences in the determination of chick skeletal muscle. Arch. Anat. microsc. Morphol. exp., 69, 81-90.

PELLISSIER J. F., 1982. Histochimie du muscle squelettique humain normal. Journées C/ub Francophone du Musc/e, p. 1-2. Marseille.

PERNOW B., HAWEL R. J., JENNINGS D., 1967. The second wind phenomenon in McArdle's syndrome. Acta med. scand., 472, (Suppl.) 294-307.

PERRY S. V., COLE H. A., 1974. Phosphorylation of Troponin and the effects of interactions between the components of the complex. Biochem. J., 141, 733-743.

PERRY S. V., 1985. Properties of the muscle proteins. A comparative approach. J. exp. Biol., 115, $31-42$.

PETER J. B., JEFFRESS R. N., LAMB D. R., 1968. Exercice : effects on hexokinase activity in red and white skeletal muscle. Science, 160, 200-201.

PETER J. B., BARNARD R. J., EDGERTON V. R., GILLESPIE C. A., STEMPEI K. E., 1972. Metabolic profiles of three fiber types of skeletal muscle in guinea pigs and rabbits. Biochemistry, 11 , 2627-2633.

PETTE D., 1966. Mitochondrial enzyme activities. 29-49. In : J. M. TAGER, S. PAPA, E. QUAG LIARIELLO,E. C. SLATER. Elsevier, Amsterdam. Regulation of metabolic processes in mitochondria, 7. 
PETTE D., SMITH M. E., STAUDTE H. W., VRBOVA G., 1973. Effects of long-term electrical stimulation on some contractile and metabolic characteristics of fast rabbit muscles. Pflügers Arch., 338, 257-272.

PETTE D., MULLER W., LEISNER E., VRBOVA G., 1976. Time dependent effects on contractile properties, fibre population, myosin light chains and enzymes of energy metabolism in intermittently and continuously stimulated fast twitch muscle of the rabbit. Pflügers Arch., 364, 103-112.

PETTE D., 1975. Some aspects of supramolecular organization of glycogenolytic and glycolytic enzymes in muscle. Acta histochemica, Suppl. 14, 47-68

PETTE D., 1978. Cytosolic organisation of carbohydrate-metabolism enzymes in cross-striated muscle. Biochem. Soc. Trans., 6, 7-9.

PETTE D., VRBOVA G., 1985. Invited review: neural control of phenotypic expression in mammalian muscle fibers. Musc/e Nerve, 8, 676-689.

PICHEY E. L., BLAISE SMITH P., 1979. Denervation and developmental alterations of glycogen synthase and glycogen phosphorylase in mammalian skeletal muscle. Exp. Neurol., 65, 118-130.

PIEROBON-BORMIOLI S., SARTORE S., VITADELLO M., SCHIAFFINO S., 1980. "Slow" myosins in vertebrate skeletal muscle. An Immunofluorescence study. J. Cel/ Biol., 85, 672-681.

PITTMAN R., OPPENHEIM R. W., 1978. Neuromuscular blockade increases motoneurone survival during normal cell death in the chick embryo. Nature, 271, 364-366.

PLUSKAL M. G., SRETER F. A., 1983. Correlation between protein phenotype and gene expression in adult rabbit fast twitch muscles undergoing a fast to slow fiber transformation in response to electrical stimulation in vivo.Biochem. Biophys. Res. Commun., 113, 325-331.

POPIELA H., 1976. In vivo limb tissue development in the absence of nerves : a quantitative study. Exp. Neurol., 53, 214-226.

POPIELA H., 1977. In vivo limb muscle differentiation in the absence of nerves : a quantitative study. Exp. Neurol., 55, 160-172.

PORTER C. W., CHIU T. H., WIECKOWSKI J., BARNARD E. A., 1973. Types and locations of cholinergic receptor like molecules in muscle fibres. Nature New Biol., 241, 3-7.

PREWITT M. A., SALAFSKY B., 1967. Effect of cross innervation on biochemical characteristics of skeletal muscles. Am. J. Physiol., 213, 295-300.

PREWITT M. A., SALAFSKY B., 1970. Enzymic and histochemical changes in fast and slow muscles after cross innervation. Am. J. Physiol., 218, 69-74.

PULLIAM D. L., APRIL E. W., 1979a. Degenerative changes at the neuromuscular junctions of red, white and intermediate muscle fibers. Part. 1. Response to short stump nerve section. $J$. neurol. Sci., 43, 205-222.

PULLIAM D. L., APRIL E. W., 1979b. Degenerative changes at the neuromuscular junctions of red, white and intermediate muscle fibers. Part. 2. Responses to long stump nerve section and colchicin treatment. $J$. neurol. Sci, 43, 223-241.

PURVES D., LICHTMAN J. W., 1980. Elimination of synapses in the developing nervous system. Science, 210, 153-157.

PURVES D., LICHTMAN J. W., 1985. Principles of neural development. Sinauer Associates Inc. Sunderland, Massachussetts.

RAMIREZ B. L., PETTE D., 1974. Effects of long-term electrical stimulation on sarcoplasmic reticulum of fast rabbit muscle. FEBS Lett., 49, 188-190.

RANDLE P. J., NEWSHOLME E. A., GARLAND P. B., 1964. Regulation of glucose uptake by muscle. 8. Effects of fatty acids, ketone bodies and pyruvate, and of alloxan-diabetes and starvation, on the uptake and metabolic fate of glucose in rat heart and diaphragm muscles. Biochem. J., 93, 652-665.

RANVIER L., 1873. Propriétés et structures différentes des muscles rouges et des muscles blancs chez les lapins et chez les raies. C.R. Acad. Sci. Paris, 77, 1030-1034.

RANVIER L., 1874. De quelques faits relatifs à l'histologie et à la physiologie des muscles striés. Arch. Physiol. norm. path., 1, 5-15.

REDFERN P. A., 1970. Neuromuscular transmission in new-born rats. J. Physiol., 209, 701-709. 
REES R. P., BUNGE M. B., BUNGE R. P., 1976. Morphological changes in the neuritic growth cone and target neuron during synaptic junction development in culture, J. Cell Biol., 68. 240-263.

REICHMANN H., PETTE D., 1982. A comparative microphotometric study of succinate dehydrogenase activity levels in type I, IIA and IIB fibres of mammalian and human muscles. Histochemistry, 74, 27-41.

REICHMANN H., 1985. Interspecies differences in aerobic-oxydative capacities of muscle fibre populations in various mammals. Acta histochem. Suppl., 31, 53-56.

REICHMANN H., HOPPELER H., MATHIEU-COSTELLO O., VON BERGEN F., PETTE D., $1985 . \quad$ Biochemical and ultrastructural changes of skeletal muscle mitochondria after chronic electrical stimulation in rabbits. Pflügers Arch., 404, 1-9.

REINESS C. G., WEINBERG C. B., 1981. Metabolic stabilization of acetylcholine receptors at newly formed neuromuscular junctions in rat. Develop. Biol., 84, 247-254.

REIST N. E., MAGILL C., McMAHAN U. J., 1987. Agrinlike molecules at synaptic sites in normal, denervated, and damaged skeletal muscles. J. Cell Biol., 105, 2457-2470.

REITMAN J., BALDWIN K. M., HOLLOSZY J. O., 1973. Intramuscular triglycerides utilization by red, white and intermediate skeletal muscle and heart during exhausting exercice. Proc. Soc. exp. Biol., 142, 628-631.

RENAUD D., LE DOUARIN G. H., KHASKIYE A., 1978. Spinal cord stimulation in chick embryo: effects on development of the posterior latissimus dorsi muscle and neuromuscular junctions. Exp. Neurol., 60, 189-200.

RENAUD D., GARDAHAUT M. F., ROUAUD T., LE DOUARIN G., 1983. Influence of chronic spinal cord stimulation upon differentiation of muscle fibers in a fast muscle (posterior latissimus dorsi) of the chick embryo. Exp. Neurol., 80, 157-166.

RENNIE M. J., JOHNSON R. H., 1974. Alteration of metabolic and hormonal responses to exercise by physical training. Eur. J. appl. Physiol., 33, 215-226.

RENNIE M. J., WINDER W. W., HOLLOSZY J. O., 1976. A sparing effect of increased plasma fatty acids on muscle and liver glycogen content in the exercising rat. Biochem. J., 156, 647-655.

RENNIE M. J., HOLLOSZY J. O., 1977. Inhibition of glucose uptake and glycogenolysis by availability of oleate in well-oxygenated perfused skeletal muscle. Biochem. J., 168, $161-170$.

RILEY D. A., 1976. Multiple axon branches innervating single endplates of kitten soleus myofibers. Brain Res, 110, 158-161.

RILEY D. A., 1977a. Spontaneous elimination of nerve terminals from the endplates of developing skeletal myofibers. Brain Res., 134, 279-285.

RILEY D. A., 1977b. Multiple innervation of fiber types in the soleus muscles of postnatal rats. Exp. Neurol., 56, 400-409.

RILEY D. A., 1978. Tenotomy delays the postnatal development of the motor innervation of the rat soleus. Brain Res., 143, 162-167.

RILEY D. A., 1981. Ultrastructural evidence for axon retraction during the spontaneous elimination of polyneural innervation of the rat soleus muscle. J. Neurocytol., 10, 425-440.

ROBBINS N., KARPATI G., ENGEL W. K., 1969. Histochemical and contractile properties in the cross-innervated guinea pig soleus muscle. Arch. Neurol., 20, 318-329.

ROBERT B., 1987. La différenciation myogénique : aspects moléculaires et cellulaires. Bull. Inst. Pasteur, 85, 37-85.

ROHDE H., WICK G., TIMPL. R., 1979. Immunochemical characterization of the basement glycoprotein laminin. Eur. J. Biochem., 102, 195-201.

ROLE L. W., MATOSSIAN V. R., O'BRIEN R. J., FISCHBACH G. D., 1985. On the mechanism of acetylcholine receptor accumulation at newly formed synapses on chick myotubes. $J$. Neurosci., 5, 2197-2204.

ROMANUL F. C. A., 1964. Enzymes in muscle: I. Histochemical studies of enzymes in individual muscle fibers. Arch. Neurol., 11, 355-368.

ROMANUL F. C. A., 1965. Capillary supply and metabolism of muscle fibers. Arch. Neurol., 12, 497-509.

ROMANUL F. C. A., HOGAN E. L., 1965. Enzymatic changes in denervated muscle. I. Histochemical studies. Arch. Neurol., 13, 263-273. 
ROMANUL F. C. A., VAN DER MEULEN J. P., 1967. Slow and fast muscles after cross innervation. Enzymatic and physiological changes. Arch. Neurol., 17, 387-402.

ROMANUL F. C. A., 1971. Reversal and enzymatic profiles and capillary supply of muscle fibers in fast and slow muscles after cross innervation. 21-32. In Muscle metabolism during exercise. Advances on experimental medicine and biology, vol. 11. Plenum Press.

ROMANUL F. C. A., SRETER F. A., SALMONS S., GERGELY J., 1974. The effect of a changed pattern of activity on histochemical characteristics of muscle fibers, 344-348. In A.T. MILHORAT, Exploratory concepts in muscular dystrophy II. Excerpta med. Amsterdam.

ROSENTHAL J. L., TARASKEVICH P. S., 1977. Reduction of multiaxonal innervation at the neuromuscular junction of the rat during development. $J$. Physiol., 270, 299-310.

ROWELL L. R., KRANING K. K., EVANS T. O., KENNEDY J. W., BLACKMAN J. R., KUSUMI F., 1966. Splanchnic removal of lactate and pyruvate during prolonged exercise in man. $J$. appl. Physiol., 21, 1773-1783

ROY R. K., SRETER F. A., SARKAR S., 1979a. Changes in tropomyosin subunits and myosin light chains during development of chicken and rabbit striated muscles. Develop. Biol., 68, 15-30.

ROY R. K., MABUCHI K., SARKAR S., MIS C., SRETER F. A., 1979b. Changes in tropomyosin subunit pattern in chronic electrically stimulated rabbit fast muscles. Biochem. Biophys. Res. Commun., 89, 181-187.

RUBIN L. L., SCHUETZE S. M., WEILL C. L., FISCHBACH G. D., 1980 . Regulation of acetylcholinesterase appearance at neuromuscular junctions in vitro. Nature, 283, 264-267.

RUBINSTEIN N. A., PEPE F. A., HOLTZER H., 1977. Myosin types during the development of embryonic chicken fast and slow muscles. Proc. nat. Acad. Sci. USA, 74, 4524-4527.

RUBINSTEIN N. A., KELLY A. M., 1978. Myogenic and neurogenic contributions to the development of fast and slow twitch muscles in rat. Develop. Biol., 62, 473-485.

RUBINSTEIN N. A., HOLTZER H., 1979. Fast and slow muscles in tissue culture synthesize only fast myosin. Nature, 280, 323-325.

RUBINSTEIN N. A., KELLY A. M., 1981. Development of muscle fiber specialization in the rat hindlimb. J. Cell Biol., 90, 128-144

RUSSEL N. J. W., 1980. Axonal conduction velocity changes following muscle tenotomy of deafferentation during development in the rat. J. Physiol., 298, 347-360.

SAITO A., ZACKS S. I, 1969. Fine structure of neuromuscular junctions after nerve section and implantation of nerve in denervated muscle. Exp. mol. Pathol., 10, 256-273.

SALMONS S., VRBOVA G., 1969. The influence of activity on some contractile characteristics of mammalian fast and slow muscles. J. Physiol., 201, 535-549.

SALMONS S., SRETER F. A., 1976. Significance of impulse activity in the transformation of skeletal muscle type. Nature, 263, 30-34.

SALMONS S., GALE D. R., SRETER F. A., 1978. Ultrastructural aspects of the transformation of muscle fibre type by long-term stimulation : changes in $Z$ discs and mitochondria. J. Anat., 127, 17-31.

SAMAHA F. J., GUTH L., ALBERS R. W., 1970. Differences between slow and fast muscle myosin. Adenosine triphosphatase activity and release of associated proteins by $\mathrm{p}$. Chloromercuriphenylsulfonate. J. biol. Chem., 245, 219-224.

SANES J. R., MARSHALL L. M., McMAHAN U. J., 1978. Reinnervation of muscle fiber basal lamina after removal of myofibers. Differentiation of regenerating axons at original synaptic sites. J. Cel/ Biol., 78, 176-198.

SANES J. R., HALL Z. W., 1979. Antibodies that bind specifically to synaptic sites on muscle fiber basal lamina. J. Cell Biol., 83, 357-370.

SANES J. R., 1982. Laminin, fibronectin, and collagen in synaptic and extrasynaptic portions of muscle fiber basement membrane. J. Cell Biol., 93, 442-451.

SANES J. R., 1983. Roles of extracellular matrix in neural development. Annu. Rev. Physiol., 45, $581-600$.

SANES J. R., CHIU A. Y., 1983. The basal lamina of the neuromuscular junction. Cold Spring Harbor Symp. Quant. Biol., 48, 667-678.

SANES J. R., FELDMAN D. H., CHENEY J. M., LAWRENCE J. G., 1984. Brain extract induces synaptic characteristics in the basal lamina of cultured myotubes. J. Neurosci., 4, 464-473. 
SARKAR S., SRETER F. A., GERGELY J., 1971. Light chains of myosins from white, red and cardiac muscles. Proc. nat. Acad. Sci. USA, 68, 946-950.

SARTORE S., GORZA L., SCHIAFFINO S., 1982. Fetal myosin heavy chains in regenerating muscle. Nature, 298, 294-296.

SARZALA M. G., SZYMANSKA G., WIEHRER W., PETTE D., 1982. Effects of chronic stimulation at low frequency on the lipid phase of sarcoplasmic reticulum in rabbit fast-twitch muscle. Eur. J. Biochem., 123, 241-245.

SCHAPIRA G., DREYFUS J. C., 1959. Biochemical changes in muscle consequent upon interruption of motor nerves. Amer. J. Phys. Med., 38, 207-215.

SCHMALBRUCH H., 1979. The membrane systems in different fibre types of the triceps surae muscle of cat. Cell Tissue Res., 204, 187-200.

SCHÜTZLE U. B., WAKELAM M. J. O., PETTE D., 1984. Prostaglandins and cyclic AMP stimulate creatine kinase synthesis but not fusion in cultured embryonic chick muscle cells. Biochim. Biophys. Acta, 805, 204-210.

SCHWARTZ K., 1978. La myosine: une famille de protéines polymorphes. La Recherche, 91, 683-685.

SCHWARTZL. M., TRUMAN J. W., 1984. Cyclic GMP may serve as a second messenger in peptide induced muscle degeneration in an insect. Proc. nat. Acad. Sci. USA, 81, 6718-6722.

SEEDORF K., SEEDORF U., PETTE D., 1983. Coordinate expression of alkali and DTNB myosin light chains during transformation of rabbit fast muscle by chronic stimulation. FEBS Lett., $158,321-324$.

SHACKELFORD J. E., LEBHERZ H. G., 1981. Effect of denervation on the levels and rates of synthesis of specific enzymes in "fast-twitch" (Breast) muscle fibers of the chicken. J. biol. Chem., 256, 6423-6429.

SHAFIO S. A., SHIMIZU T., FISHMAN D. A., 1984. Heterogeneity of type 1 skeletal muscle fibers revealed by monoclonal antibody to slow myosin. Muscle Nerve, 7, 380-387.

SHIMIZU N., OBINATA T., 1980. Presence of three actin types in skeletal muscle of chick embryos. Develop. Growth Differ., 22, 789-796.

SHIMIZU N., SHIMADA Y., 1985. Immunochemical analysis of troponi T isoforms in adult, embryonic, regenerating and denervated chicken fast skeletal muscles. Develop. Biol., 111, 324-334.

SICA R. E. P., McCOMAS A. J., UPTON A. R. M., LONGMIRE D., 1974. Motor unit estimations in small muscles of the hand. J. Neurol. Neurosurg. Psychiat., 37, 55-67.

SNOW M. H., 1983. A quantitative ultrastructural analysis of satellite cells in denervated fast and slow muscles of the mouse. Anat. Rec., 207, 593-604.

SOHAL G. S., HOLT R. K., 1980. Role of innervation on the embryonic development of skeletal muscle. Cell Tissue Res., 210, 383-393.

SPAMER C., PETTE D., 1977. Activity patterns of phosphofructokinase, glyceraldehydephosphate dehydrogenase, lactate dehydrogenase and malate dehydrogenase in microdissected fast and slow fibres from rabbit Psoas and Soleus muscle. Histochemistry, 52, 201-216.

SPURWAY N., 1981. Interrelationships between myosin-based and metabolism-based classifications of skeletal muscle fibers. J. Histochem. Cytochem., 29, 87-88.

SRETER F. A., SEIDEL J. C., GERGELY J., 1966. Studies on myosin from red and white skeletal muscles of the rabbit. I. Adenosine triphosphatase activity. J. biol. Chem., 241, 5772-5776.

SRETER F. A., GERGELY J., LUFF A. L., 1974. The effect of cross-reinnervation on the synthesis of myosin light chains. Biochem. Biophys. Res. Commun., 56, 84-89.

SRETER F. A., LUFF A. R., GERGELY J., 1975. Effect of cross-reinnervation on physiological parameters and on properties of myosin and sarcoplasmic reticulum of fast and slow muscles of the rabbit. J. gen. Physiol., 66, 811-821.

SRETER F. A., PINTER K., JOLESZ F., MABUCHI K., 1982. Fast to slow transformation of fast muscles in response to long-term phasic stimulation. Exp. Neurol., 75, 95-102.

SRIHARI T., VRBOVA G., 1978. The role of muscle activity in the differentiation of neuromuscular junctions in slow and fast chick muscles. J. Neurocytol., 7, 529-540.

STEIN J. M., PADYKULA H. A., 1962. Histochemical classification of individual skeletal muscle fibers of the rat. Amer J. Anat., 110, 103-124. 
STEINBACH J. H., SCHUBERT D., ELDRIDGE L., 1980. Changes in cat muscle contractile proteins after prolonged muscle inactivity. Exp. Neural., 67, 655-669.

STEINBACH J. H., 1981. Developmental changes in acetylcholine receptor aggregates at rat skeletal neuromuscular junctions. Develop. Biol., 84, 267-276.

STETTEN D. Jr., STETTEN M. R., 1960. Glycogen metabolism. Physiol. Rev., 40, 505-537.

STEWART D. M., SOLA O. M., MARTIN A. W., 1972. Hypertrophy as a response to denervation in skeletal muscle. Z. Vergl. Physiol., 76, 146-167.

STOCKDALE F. E., CROW M. T., OLSON P. S., 1982. Myosin light chain isozymes in developing avian skeletal-muscle cells in ovo and in culture, 345-354. In M. L. PEARSON, H. F. EPSTEIN, Muscle development. Molecular and cellular control. Cold Spring Harbor Laboratory.

SUMIKAWA K., MEHRABAN F., DOLLY J. O., BARNARD E. A., 1982a. Similarity of acetylcholine receptors of denervated, innervated and embryonic chicken muscles. 1. Molecular species and their purification. Eur. J. Biochem., 126, 465-472.

SUMIKAWA K., BARNARD E. A., DOLLY J. O., 1982b. Similarity of acetylcholine receptors of denervated, innervated and embryonic chicken muscles. 2. Subunit compositions. Eur. J. Biochem., 126, 473-479.

SUZUKI A., 1970. Histochemical classification of individual skeletal muscle fibers in the sheep. I. On M.Semitendinosus, M.Longissimus dorsi, M.Psoas major, M.Latissimus dorsi and M.Gastrocnemius. Jap. J. zootech. Sci, 42, 39-54.

SUZUKI A., TAMATE H., 1974. Histochemical classification of skeletal muscle fibers in the cattle. Acta Histochem. Cytochem., 7, 319-327.

SUZUKI A., CASSENS R. G., 1980. pH sensitivity of myosin adenosine triphosphatase and subtypes of myofibres in porcine muscle. Histochem. J., 12, 687-693.

SWATLAND H. J., CASSENS R. G., 1973. Prenatal development, histochemistry and innervation of porcine muscle. J. anim. Sci, 36, 343-354.

SWEENEY L. J., CLARK W. A. Jr., UMEDA P. K., ZAK R., MANAZEK F. J., 1984 . Immunofluorescence analysis of the primordial myosin detectable in embryonic striated muscle. Proc nat. Acad. Sci. USA, 81, 797-800.

SYTKOWSKI A. J., VOGEL Z., NIREMBERG M. W., 1973. Development of acetylcholine receptor clusters on cultured muscle cells. Proc. nat. Acad. Sci. USA, 70, 270-274.

TELERMAN-TOPPET N., COERS C., 1973. L'histochimie des fibres musculaires normales. Ann. Anat. Path., 18, 35-48.

TELLO J. F., 1917. Genesis de las terminaciones nerviosas motrices y sensitivas. Trad. Lab. Invest. Biol. Univ. Madr., 15, $101-199$.

TERAVAINEN H., 1968. Development of the myoneural junction in the rat. Z. Zellforsch. Mikrosk. Anat., 90, 372-388.

THESLEFF S., 1960. Effects of motor innervation on the chemical sensitivity of skeletal muscle. Physiol. Rev., 40, 734-752.

THOMPSON W. J., KUFLER D. P., JANSEN J. K. S., 1979. The effect of prolonged, reversible block of nerve impulses on the elimination of polyneuronal innervation of new-born rat skeletal muscle fibers. Neuroscience, 2, 271-281.

THOMPSON W. J., 1983. Synapse elimination in neonatal rat muscle is sensitive to pattern of muscle use. Nature, 302, 614-616.

THOMPSON W. J., SUTTON L. A., RILEY D. A., 1984. Fibre type composition of single motor units during synapse elimination in neonatal rat soleus muscle. Nature, 309, 709-711.

TIMPL R., ROHDE M., GEHRON-ROBEY P., RENNARD S. I., FOIDART J. M., MARTIN G. R., 1979. Laminin - a glycoprotein from basement membranes. J. biol. Chem. 254. 9933-9937.

TIMPL R., DZIADEK M., FUJIWARA S., NOWACK H., WICK G., 1983. Nidogen: a new, self-aggregating basement membrane protein. Eur. J. Biochem., 137, 455-465.

TIMPL R., FUJIWARA S., DZIADEK M., AUMAILLEY M., WEBER S., ENGEL J., 1984. Laminin, proteoglycan, nidogen and collagen IV : structural models and molecular interactions. In Basement membranes and cell movement, ClBA Fdn. Symp., 108, 25-43. Pitman, London. 
TIPNIS U., MALHOTRA S. K., 1978. Nerve-muscle interaction : changes in the cellular organization of a skeletal muscle upon denervation. Cytobios, 19,181-227.

TOMANEK R. J., 1976. Ultrastructural differentiation of skeletal muscle fibers and their diversity. $J$. Ultrastruct. Res., 55, 212-227.

TOURAINE B., 1981. Influence du mode d'élevage sur la composition de la carcasse et les caractéristiques musculaires de l'agneau Mérinos d'Arles. Thèse Doct. Ing. ENSA, Montpellier. $79 \mathrm{pp}$.

TOUTANT J. P., TOUTANT M., RENAUD D., LE DOUARIN G. H., 1979. Enzymatic differentiation of muscle fibre types in embryonic Latissimus dorsi of the chick : effects of spinal cord stimulation. Cell Diff., 8, 375-382.

TOUTANT J. P., ARPAGAUS M., 1984. Les matrices extracellulaires des cellules animales. $B u / l$. pédag. Biology-Géologie APBG, 2, 395-418.

TOUTANT M., BOURGEOIS J. P., TOUTANT J. P., RENAUD D., LE DOUARIN G., CHANGEUX J. P., 1980. Chronic stimulation of the spinal cord in developing chick embryo causes the differentiation of multiple clusters of acetylcholine receptor in the posterior latissimus dorsi muscle. Develop. Biol., 76, 384-395.

TROUT J. J., STAUBER W. T., SCHOTTELIUS B. A., 1981. Degeneration and regeneration in denervated tonic and phasic skeletal muscle : morphology and acid phosphatase cytochemistry. Virchows Arch. (Cell Pathol.), 38, 67-76.

TURNER L. V., MANCHESTER K. L., 1972a. Effects of denervation on the glycogen content and on the activities of enzymes of glucose and glycogen metabolism in rat diaphragm muscle. Biochem. J., 128, 789-801.

TURNER L. V., MANCHESTER K. L., 1972b. Effects of denervation on the activities of some Tricarboxylic Acid-Cycle-associated dehydrogenases and adenin-metabolizing enzymes in rat diaphragm muscle. Biochem. J., 128, 803-809.

TURNER L. V., MANCHESTER K. L., 1973. Effects of denervation hypertrophy in rat diaphragm muscle on the activity of ribosomes and sap fractions in protein synthesis. Biochim. Biophys. Acta, 299, 612-620.

VIGNERON P., BACOU F., ASHMORE C. R., 1976. Distribution heterogeneity of muscle fiber types in the rabbit Longissimus muscle. J. anim. Sci., 43, 985-988.

VIGNERON P., DAINAT J., BACOU F., 1989. Propriétés des fibres musculaires squelettiques. II. Influences hormonales. Reprod. Nutr. Dévelop., 29 (sous presse).

VIGNY M., MARTIN G. R., GROTENDORST G. R., 1983. Interactions of asymmetric forms of acetylcholinesterase with basement membrane components. J. biol. Chem., 258, 8794-8798.

VILLA MORUZZI E., BERGAMINI E., GORI BERGAMINI Z., 1981. Glycogen metabolism and the fonction of fast and slow muscles of the rat. Pflügers Arch., 391, 338-342.

VINCENT-ABLAZEY M., BAKER T., LOWNDES H. E., 1978. Motor nerve terminal defect following tenotomy. Experientia, 34, 1479-1480.

VOGEL Z., CHRISTIAN C. N., VIGNY M., BAUER H. C., SONDEREGGER P., DANIELS M. P. 1983. Laminin induces acetylcholine receptor aggregation on cultured myotubes and enhances the receptor aggregation activity of a neuronal factor. J. Neurosci., 3, 1058-1068.

VRBOVA G., 1963. Changes in the motor reflexes produced by tenotomy. J. Physiol., 166, 241 -250.

WAGNER P. D., WEEDS A. G., 1977. Studies on the role of myosin alkali light chains. Recombination and hybridization of light chains and heavy chains in subfragment-1 preparation. J. mol. Biol., 109, $455-473$.

WAGNER P. D., GINIGER E., 1981. Hydrolysis of ATP and reversible binding to F-actin by myosin heavy chains free of all light chains. Nature, 292, 560-562.

WALLACE B. G., NITKIN R. M., REIST N. E., FALLON J. R., MOAYERI N. N., McMAHAN U. J., 1985. Aggregates of acetylcholinesterase induced by acetylcholine receptor-aggregating factor. Nature, 315, 574-577

WALLACE B. G., 1986. Aggregating factor from Torpedo electric organ induces patches containing acetylcholine receptors, acetylcholinesterase and butyrylcholinesterase on cultured myotubes. J. Cell Biol., 102, 783-794.

WARNICK J. E., ALBUQUERQUE E. X., GUTH L., 1977. The demonstration of neurotrophic function by application of colchicine or vinblastine to the peripheral nerve. Exp. Neurol., 57. 622-636. 
WEEDS A. G., LOWEY S., 1971. Substructure of the myosin molecule. II. The light chains of myosin. J. mol. Biol., 61, $701-725$.

WEEDS A. G., POPE B., 1971. Chemical studies on light chains from cardiac and skeletal muscle myosins. Nature, 234, 85-88.

WEEDS A. G., TRETHAM D. R., KEAN C. J. C., BULLER A. J., 1974. Myosin from cross-innervated cat muscles. Nature, 247, 135-139.

WEEDS A. G., McLACHLAN A. D., 1974. Structural homology of myosin alkali light chains, troponin $C$ and carp calcium binding protein. Nature, 252, 646-649.

WEEDS A. G., 1980. Myosin light chains, polymorphism and fibre types in skeletal muscles, 55-68. In D. PETTE, Plasticity of muscle. Walter de Gruyter, Berlin.

WEIDERT A., 1988. Myogenesis and gene expression. Bull. Inst. Pasteur, 86, 159-210.

WEINBERG C. B., SANES J. R., HALL Z.W., 1981. Formation of neuromuscular junctions in adult rats : accumulation of acetylcholine receptor, acetylcholinesterase, and components of synaptic basal lamina. Develop. Biol., 84, 255-266.

WHALEN R. G., SCHWARTZ K., BOUVERET P., SELL S. M., GROS F., 1979. Contractile protein isozymes in muscle development : identification of an embryonic form of myosin heavy chain. Proc. nat. Acad. Sci. USA, 76, 5197-5201.

WHALEN R. G., SELL S. M., BUTTLER-BROWNE G. S., SCHWARTZ K., BOUVERET P., PINSET - HÄRSTRÖM I., 1981. The myosin heavy chain isozymes appear sequentially in rat muscle development. Nature, 292, 805-809.

WHALEN R. G., BUGAISKY L. B., BUTTLER-BROWNE G. S., SELL S. M., SCHWARTZ K., PINSET-HÄRSTRÖM I., 1982. Characterization of myosin isozymes appearing during muscle development, 25-33. In M. L. PEARSON and H. F. EPSTEIN. Musc/e development. Molecular and cellular. control. Cold Spring Harbor Laboratory.

WIECZOREK D. F., PERIASAMY M., BUTTLER-BROWNE G. S., WHALEN R. G., NADAL-GINARD B., 1985. Co-expression of multiple myosin heavy chain genes, in addition to a tissuespecific one, in extraoccular musculature. J. Cell Biol., 101, 618-629.

WILKINSON J. M., 1978. The components of troponin from chicken fast skeletal muscle. A comparison of troponin $T$ and troponin I from breast and leg muscle. Biochem. J., 169. 229-238.

WILKINSON J. M., GRAND R. J. A., 1978. Comparison of aminoacid sequence of Troponin I from different striated muscles. Nature, 271, $31-35$

WILKINSON J. M., MOIR A. J. G., WATERFIELD M. D., 1984. The expression of multiple forms of Troponin $\mathrm{T}$ in chicken-fast-skeletal muscle may result from differential splicing of a single gene. Eur. J. Biochem., 143, 47-56.

WILLIAMS P. E., GOLDSPINK G., 1971. The effect of immobilization on the longitudinal growth of striated muscle fibres. J. Anat., 116, 45-55.

WILSON F. J., CAMISCOLI D., IRISH M. J., HIRABAYASHI T., 1978. Immunohistochemical and ultrastructural distribution of antibodies to troponin-C and troponin-I in normal and dystrophic chicken skeletal muscle. J. Histochem. Cytochem., 26, 258-266.

WINDER W., FITTS R., HOLLOSZY J., KAISER K., BROOKE M., 1980. Effects of thyroid hormones on different types of skeletal muscle, 582-591. In D. PETTE, Plasticity of muscle, Walter de Gruyter. Berlin.

WINKELMANN D. A., LOWEY S., PRESS J. L., 1983. Monoclonal antibodies localyse changes on myosin heavy chain isozymes during avian myogenesis. Cell, 34, 295-306.

WIRSEN C., LARSSON K. S., 1964. Histochemical differentiation of skeletal muscle in foetal and newborn mice. J. Embryol. exp. Morphol., 12, 759-767.

WIRTZ P., LOERMANS H. M., PEER P. G. M., REINTJES A. G. M., 1983. Postnatal growth and differentiation of muscle fibres in the mouse. I. A histochemical and morphometrical investigation of normal muscle. J. Anat., 137, 109-126.

YAMADA K. M., OLDEN K., 1978. Fibronecting-adhesive glycoproteins of cell surface and blood. Nature, 275, 179-184.

YAMADA K. M., 1983. Cell surface interactions with extracellular materials. Annu. Rev. Biochem., 52, $761-799$.

YAMADA K. M., AKIYAMA S. K., HASEGAWA T., HASEGAWA E., HUMPHRIES M. J., KENNEDY D. W., NAGATA K., URUSHIHARA H., OLDEN K., CHEN W.-T., 1985. Recent advances in 
research of fibronectin and other cell attachment proteins, 199-217. In A. HARI REDDI, Extracellular matrix : structure and function. Alan R. Liss New-York.

YATES L. D., GREASER M. L., 1983. Quantitative determination of myosin and actin in rabbit skeletal muscle. J. mol. Biol., 168, 123-141.

YELLIN H., 1974. Changes in fiber type of the hypertrophying denervated hemidiaphragm. Exp. Neurol., 42, 412-428.

YOUNKIN S. G., BRETT R. S., DAVEY B., YOUNKIN L. H., 1978. Substances moved by axonal transport and released by nerve stimulation have an innervation-like effect on muscle. Science, 200, 1292-1295.

ZELENA J., VYKLICKY L., JIRMANOVA I., 1967. Motor endplates in fast and slow muscles after cross union of their nerves. Nature, 214, 1010-1011.

ZELENA J., JIRMANOVA 1., 1973. Ultrastructure of chicken slow muscle after nerve cross union. Exp. Neurol., 38, 272-285. 